\title{
Anxiety in older adults
}

Citation for published version (APA):

Gulpers, B. J. A. (2019). Anxiety in older adults: Correlates, comorbidities and prognosis with lifespan perspectives. [Doctoral Thesis, Maastricht University]. Universiteit Maastricht.

https://doi.org/10.26481/dis.20190626bg

Document status and date:

Published: 01/01/2019

DOI:

$10.26481 /$ dis.20190626bg

Document Version:

Publisher's PDF, also known as Version of record

\section{Please check the document version of this publication:}

- A submitted manuscript is the version of the article upon submission and before peer-review. There can be important differences between the submitted version and the official published version of record.

People interested in the research are advised to contact the author for the final version of the publication, or visit the DOI to the publisher's website.

- The final author version and the galley proof are versions of the publication after peer review.

- The final published version features the final layout of the paper including the volume, issue and page numbers.

Link to publication

\footnotetext{
General rights rights.

- You may freely distribute the URL identifying the publication in the public portal. please follow below link for the End User Agreement:

www.umlib.nl/taverne-license

Take down policy

If you believe that this document breaches copyright please contact us at:

repository@maastrichtuniversity.nl

providing details and we will investigate your claim.
}

Copyright and moral rights for the publications made accessible in the public portal are retained by the authors and/or other copyright owners and it is a condition of accessing publications that users recognise and abide by the legal requirements associated with these

- Users may download and print one copy of any publication from the public portal for the purpose of private study or research.

- You may not further distribute the material or use it for any profit-making activity or commercial gain

If the publication is distributed under the terms of Article $25 \mathrm{fa}$ of the Dutch Copyright Act, indicated by the "Taverne" license above, 


\section{ANXIETY IN OLDER ADULTS}

Correlates, comorbidities and prognosis with lifespan perspectives

Bernice Gulpers 
(C) Bernice Gulpers, Maastricht 2019

Cover design and illustration: Evelien Jagtman

Lay-out: XML 2 publish

Printing: Gildeprint BV

ISBN:978-94-6323-680-5 


\title{
ANXIETY IN OLDER ADULTS \\ Correlates, comorbidities and prognosis with lifespan perspectives
}

\author{
Proefschrift \\ ter verkrijging van de graad van doctor aan de Universiteit Maastricht, \\ op gezag van de Rector Magnificus, Prof.dr. Rianne M. Letschert \\ volgens het besluit van het College van Decanen, \\ in het openbaar te verdedigen \\ op woensdag 26 juni 2019 om 14:00 uur \\ door
}

Bernice Josina Astrid Gulpers 
Promotores:

Co-promotores:

Beoordelingscommissie:
Prof. Dr. F.R.J. Verhey

Prof. Dr. R.C. Oude Voshaar

Dr. S. Köhler

Prof. Dr. M.E. de Vugt (voorzitter)

Dr. J.M.H. Joosten

Dr. A.M. Roest (Rijksuniversiteit Groningen)

Prof. Dr. K.R.J Schruers

Prof. Dr. M.L. Stek

(GGZ in Geest/ VU medisch centrum Amsterdam) 


\title{
TABLE OF CONTENTS
}

Chapter 1 General introduction

Page

\author{
Chapter 1 General introduction
}

for cognitive decline and dementia:

Chapter 2 Anxiety as a predictor for cognitive decline and dementia:

a systematic review and meta-analysis

Chapter 3 Anxiety disorders and figural fluency:

a measure of executive function

Chapter 4 Anxiety as a risk factor for cognitive decline:

a twelve year follow-up cohort study

Chapter 5 Personality and negative life-events predicts course of anxiety in older adults with late-life depression

Chapter 6 The impact of personality pathology on treatment outcome in late-life panic disorder

Chapter 7 General discussion

Summary

Samenvatting

Valorisation addendum

Acknowledgements

165

Curriculum Vitae

171

List of publications

175 



\section{Chapter 1}

General introduction 


\section{GENERAL INTRODUCTION}

\section{Background}

Anxiety disorders are the most common psychiatric disorders in older adults with a lifetime prevalence of $15.3 \%$, outnumbering mood disorders like depression, which have a lifetime prevalence of $11.9 \%$.(Kessler et al., 2005) Subsyndromal anxiety is even more prevalent than anxiety disorders in older adults, with a lifetime prevalence of $18.5 \%$.(Heun et al., 2000) Anxiety is associated with pervasive social and health consequences and a significantly lower quality of life, which might even be greater than those associated with a major depression.(Markowitz et al., 1989)

In clinical practice, anxiety disorders are often missed due to various reasons. First, the DSM-criteria are not adapted to the different clinical presentation of anxiety in older adults. For example, older adults with panic disorder present with less agoraphobic cognitions (like the thought of having a heart attack) than younger adults, possibly eliminating one of the needed DSM-criteria to diagnose panic disorder.(Hendriks et al., 2010) Second, older adults feel less comfortable discussing their mental health due to the stigma. Approximately $70 \%$ of older adults with mood and anxiety disorders do not use mental health services.(Byers et al., 2012) Third, anxiety complaints, especially avoidance behavior, in older adults are more accepted in the society.(Farabaugh et al., 2012) Fear of falling is often encountered as a normal phenomenon in older adults, without checking whether this fear might be excessively related to their physical status. Fourth, during consultations at the general practitioner priority is given to somatic complaints, and after excluding a somatic cause no attention is given to a possible psychiatric cause.(Farabaugh et al., 2012) Fifth, somatic complaints often are triggers to either the beginning of anxiety or the worsening of it, which complicates the diagnostic process.(Farabaugh et al., 2012)

Recognition of anxiety in older adults is therefore important, especially since research showed that older adults benefit from treatment as similar to younger adults. Cognitive behavioral treatment (CBT) is effective in older adults with effect sizes comparable to those for CBT in the general population.(Thorp et al., 2009, Ramos and Stanley, 2018) Alternative treatments also seem to be effective and are not inferior to CBT, e.g. supportive therapy or relaxation therapy.(Ramos and Stanley, 2018, Thorp et al., 2009) Pharmacotherapy with selective serotonin reuptake inhibitors (SSRIs) or serotonin-norepinephrine reuptake inhibitors (SNRIs) results in less anxiety in older adults with an effect comparable with younger adults.(Wolitzky-Taylor et al., 2010, Ramos and Stanley, 2018) Clinicians, however, should be aware of a higher risk for falling, fractures and cognitive complaints. (French et al., 2006, Liu et al., 1998, Petrovic et al., 2003) Benzodiazepines are the most prescribed drugs, however they are not effective on the long term.(Schuurmans et al., 2005) Clinicians should be cautious with benzodiazepines, since patients will develop tolerance 
and addiction next to the higher risk for falls, fractures and cognitive complaints.(Kan et al., 1998, GGZ, 2008)

Despite the importance of recognizing and treating the high prevalent anxiety disorders in older adults, relative little research is conducted compared to the bulk of research about depression in older adults. This thesis tries to fill this gap of research by examining anxiety in later life from a lifespan perspective.

This thesis consists of two parts for pragmatic reasons. The first part is about correlates and comorbidities of anxiety related to cognitive functioning. Lifespan perspectives are included as the influence of age is thoroughly studied. The second part is about comorbidities and prognosis of anxiety. More specifically, the influence of comorbid personality pathology on the course of anxiety in older adults, and on the treatment outcome in younger and older adults with anxiety is studied.

\section{PART A}

\section{Correlates and comorbidities of anxiety related to cognitive functioning}

Although most anxiety disorder originate earlier in life, geriatric psychiatrists are often confronted with new-onset anxiety symptoms in later life. Although this might be explained by the fact that invalidating symptoms presenting at a higher age more strongly motivates patients to seek (mental) help compared to patients "accustomed" to longstanding anxiety symptoms, anxiety is often regarded as a sign of early cognitive decline.

Case A

Mr. M. is 79 years old and has never had psychological complaints in the past. At the time of presentation at the outpatient psychiatric clinic due to late-onset anxiety, a malignant kidney tumor with no metastasis was diagnosed. Mr. M. called his general practitioner and medical specialists often.

At the first visit by the psychiatrist, $\mathrm{Mr} \mathrm{M}$. explained feeling nervous. It was noted that the patient had difficulties describing chronologically the medical problems and the interventions from the doctors. He sat at his table with a bunch of notes around him with the advices he has gotten from the different doctors. However, he had no overview and kept trying to comprehend his somatic complaints and the best strategy of how to deal with them. The MMSE score was 25 out of 30 , and the clock-drawing test had a score of four out of five (especially problems on delayed recall).

After successfully treating his kidney tumor, the nervous feeling persevered and $\mathrm{Mr}$. M. got problems with sleeping at nights due to worrying. He was preoccupied with his micturition or his bowel movements as he was also known with chronic obstipation. $\mathrm{He}$ could not be put at ease by his doctors. 
An SSRI was started and had a positive effect. The anxiety disappeared while sleep improved, and he had less problems keeping overview. His score on the MMSE improved to 29 out of 30, and on the clock-drawing test he had a score of five out of five (still one point missing on delayed recall).

During the follow-up, his family mentioned that they noticed a decline in cognitive functioning in the past year. He forgot information that was recently shared with him, and he kept having troubles keeping overview regarding to the doctor appointments and advices. There was no interference in daily life, yet. A neuropsychological test was performed, concluding that there was a cognitive disorder on the domain of executive functioning. The anxiety complaints were diagnosed as 'other specified anxiety disorder', presenting due to diminished cognitive abilities while being confronted with (new) somatic problems.

The clinician and his family were wondering whether Mr. M. would develop dementia in the future.

What can we learn from this case?

Case A again illustrates the difficulties in diagnosing anxiety disorders in patients with somatic comorbidities. When is anxiety irrational when you have been treated for a malignant kidney tumor? The presentation of the anxiety also differed over time, but not fulfilling the criteria of one of the specified anxiety disorders. A good treatment response was achieved after starting the SSRI, which was well tolerated.

Case A also illustrates the difficulties when cognitive problems are comorbid. Crosssectional studies have shown lower cognitive performances in the presence of anxiety. (Beaudreau and O'Hara, 2008) In some studies larger effect sizes are noted for memory than for other cognitive domains.(Beaudreau and O'Hara, 2008) Eysenk's processing theory however specifically hypothesizes that anxiety interferes with executive functioning.(Eysenck and Calvo, 1992) Which cognitive domains are indeed affected by anxiety is unclear. More knowledge will be helpful to differentiate between other possible causes of cognitive dysfunction, and could lead to a better judgement of the prognosis in patients presenting with anxiety. In case A, the scores on the cognitive screening tests (MMSE and clock drawing test) are lower while the patient is experiencing anxiety symptoms compared to when the anxiety symptoms are in remission. Despite a high score on the MMSE and clock-drawing test, the family noticed a decline in memory and executive functioning. The MMSE is not very sensitive in detecting problems with executive functioning. In clinical practice you also have to take into account that the MMSE is sensitive to educational level, as high educated persons can compensate better and score high on the MMSE even when they are cognitively impaired.(Monsch et al., 1995, Naugle and Kawczak, 1989) The extensive neuropsychological examination confirmed the problems according to executive functioning, but did not objectify the memory complaints. It is not clear whether Mr. M. has an underlying neurodegenerative disorder. The course of cognitive disorders (no dementia) 
is variable.(Jonker et al., 2009) Some cognitive disorders will go in remission, others will stay stable and others will deteriorate further into dementia.(Jonker et al., 2009) The course depends, among other things, on age and the setting (i.e. general population or specialized memory clinics) in which the patient has been seen, with the highest rates of reversibility of cognitive disorders being present in adults younger than 65 years in the general population. (Jonker et al., 2009)

\section{Research questions:}

Next to the positive treatment effects for anxiety, the value of anxiety as a prognostic factor might also make it important to adequately diagnose anxiety. Previous research has postulated anxiety as a risk factor for cognitive decline in older adults. The results however are conflicting (Brodaty et al., 2012, Wadsworth et al., 2012, Bierman et al., 2008, Pietrzak et al., 2014). It is especially important to take the setting into account when studying anxiety, which in itself may drive referral seeking for reassurance.

1. Is anxiety indeed a risk factor for cognitive impairment or dementia? (Chapter 2)

2. Is this risk influenced by the setting of the research? (Chapter 2)

We hypothesize that anxiety is a risk factor for cognitive impairment or dementia, and that this risk is influenced by the setting. This is considered to partly explain the conflicting results in previous research. This was studied by performing a meta-analysis of previous studies. A systematic review was performed to study the effect of anxiety on decline of specific cognitive domains. Meta-analysis was not possible because of heterogeneity in the cognitive domains as well as the used cognitive tests.

3. Is executive functioning negatively affected during a state of anxiety, and is there a differential effect between younger and older adults? (Chapter 3)

We hypothesize that executive functioning is worse during a state of anxiety as described by Eysenk's processing theory.(Eysenck and Calvo, 1992) We hypothesize that this effect is larger in older adults as the risk for an underlying neurodegenerative disease is higher. This was studied using the cross-sectional data of the Lifelines population-based cohort study.

Based on our findings in chapter 1 , we studied the association between anxiety and decline on specific cognitive domains.

4. Which cognitive domains are negatively affected in older adults by anxiety over time? (Chapter 4)

We hypothesize that executive functioning is affected negatively over time as this was suggested by the systematic review in chapter 2 . This was studied with the data of a twelve-year follow-up cohort study (the Maastricht Aging Study). 


\section{PART B}

\section{Comorbidities and prognosis of anxiety with lifespan perspectives}

As said, anxiety disorders are a highly prevalent problem in older adults with effective treatment regimens when recognized appropriately. In the clinical practice of specialized mental health care however, patients are encountered with less favorable treatment outcomes. It is important to understand the predictors of non-response or partial-response to be able to adapt the treatment for the individual patient leading to better results.

Case B

Mrs. V. is 77 years old, and she had experienced periods with anxiety complaints for more than fifty years. After the death of her husband, the anxiety complaints became worse. For the first time, Mrs. V. visited a psychiatric outpatient clinic for panic symptoms. She often felt heart palpitations and dizziness. At these moments she was afraid to get a heart attack or that she will faint. She had visited the general practitioner many times and every time the physical examination and the electrocardiogram showed no abnormalities. At those moments, Mrs V. was put at ease, but when she would experience the heart palpitations or the dizziness on a later moment the same anxiety complaints occurred. Other possible somatic equivalents of anxiety, like nausea and diarrhea, were present but appeared to be chronic complaints of Mrs. V. rather than an expression of the anxiety complaints. At the outpatient clinic, the anxiety complaints with somatic equivalents were diagnosed as panic attacks. During a panic attack, she would take an extra Lorazepam resulting in diminishing of the panic attack. Mrs. V. was scared of having new panic attacks, especially when she was alone and no direct help was available. Despite of this anxiety she often engaged in activities outside the house. She did not avoid certain activities or places. When asked thoroughly, it appeared that Mrs. V. almost always undertook activities in the presence of a family member or friend, or she would take an extra Lorazepam before she would leave the house. It became obvious that the general practitioner had prescribed benzodiazepines and slowly increased the dosages over the years. A panic disorder with agoraphobia and benzodiazepine dependence was diagnosed. CBT was started and led to less frequent panic attacks, however the safety behavior persevered. Then, an SSRI was added to the treatment, but it was soon stopped due to perceived side-effects. No complete remission was achieved, but Mrs. V. was happy with the improvement she had made. The treatment was ended.

After 1.5 years, Mrs. V. had a relapse according to her anxiety complaints. This time, a structured personality interview was conducted (Structured Clinical Interview for DSM-IV Axis II Personality Disorders; SCID-II). An avoidant and obsessive-compulsive personality disorder was diagnosed next to the panic disorder with agoraphobia and benzodiazepinedependency. Mrs. V. was not inclined to start with psychotherapy focusing on her per- 
sonality. Instead, five booster sessions of CBT were given. Improvement of the anxiety complaints was again achieved with Mrs. V being satisfied at the end of the sessions.

After the first treatment the clinician wondered why the treatment only had a modest effect. Therefore, after the new referral, the possibility of comorbid personality pathology was examined. After the comorbid personality pathology was established, the clinician wondered whether the personality disorder had an unfavorable effect on the course of the panic disorder leading to the relapse.

What can we learn from this case?

Case B illustrates the difficulties in diagnosing anxiety disorders in patients with somatic comorbidities. A general problem in diagnosing panic disorder with agoraphobia occurs when the avoiding is successful. Panic attacks are then rare, or activities are undertaken but only with safety measures. Another problem in diagnosing panic disorder is the differential diagnosis with personality pathology.(Hengeveld and van Balkom, 2005) For example, an avoidant personality disorder can resemble avoidance behavior in panic disorder. To diagnose a personality disorder, the dysfunctional patterns have to be stable, of long duration, and its onset can be traced back at least to adolescence or early adulthood.(Association, 2014) However, the course of anxiety disorders can also be chronic, but is generally less stable with periods with minimal or no anxiety complaints. Furthermore, in previous research, personality pathology has been shown to be less stable than one might expect with patients reaching remission, i.e. not fulfilling DSM-criteria anymore after just one or two years.(Skodol et al., 2005) One might thus speculate that persistent personality pathology represents more severe personality pathology.

The improvement of the panic symptoms seen in case B with CBT is in line with previous research in older adults.(Hendriks et al., 2008) However, complete remission was not achieved. In the clinical practice of a psychiatric outpatient clinic, as illustrated in case B, one often sees more severe patients (e.g. more severe complaints, or with more comorbidities like depression or personality disorder) than the persons included in research. In clinical practice, it is often assumed that comorbid personality disorders have a negative influence on treatment outcome due to e.g. poor compliance to treatment regimes, problems in the therapeutic alliance, or a poor motivation for treatment.(Padesky, 1988, Reich, 2003b, Slaap and den Boer, 2001) Research in young adults often show a worse treatment outcome of anxiety (CBT and pharmacotherapy) in the presence of comorbid personality pathology, also specifically in panic disorder (Mennin and Heimberg, 2000, Reich, 2003a, Slaap and den Boer, 2001). In older adults the possible aspect of personality pathology as predictor of treatment outcome is hardly investigated, but of great importance for clinical practice.

Also the course of anxiety complaints in older adults are possibly influenced by comorbid personality pathology, as in younger adults it predicts chronicity and higher relapse rates. (Pollack et al., 1992, Green and Curtis, 1988) This could possibly enlarge the percentages 
of comorbid personality pathology in older adults presenting with anxiety, as it often are chronic complaints present throughout the lifespan.

\section{Research questions}

In part B of this thesis, we will focus on the course of (often long-standing) anxiety symptoms in older persons, as less than $1 \%$ of lifetime anxiety disorders has an onset in later life.(Kessler et al., 2005) As stated earlier, subsyndromal anxiety is even more prevalent than anxiety disorders in older adults.(Heun et al., 2000) High anxiety levels not fulfilling the DSM-criteria can also be specified as anxious distress in a major depressive disorder (DSM-V specifier), which represents a subtype of depression with more impairment, and worse treatment outcome in younger and older adults.(Farabaugh et al., 2012, Fava et al., 2008, Lenze et al., 2002) Among depressed older patients, comorbid anxious distress or comorbid anxiety disorders identify completely different patients. (van der Veen et al., 2014) Studies on remission rates in patients with depressive disorder only focus on remission of the depressive disorder and ignores the often comorbid anxiety symptoms. Meaningful remission for patients however, is remission of the depressive disorder and the comorbid anxiety. By our knowledge, no previous studies have studied predictors of complete remission, defined as no depressive and no anxiety disorder at follow-up, in older adults with depressive disorder.

Personality traits and life-events have been extensively studied in depressive disorder, mostly in younger adults. Studies about the specific association between personality traits and life-events with the anxiety specifier in depression is scarce, while anxious depression denotes an important and different subgroup within patients with a major depressive disorder.

1. Which predictors influences complete remission rates, defined as no depressive or anxiety disorder at follow-up, in older patients with a major depressive disorder? (Chapter 5)

This research question was studied with longitudinal data from the Netherlands Study of Depression in Older persons (NESDO), which is a multi-site naturalistic cohort study. Previous studies in late-life depression showed that female gender, a greater medical burden, high levels of neuroticism and negative life-events, and in anxiety that also female gender and high levels of neuroticism are predictors for non-remission. (Kotov et al., 2010, Kraaij et al., 2002, Andreescu et al., 2008, de Beurs et al., 2000) Whether negative life events are also predictors for late-life anxiety remains ambiguous. It is important to distinguish between the exposure to stressors and the perception of stressors when studying the impact of negative life events.(Vasunilashorn et al., 2015) The destabilizing appraisal of stress and the dysfunctional coping with negative life events are closely related to personality traits as neuroticism and sense of mastery. We hypothesize that high levels of neuroticism and low levels of mastery are moderators of a negative effect of negative life events on anxiety symptoms, which may partly explain inconsistent findings in previous studies. 
2. Do negative life events in older adults predict the course of anxiety symptoms comorbid to a depressive disorder and is this impact moderated by personality features? (Chapter 5) We hypothesize that high levels of neuroticism and a low sense of mastery in the presence of negative life-events are associated with anxiety levels in patients with a depressive disorder, whereas other personality characteristics are expected to have no conclusive moderating effects. This research question was also studied with longitudinal data from the NESDO cohort study.

Long-standing anxiety symptoms are easily mixed up with personality problems but need a different approach in clinical practice. As stated earlier, in young adults, personality pathology generally worsens the outcome of anxiety disorders. This is highly relevant as metaanalyses have shown that up to half of the patients with an anxiety disorder also suffer from a personality disorder.(Friborg et al., 2013) By our knowledge, research in older persons with anxiety disorders studying the effects of comorbid personality pathology on treatment outcome are lacking. More specifically, we will address the following research questions:

3. Does personality pathology negatively interfere with treatment outcome of CBT for panic disorder with agoraphobia and does this interference changes with increasing age? (Chapter 6)

We hypothesize that personality pathology also has a negative effect on CBT treatment outcome in late-life panic disorder as it does in younger adults with panic disorder. We hypothesize that the negative effect is larger in older adults than in younger adults as persisting comorbid personality pathology throughout the lifespan might represent more severe personality pathology. For this research question we combined two groups of older patients from two historical treatment studies of CBT (one also comparing Paroxetine, an SSRI, with CBT).

4. Has personality pathology a differential impact on evidence-based treatment modalities for panic disorder in later life (i.e. SSRI versus CBT)? (Chapter 6)

We hypothesize that both treatment modalities (Paroxetine and CBT) are influenced negatively by comorbid personality pathology in late-life panic disorder, as it does in younger adults.

We hypothesize that the effect is larger when treated with CBT as it requires an active attitude from the patient, e.g. making homework or exposing themselves to situations they are afraid of with or without the therapist. As comorbid personality pathology is associated with poor compliance to treatment regimens, problems in the therapeutic alliance and a poor motivation for treatment this might interfere more with CBT requiring an active attitude, compared to 'passive' treatment with a SSRI. This was studied using the data of the randomized controlled trial in older adults. The participants either being randomized in the CBT group or Paroxetine group were included, excluding the participants randomized to the waiting-list condition. 


\section{REFERENCES}

ANDREescU, C., CHANG, C. C., MUlSANT, B. H. \& GANGUli, M. 2008. Twelve-year depressive symptom trajectories and their predictors in a community sample of older adults. Int Psychogeriatr, 20, 221-236.

ASSOCIATION, A. P. 2014. Handboek voor de classificatie van psychische stoornissen (DSM-5). Boom uitgevers Amsterdam.

BEAUDREAU, S. A. \& O'HARA, R. 2008. Late-life anxiety and cognitive impairment: a review. Am J Geriatr Psychiatry, 16, 790-803.

BIERMAN, E. J., COMIJS, H. C., RIJMEN, F., JONKER, C. \& BEEKMAN, A. T. 2008. Anxiety symptoms and cognitive performance in later life: results from the longitudinal aging study Amsterdam. Aging Ment Health, 12, 517-523.

BRODATY, H., HEFFERNANA, M., DRAPERA, B., REPPERMUND, S., KOCHAN, N. A., SLAVINA, M. J., TROLLORB, J. N. \& SACHDEVA, P. S. 2012. Neuropsychiatric Symptoms in Older People with and Without Cognitive Impairment. Journal of Alzheimer's disease, 31, 411-420.

BYERS, A. L., AREAN, P. A. \& YAFFE, K. 2012. Low use of mental health services among older Americans with mood and anxiety disorders. Psychiatr Serv, 63, 66-72.

DE BEURS, E., BEEKMAN, A. T., DEEG, D. J. \& AL., E. 2000. Predictors of change in anxiety symptoms of older persons: results from the Longitudinal Aging Study Amsterdam. Psychol Med, 30, 515-527.

EYSENCK, M. W. \& CALVO, M. G. 1992. Anxiety and performance: the processing efficiency theory. . Cogn. Emot., 6, 409-434.

FARABAUGH, A., ALPERT, J., WISNIEWSKI, S. R., OTTO, M. W., FAVA, M., BAER, L. \& THASE, M. E. 2012. Cognitive therapy for anxious depression in STAR(*) D: What have we learned? Journal of Affective Disorders, 142, 213-218.

FAVA, M., RUSH, A. J., ALPERT, J. E., BALASUBRAMANI, G. K., WISNIEWSKI, S. R., CARMIN, C. N. \& TRIVEDI, M. H. 2008. Difference in treatment outcome in outpatients with anxious versus nonanxious depression: A STAR*D report. The American Journal of Psychiatry, 165, 342-351.

FRENCH, D. D., CAMPBELL, R., SPEHAR, A., CUNNINGHAM, F., BULAT, T. \& LUTHER, S. L. 2006. Drugs and falls in community-dwelling older people: a national veterans study. Clin Ther, 28, 619630 .

FRIBORG, O., MARTINUSSEN, M., KAISER, S., OVERGÅRD, K. T. \& ROSENVINGE, J. H. 2013. Comorbidity of personality disorders in anxiety disorders: a meta-analysis of 30 years of research. $J$ Affect Disord, 145, 143-155.

GGZ, L. S. M. R. I. D. 2008. Multidisciplinaire ichtlijn angststoornissen addendum ouderen. www.trimbos. $n l$.

GREEN, M. \& CURTIS, G. C. 1988. Personality disorders and panic patients: Response to termination of antipanic medication. J Person Disord, 2, 303-314.

HENDRIKS, G. J., KEIJSERS, G. P., KAMPMAN, M., VOSHAAR, R. C. \& HOOGDUIN, C. A. 2010. Agoraphobic cognitions in old and young patients with panic disorder. Am J Geriatr Psychiatry, 18, 1155-1158.

HENDRIKS, G. J., OUDE VOSHAAR, R. C., KEIJSERS, G. P. J., HOOGDUIN, C. A. L. \& VAN BALKOM, A. J. L. M. 2008. Cognitive-behavioural therapy for late-life anxiety disorders: a systematic review and meta-analysis. Acta Psychiatr Scand, 117, 403-411.

HENGEVELD, M. W. \& VAN BALKOM, A. J. L. M. 2005. Leerboek psychiatrie. de Tijdstroom.

HEUN, R., PAPASSOTIROPOULOS, A. \& PTOK, U. 2000. Subthreshold depressive and anxiety disorders in the elderly. Eur Psychiatry, 15, 173-182. 
JONKER, C., SLAETS, J. P. J. \& VERHEY, F. R. J. 2009. Handboek dementie. Bohn Stafleu van Loghum.

KAN, C. C., BRETELER, M. H. \& ZITMAN, F. G. 1998. High prevalence of benzodiazepine dependence in out-patient users, based on the DSM-III-R and ICD-10 criteria. Acta Psychiatr Scand, 96, 85-93.

KESSler, R. C., BERGlund, P., DEMLER, O., JIN, R., MERIKANGAS, K. R. \& WALTERS, E. E. 2005. Lifetime prevalence and age-of-onset distributions of DSM-IV disorders in the National Comorbidity Survey Replication. Arch Gen Psychiatry, 62, 593-602.

KOTOV, R., GAMEZ, W., SCHMIDT, F. \& WATSON, D. 2010. Linking "big” personality traits to anxiety, depressive, and substance use disorders: a meta-analysis. Psychol Bull, 136, 768-821.

KRAAIJ, V., ARENSMAN, E. \& SPINHOVEN, P. 2002. Negative life events and depression in elderly persons: a meta-analysis. Gerontol B Psychol Sci Soc Sci 57, 87-94.

LENZE, E. J., MULSANT, B. H., SHEAR, M. K., HOUCK, P. \& REYNOLDS III, C. F. 2002. Anxiety symptoms in elderly patients with depression: What is the best approach to treatment? Drugs \& Aging, 19, 753-760.

LIU, B., ANDERSON, G., MITTMANN, M., TO, T., AXCELL, T. \& SHEAR, N. 1998. Use of selective serotonin-reuptake inhibitors or tricyclic antidperessants and risk of hip fractures in elderly people. The Lancet, 351, 1303-1307.

MARKOWITZ, J. S., WEISSMAN, M. M., OUELletTE, R., LISH, J. D. \& KLERMAN, G. L. 1989. Quality of life in panic disorder. Arch Gen Psychiatry, 46, 984-92.

MENNIN, D. S. \& HEIMBERG, R. G. 2000. The impact of comorbid mood and personality disorder in the cognitive-behavioral treatment of panic disorder. Clinical Psychology Review, 20, 339-357.

MONSCH, A. U., FOLDI, N. S., ERMINI-FÜNFSCHILlinG, D. E., BERRES, M., TAYLOR, K. I., SEIFRITZ, E., STÄHELIN, H. B. \& SPIEGEL, R. 1995. Improving the diagnostic accuracy of the Mini-Mental State Examination. Acta Neurol Scand, 92, 145-150.

NAUGLE, R. I. \& KAWCZAK, K. 1989. Limitations of the Mini-Mental State Examination. Cleve Clin J Med, 56, 277-281.

PADESKY, C. A. 1988. Schema-focused CT: comments and questions. Int Cogn Ther Newsletter, 4, 5-7.

PETROVIC, M., MARIMAN, A., WARIE, H., AFSCHRIFT, M. \& PEVERNAGIE, D. 2003. Is there a rationale for prescription of benzodiazepines in the elderly? Review of the literature. Acta Clin Belg, $58,27-36$

PIETRZAK, R. H., SCOTT, J. C., NEUMEISTER, A., LIM, Y. Y., AMES, D., ELLIS, K. A., HARRINGTON, K., LAUTENSCHLAGER, N. T., SZOEKE, C., MARTINS, R. N., MASTERS, C. L., VILLEMAGNE, V. L., ROWE, C. C. \& MARUFF, P. 2014. Anxiety symptoms, cerebral amyloid burden and memory decline in healthy older adults without dementia: 3-year prospective cohort study. Br J Psychiatry, 204, 400-401.

POLlACK, M. H., OTTO, M. W., ROSENBAUM, J. F. \& SACHS, G. S. 1992. Personality disorders in patients with panic disorder: association with childhood anxiety disorders, early trauma, comorbidity, and chronicity. Compr Psychiatry, 33, 78-83.

RAMOS, K. \& STANLEY, M. A. 2018. Anxiety Disorders in Late Life. Psychiatr Clin North Am, 41, 55-64.

REICH, J. 2003a. The effect of axis II disorders in the outcome of treatment of anxiety and unipolar depressive disorders: a review. Journal of Personality Disorders, 17, 387-405.

REICH, J. 2003b. The effect of Axis II disorders on the outcome of treatment of anxiety and unipolar depressive disorders: a review. J Pers Disord, 17, 387-405.

SCHUURMANS, J., COMIJS, H. C., BEEKMAN, A. T., DE BEURS, E., DEEG, D. J., EMMELKAMP, P. M. \& VAN DYCK, R. 2005. The outcome of anxiety disorders in older people at 6-year follow-up: results from the Longitudinal Aging Study Amsterdam. Acta Psychiatr Scand, 111, 420-428. 
SKODOL, A. E., GUNDERSON, J. G., SHEA, M. T., MCGLASHAN, T. H., MOREY, L. C., SANISLOW, C. A., BENDER, D. S., GRILO, C. M., ZANARINI, M. C., YEN, S., PAGANO, M. E. \& STOUT, R. L. 2005. The Collaborative Longitudinal Personality Disorders Study (CLPS): overview and implications. J Pers Disord, 19, 487-504.

SLAAP, B. R. \& DEN BOER, J. A. 2001. The prediction of nonresponse to pharmacotherapy in panic disorder: a review. Depress Anxiety, 14, 112-22.

THORP, S. R., AYERS, C., NUEVO, R. \& AL., E. 2009. Meta-analysis comparing different behavioral treatments for late-life anxiety. Am J Geriatr Psychiatry, 17, 105-115.

VAN DER VEEN, D. C., COMIJS, H. C., SCHOEVERS, R. A., VAN ZELST, W. H. \& OUDE VOSHAAR, R. C. 2014. Defining anxious depression in later life: A scaring heterogeneity in results. American Journal of Geriatric Psychiatry, 22, 1375-1378.

VASUNILASHORN, S., LYNCH, S. M., GLEI, D. A. \& AL., E. 2015. Exposure to stressors and trajectories of perceived stress among older adults. J Gerontol B Psychol Sci Soc Sci, 70, 329-337.

WADSWORTH, L. P., LORIUS, N., DONOVAN, N. J., LOCASCIO, J. J., RENTZ, D. M., JOHNSON, K. A., SPERlinG, R. A. \& MARShALL, G. A. 2012. Neuropsychiatric symptoms and global functional impairment along the Alzheimer's continuum. Dement Geriatr Cogn Disord, 34, 96-111.

WOLITZKY-TAYLOR, K. B., CASTRIOTTA, N., LENZE, E. J., STANLEY, M. A. \& CRASKE, M. G. 2010. Anxiety disorders in older adults: a comprehensive review. Depress Anxiety, 27, 190-211. 



\section{Chapter 2}

\section{Anxiety as a predictor for cognitive decline and dementia: a systematic review and meta-analysis}




\section{ABSTRACT}

Background -Since anxiety is postulated as a risk factor for dementia, we performed a systematic review and meta-analysis to investigate whether anxiety predicts cognitive decline and/or dementia taking the stage of cognitive decline as well as setting into account.

Method - A systematic literature search up to January 2015 was performed to identify all longitudinal studies on the association between anxiety and cognition. Data-extraction and methodological quality assessment were conducted independently by two authors. Where possible, pooled relative risks were calculated to examine anxiety as a possible risk factor for cognitive decline cognitive impairment and dementia in community studies (objective 1), as well as for conversion to dementia patients referred to memory clinics (objective 2).

Results - Twenty studies met inclusion criteria. Data on cognitive decline were too heterogeneous for meta-analysis. Anxiety predicted incident cognitive impairment (4 studies, $\mathrm{RR}=1.77$ [95\% CI: 1.38-2.26], $\mathrm{z}=4.50, \mathrm{p}<.001)$ and dementia (6 studies, $\mathrm{RR}=1.57[95 \%$ CI: $1.02-2.42], \mathrm{z}=2.05, \mathrm{p}=.040$ ) in the community, the latter driven by studies with a mean age of 80 or above. Among clinical MCI samples, anxiety did not predict conversion to dementia $(\mathrm{RR}=1.21$ [95\% CI: $0.90-1.63], \mathrm{z}=1.28, \mathrm{p}=.200)$.

Conclusion - Anxiety is associated with an increased risk for cognitive impairment and dementia in the community. Stronger associations were driven by higher age suggesting it is a prodromal symptom. Causal biological pathways have been described too, which could explain the risk for incident cognitive impairment in the community. Future studies should include mediating mechanism when studying anxiety as a predictor for cognitive decline and/or dementia. 


\section{INTRODUCTION}

It is important to study risk factors that affect dementia rates. Studies have noted decreased prevalence rates for dementia among people born in the first half of the $20^{\text {th }}$ century.(Larson et al., 2013) Explanations for this trend are possibly higher education and better control of cardiovascular risk factors.(Larson et al., 2013) Neuropsychiatric symptoms have often been proposed as possible risk factors for developing dementia. Depression and anxiety are among the most common neuropsychiatric symptoms presenting in mild cognitive impairment (MCI).(Geda et al., 2004) Depression has been studied extensively as a possible risk factor, and it is supposed that depressive symptoms predicts conversion from MCI to dementia as well as incident dementia in the general population.(Gao et al., 2013) In contrast, the effect of anxiety is less clear as studies are scarce and vary in methodology, especially according to the setting and stage of the neurodegenerative process.(Beaudreau and O'Hara, 2008)

People with MCI have a greater risk for dementia, compared to the general population, respectively $10-15 \%$ vs $1-2 \%$ per year.(Petersen et al., 2001) In the present paper, we will specifically address potential heterogeneity due to the stage of the disease as well as the setting. To study causal risk factors for dementia it is necessary to avoid referral bias and thus population studies are preferred over samples recruited in memory clinics. This is especially important with respect to anxiety, which in itself may drive referral seeking for reassurance. The prevalence rate of anxiety in MCI populations for example differs between 3 and 45\%, while limited to community-dwelling MCI patients figures between 2 and $4 \%$ are reported.(Apostolova and Cummings, 2008, Petersen et al., 2001)

Nonetheless, many studies have examined neuropsychiatric symptoms in populations with MCI, looking at the conversion rates to dementia. This is important information for patients and clinicians working in memory clinics irrespective of an association is causal or not. Neuropsychiatric symptoms in MCI subjects could be a prodromal expression of the underlying neurodegenerative process or a causal factor of the dementia. Therefore, reverse causality may lead to false positive results when examining anxiety as a causal risk factor for dementia. This issue can be partly addressed by investigating anxiety as a risk factor for cognitive decline, incident cognitive impairment and finally dementia, separately.

In this systematic review and meta-analysis, we therefore addressed whether anxiety is predictive for cognitive decline, cognitive impairment and/or dementia in the community, including a subgroup analysis to explore the effect of MCI in community-based samples (objective 1). In addition, the effect of anxiety on conversion to dementia in patients referred to specialised memory clinics was evaluated (objective 2). 


\section{METHODS}

\section{Search strategy}

We searched the Pubmed, Psycinfo, Embase and Cinahl databases for relevant publications until January 2015 on cohort studies about the association between anxiety and cognitive decline or conversion to dementia. A related term for anxiety, cognition and cohort needed to be present in either the title or the abstract. The following search terms were used: 'anxiety symptoms', 'anxiety disorders', 'anxiety', 'worry', 'worries', 'fear', 'anxious', 'neuroticism', 'cognitive function*', 'cognitive impairment', 'cognitive decline', 'cognitive deficit*', 'cognition loss*', 'cognitive loss*', 'cognitive abilit*', 'dement*', 'alzheimer*', 'cognition', 'cognitive status', 'cognitive change', 'cognition change', 'cognitive performance', 'cognitive dysfunction*', 'mild cognitive impairment', 'subjective cognitive complaints', 'memory', 'memory complaints', 'follow-up', 'longitudinal', 'cohort', 'prospective', 'progress*' or 'conversion'. The search resulted in 7758 hits. Additional studies were obtained from the reference lists of the selected articles or from relevant reviews about the subject.

\section{Study selection}

The inclusion criteria were: a) longitudinal cohort studies, b) clinically relevant anxiety (dichotomous) based on either a validated scale or an anxiety disorder according to either International Classification of Diseases (ICD) or Diagnostic and Statistical criteria of Mental disorder (DSM) criteria in specialized care and International Classification of Primary Care (ICPC) criteria or equivalent in primary care, and c) for objective 1 and 2 recruitment of people in the community, for objective 3 recruitment of patients at memory clinics. The exclusion criteria were: a) anxiety only assessed as a trait or personality characteristic, b) dementia at baseline, c) samples restricted to specific somatic diseases at baseline (for example diabetes, stroke or depression), and finally d) studies about mild cognitive disorder with established underlying neurodegenerative pathology (inflating the conversion rate to dementia). Relevant studies were identified based upon the titles or abstracts, and when possible relevant upon the full-text article. English, German, French and Dutch papers were allowed. Once judged as relevant, the study was assessed regarding the two objectives. When different studies referred to the same cohort, only the study that addressed the objective most specifically was included.

\section{Data-extraction}

The relevant information was independently extracted from the included studies by two authors (BG, RH). The relevant information constituted of the number and percentage of cognitive decline or dementia, the cross table for anxiety and cognitive decline or dementia, the odds ratios, hazard ratios, relative risks or $\beta, 95 \%$ confidence interval, $\mathrm{p}$-value, the covariates and the overall conclusion of the study. In addition, the following study characteristics were extracted: cohort, baseline diagnosis, definition of cognitive status at 
baseline, setting, included ages, in- and exclusion criteria, cognition scale, anxiety scale, number of subjects, mean age and standard deviation, number of females and males, education in years, mean score of Mini Mental State Examination (MMSE) and standard deviation, mean score on the anxiety scale and the standard deviation, mean of follow-up years and the standard deviation. When there was no agreement about the data, a third reviewer was engaged to reach consensus (IR). In case of incomplete data, we contacted the corresponding authors to obtain additional information for the meta-analysis.

\section{Assessment of methodological quality}

Two authors (BG, RH) rated the quality of the studies based on the framework for considering study quality and likelihood of bias in prognostic studies. (Altman, 2001, Hayden et al., 2006) A total of 26-items were rated, related to 1) the sample of patients, 2) the follow-up of patients, 3) the loss-to-follow-up, 4) the outcome, 5) the prognostic variable and 6) the analysis (see table 1).

Table 1: Methodological quality assessment form

\begin{tabular}{|c|c|}
\hline Sample of patients: & Consecutive referrals or randomly selected patients \\
\hline & Inclusion and exclusion criteria fully described \\
\hline & Sample selection explained \\
\hline & Adequate description of diagnostic criteria \\
\hline & Clinical and demographic characteristics fully described \\
\hline & Representative sample \\
\hline & Assembled at common (usually early) point in course of disease \\
\hline & Complete (all eligible patients included) \\
\hline & Large sample size \\
\hline \multirow[t]{2}{*}{ Follow-up of patients: } & Sufficient length of follow-up \\
\hline & Low variability in follow-up length \\
\hline \multirow[t]{4}{*}{ Loss-to-follow-up: } & Attempts to collect information in participants who dropped out \\
\hline & Reasons for loss-to-follow-up \\
\hline & Key characteristics for participants loss-to-follow-up \\
\hline & $\begin{array}{l}\text { Important differences between key characteristics and outcomes in participants } \\
\text { who completed the study and who did not. }\end{array}$ \\
\hline \multirow[t]{4}{*}{ Outcome: } & Objective unbiased (for example, assessment blinded to prognostic information) \\
\hline & Fully defined \\
\hline & Based on the same tests and same information in all patients \\
\hline & Known for all or high proportion of patients \\
\hline \multirow[t]{5}{*}{ Prognostic variable } & Fully defined \\
\hline & Precisely measured \\
\hline & Method is valid \\
\hline & Available for all or high proportion of patients \\
\hline & All results described \\
\hline \multirow[t]{2}{*}{ Analysis } & Predictor variable analysed appropriately \\
\hline & Statistical adjustment for all important prognostic factors \\
\hline
\end{tabular}


Each of the 26 items was rated as present (1), questionable (0.5), or absent (0) according to the description of the study in the publication. When there was disagreement between the two authors, the third author (IR) was involved to reach consensus. In order to obtain a global measure of study quality the scores on the quality items were summed and divided by the total number of items (range 0-1.0). Outcome was considered fully defined in case validated cognitive tests were applied when looking at cognitive decline or when the dichotomous outcomes (cognitive impairment or dementia) had specified their criteria. The criterion whether the outcome was unbiased or not, was eliminated when the statistic program calculated the decline on the individual cognitive domains.

\section{Statistical analysis}

The Stata statistical software package, version 12.0 (StataCorp, College Station, Texas, USA) was used to perform the meta-analysis with a random effect model using the method by DerSimonian \& Laird, calculating pooled relative risks (RR) and $95 \%$ confidence intervals (CI). When a study did not report relative risks, the available hazard ratio or odd's ratio were used to calculate the relative risk whenever possible. In case multivariate analyses were presented by the authors, the relative risk adjusted for confounders in the final model was included in the meta-analysis. In order to include as much studies as possible, unadjusted relative risks were included when studies did not report adjusted estimates. The effect of including adjusted and unadjusted relative risks was explored by meta-regression analyses as well as by sensitivity analyses limited to studies using adjusted estimates. The possibility for publication bias was analysed by inspection of Funnel plots and Egger's test. When the Q-tests for heterogeneity (chi-squared) were significant, different variables were tested in a meta-regression analysis as possible sources of between-study differences (setting, mean age, mean MMSE, self-report-, informant based- or clinician based anxiety scale, follow-up years, methodological quality, adjustment for depression, and adjusted relative risks versus crude relative risks). Since a number of community-based studies examining incident dementia explicitly assessed baseline cognitive performance, we a priori planned a subgroup analysis of the effect of anxiety on the conversion of MCI into dementia among community-dwelling people. In addition, population attributable risks (PAR) were calculated as a measure of public health impact. The PAR shows the proportion of incident cognitive impairment or dementia that are due to anxiety, assuming a causal effect and unbiased estimates, and is a function of both the risk estimates and the prevalence of anxiety. For the latter, we pooled prevalence estimates for anxiety from random effect meta-analysis and calculated PAR using Levin's formula (Levin, 1953) . 


\section{RESULTS}

\section{Search Results and Validity}

The results of the search strategy are shown in figure 1 . Of the 7,758 hits the majority was excluded based upon the title and abstracts. Three additional studies were identified by checking the reference lists. For seven studies additional data had to be requested. No response by the corresponding author led to exclusion of three studies. Two studies were eligible for either two or three objectives.(Brodaty et al., 2012, de Bruijn et al., 2014) One study was only included for one objective while being eligible for more, since necessary data were not provided.(Palmer et al., 2007) One article was excluded for one objective due to an overlapping population, but could be included for another objective.(Wadsworth et al., 2012) Twenty studies were eventually included in the systematic review and meta-analysis.

Figure 1: Flow diagram of study selection

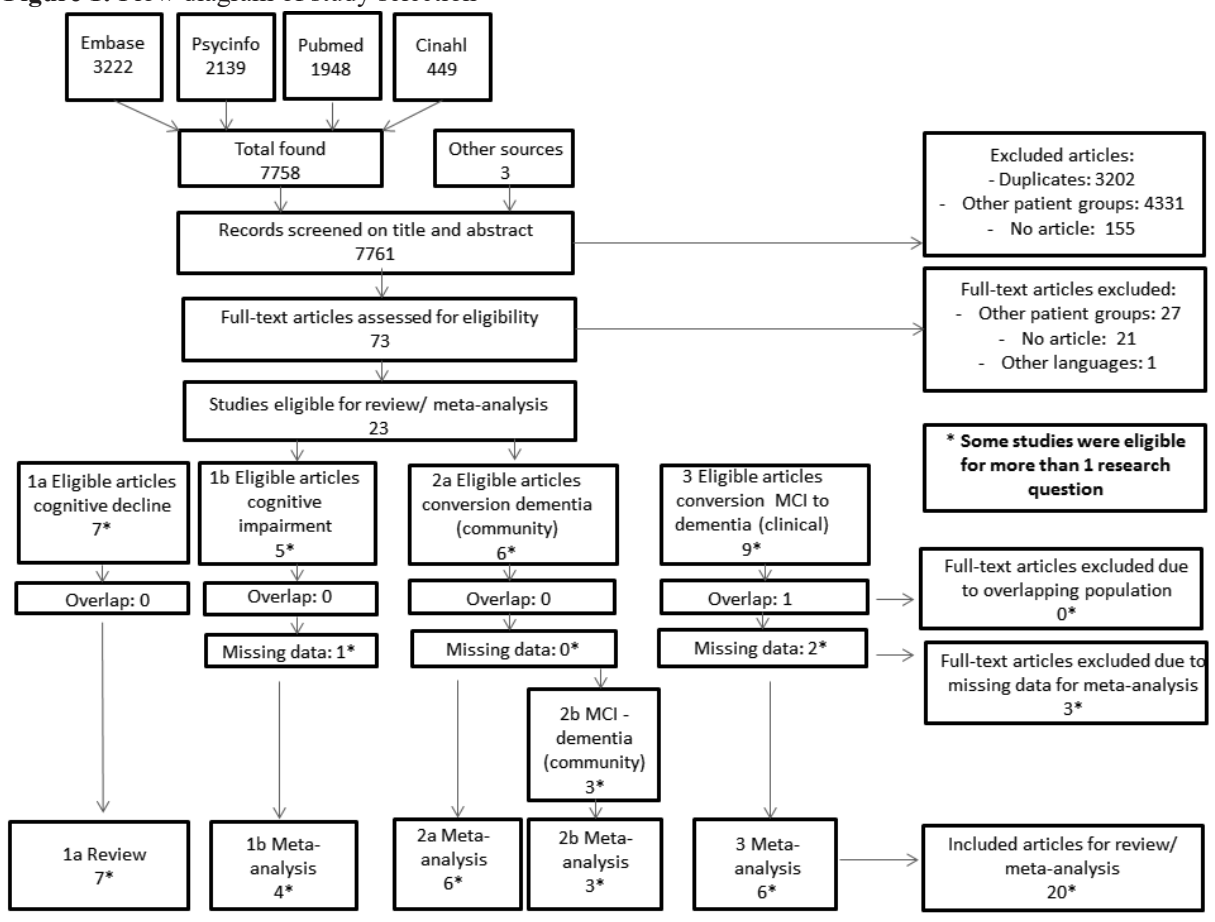

\section{Objective 1: Community-based studies}

\section{Anxiety and rate of cognitive decline}

Seven studies ( $\mathrm{N}=23,871$ subjects) assessed anxiety in relation to decline on individual cognitive domains in the community. The characteristics of these studies are summarized 
in table 2. The methodological quality of the studies varied between 0.63 and 0.88 , with an average of 0.74 . The seven studies selected for this objective, had varying sample sizes ranging from 178 (Pietrzak et al., 2014) to 16,315 subjects (Okereke and Grodstein, 2013). The follow-up duration had a broad range and differed between 1.5 to 12 years.

Meta-analysis was not possible due to heterogeneity in the cognitive domains as well as the used cognitive tests. Therefore, these studies will only be described. All seven studies investigated the association between anxiety and memory decline, of which only one study showed a significant decline.(Pietrzak et al., 2012) Three out of five studies assessing executive functioning ( $\mathrm{N}=22,721$ subjects), concluded that anxiety predicted decline on this cognitive domain ((de Bruijn et al., 2014, Brodaty et al., 2012, Pietrzak et al., 2014). Findings on all other cognitive domains were non-significant without any clues for a specific trend on some of the domains.

\section{Anxiety and risk for incident cognitive impairment}

Four studies ( $\mathrm{N}=4,155$ subjects) established the risk for incident cognitive impairment in the community. The methodological quality of the studies had a range between $0.73-0.84$ with an average of 0.80 . The size of the samples differed with 229 subjects for Wadsworth (Wadsworth et al., 2012), 397 subjects for Brodaty (Brodaty et al., 2012) and larger samples for Geda and Potvin, respectively 1,587 and 1,942 subjects.(Geda et al., 2014, Potvin et al., 2011b) The follow-up duration differed between 1 and 5 years. The pooled prevalence of anxiety in these community samples of persons without MCI at baseline was $9 \%$ [95\% CI $4-14 \%$ ].

The meta-analysis showed a significant association of anxiety as a predictor for incident cognitive impairment in the community $(\mathrm{RR}=1.77$, [95\% CI 1.38-2.26], $\mathrm{z}=4.50, \mathrm{p}<.001)$ (see figure 2). No heterogeneity across studies was found (I-square $=0.0 \%, \mathrm{Q}=1.18, \mathrm{df}=3$, $\mathrm{p}=0.813)$. The sensitivity analysis including only studies with adjusted relative risks $(\mathrm{N}=2$; 2,386 subjects) also showed a significant association $(\mathrm{RR}=1.92 \quad$ [95\% CI 1.41-2.63], $\mathrm{z}=$ $4.10, \mathrm{p}<.001 ; \mathrm{I}=0.0 \%, \mathrm{Q}=0.06, \mathrm{df}=1, \mathrm{p}=0.799$ ). The PAR suggested that $6.5 \%$ of the risk for incident cognitive impairment is attributable to anxiety, assuming a causal relationship.

\section{Anxiety and risk for incident dementia}

There were six studies ( $\mathrm{n}=6,004$ subjects) that investigated whether anxiety is a predictor for incident dementia in the community. The average methodological quality score was 0.75. The size of the samples ranged between 321 (Chan et al., 2011) and 2,708 subjects (de Bruijn et al., 2014). One study constituted of a sample smaller than 100 subjects $(\mathrm{N}=47)$. (Palmer et al., 2007) Follow-up duration differed between 2 and 3.4 years, with one study as an exception with 11.8 years.(de Bruijn et al., 2014) The pooled prevalence of anxiety for these community samples in persons with or without MCI at baseline, was $15 \%$ [95\% CI $10-20 \%]$. 
Anxiety as a predictor for cognitive decline and dementia

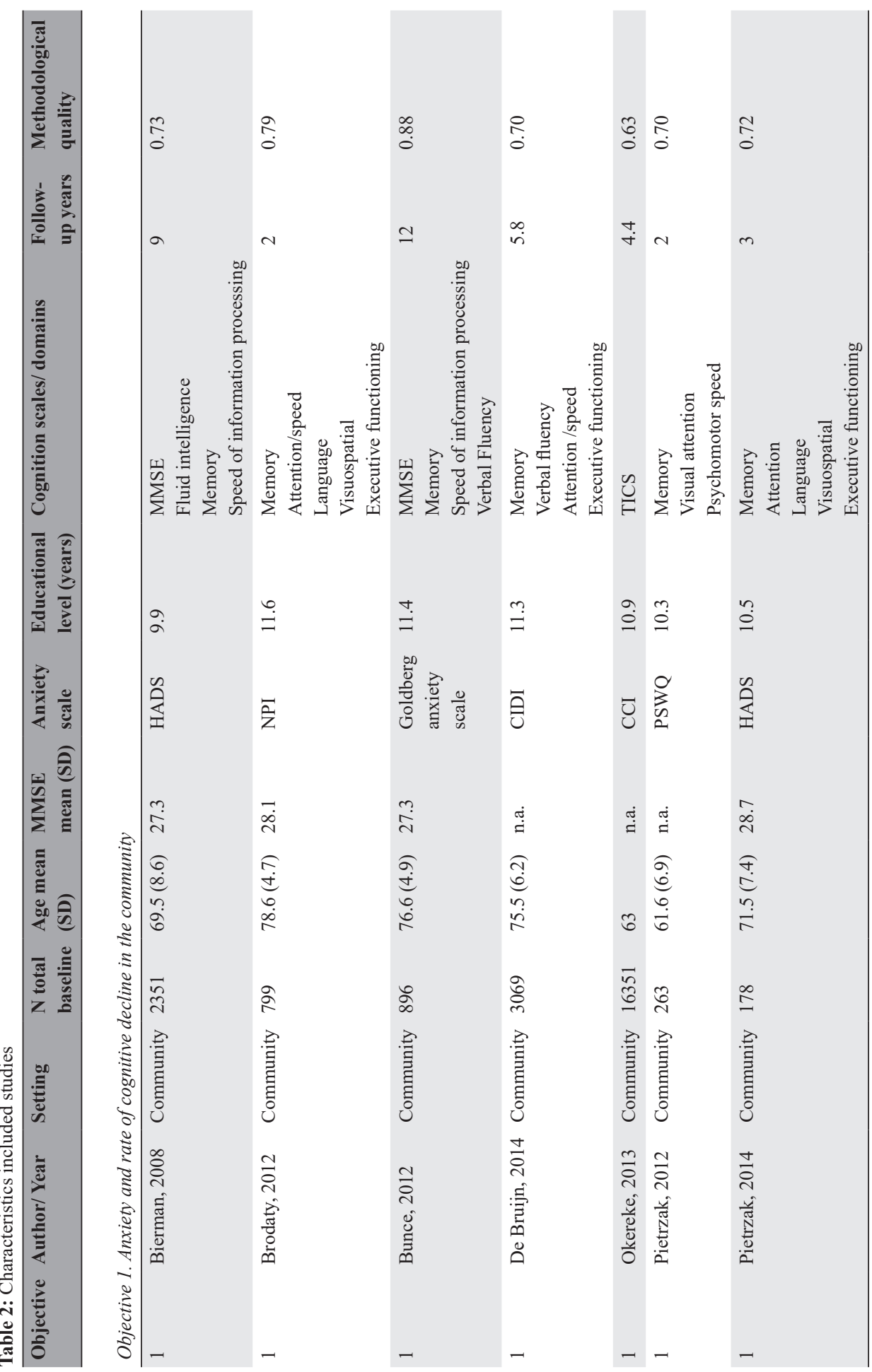


Chapter 2

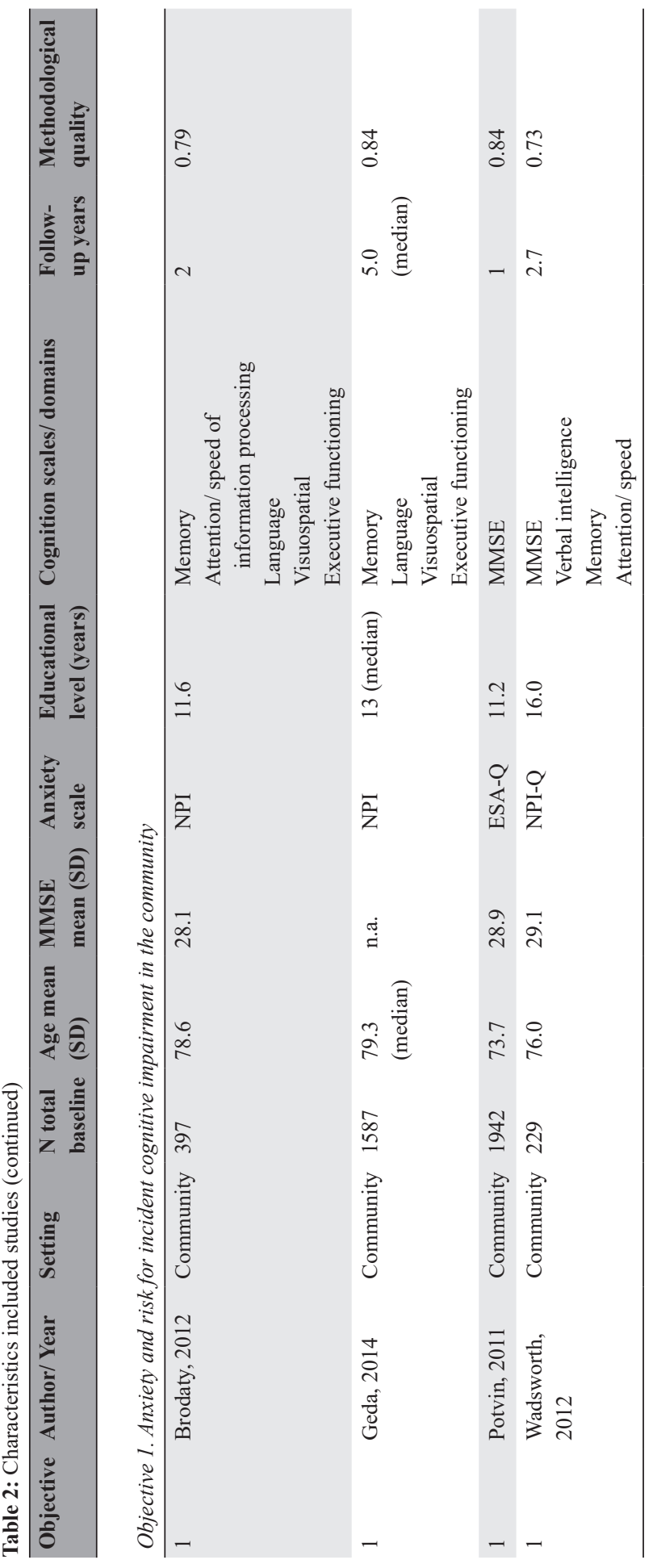


Anxiety as a predictor for cognitive decline and dementia

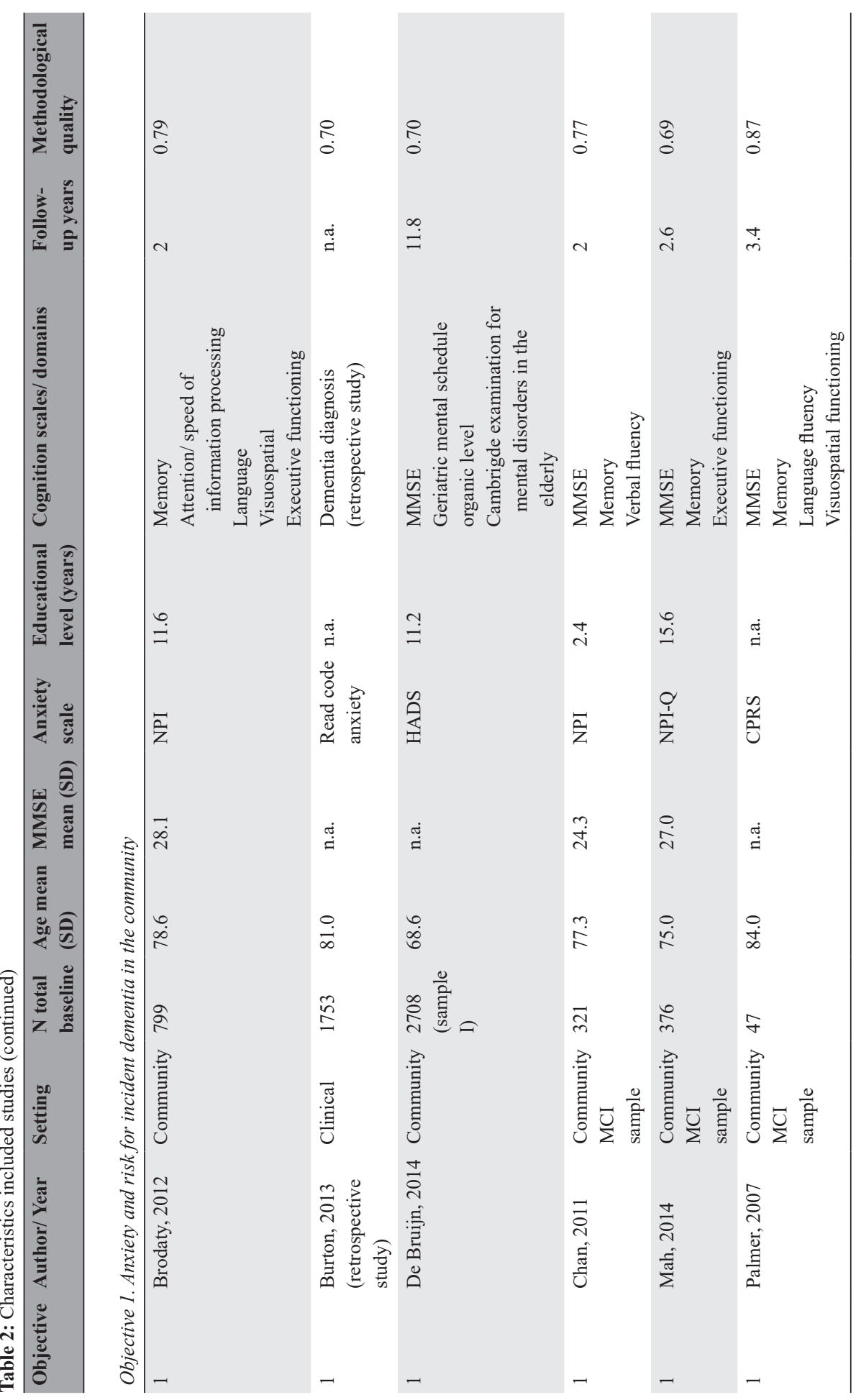


Chapter 2

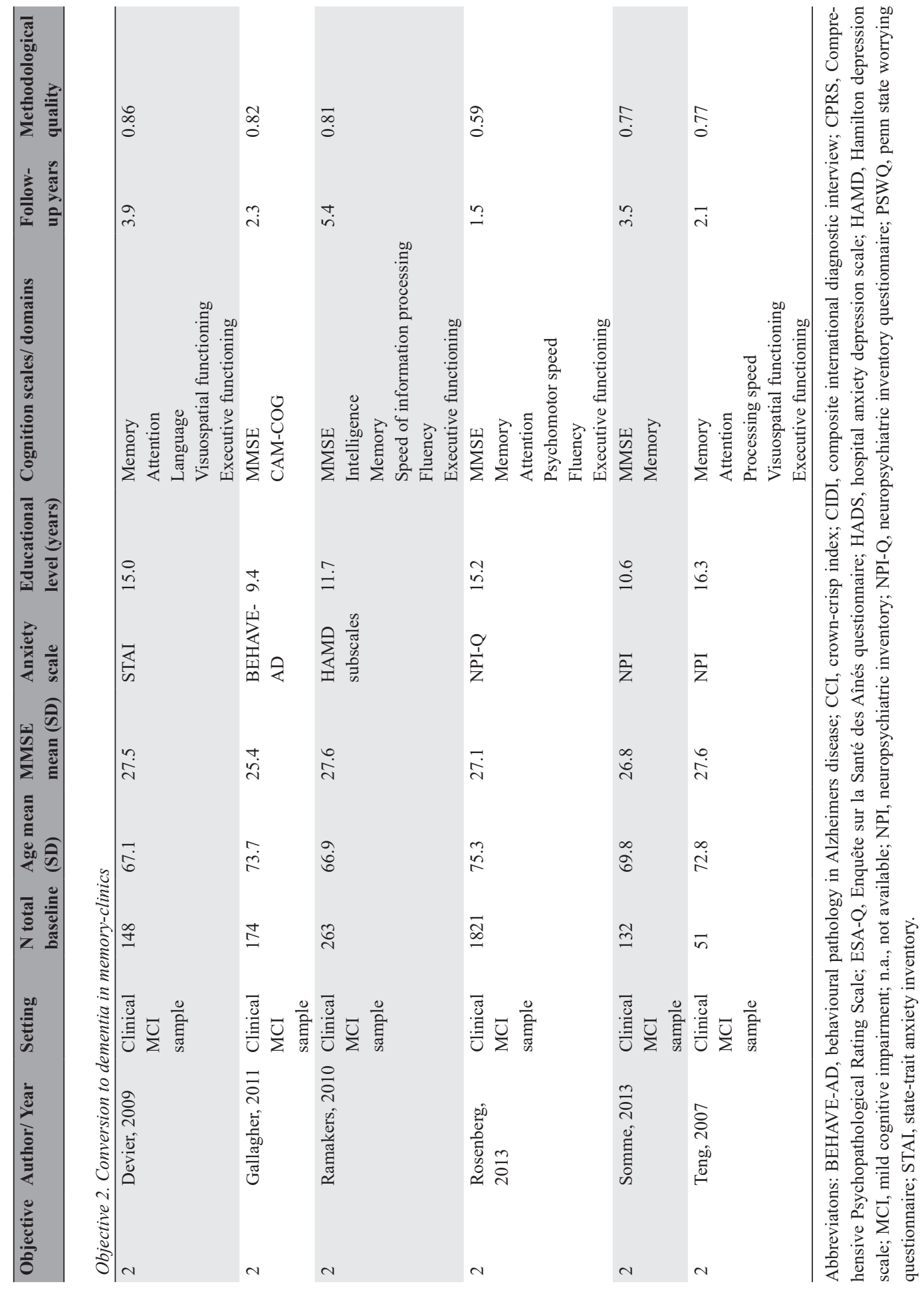


Figure 2: Box-plot predictive value of anxiety for incident cognitive impairment in the community

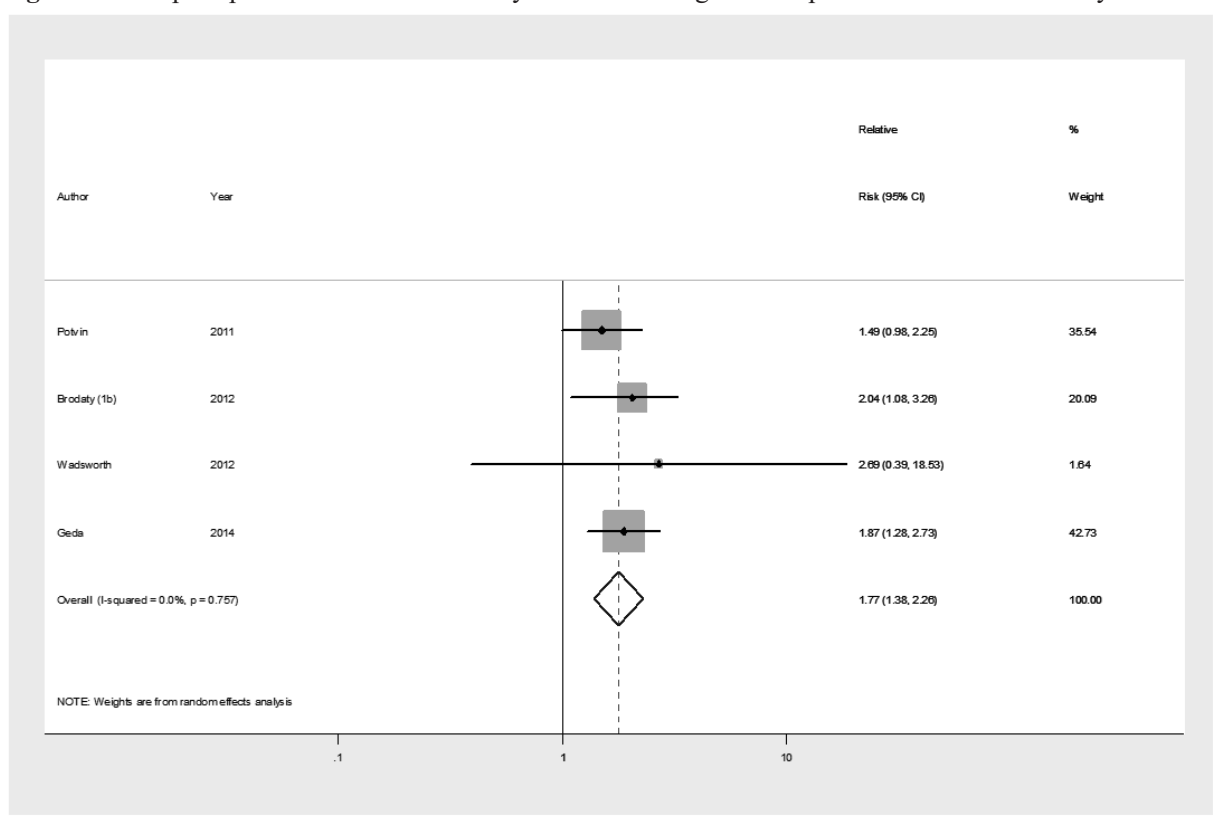

The meta-analysis showed that anxiety was a significant predictor for dementia with a relative risk of 1.57 ([95\% CI 1.02-2.42], $\mathrm{z}=2.05, \mathrm{p}=.040$ ) (see figure 3). There was significant heterogeneity across studies $\left(\mathrm{I}^{2}=74.5 \%, \mathrm{Q}=21.25, \mathrm{df}=5, \mathrm{p}<.001\right)$. Therefore, meta-regressions were conducted showing that the mean age of the study sample had a significant effect on the heterogeneity ( $\beta=0.070,[95 \%$ CI 0.004-0.137], $z=2.06, p=.039$ ). The association with anxiety was greater in people aged 80 years or older with a relative risk of 2.51 ([95\% CI 1.96-3.22], $\mathrm{z}=7.24, \mathrm{p}<0.01 ; \mathrm{I}^{2}=0.0 \%, \mathrm{Q}=0.78, \mathrm{df}=1, \mathrm{p}<0.377$ ), versus 1.23 for people younger than 80 years ([95\% CI $0.89-1.69], z=1.24, p=0.215 ; I^{2}=$ $11.3 \%, \mathrm{Q}=3.38, \mathrm{df}=3, \mathrm{p}<0.336)$. Also, the use of different anxiety scales had an effect on the outcome, with stronger associations in the two studies using clinician based anxiety scales. It should be noted that these two studies were also the two studies with a mean age of 80 years or older.(Burton et al., 2013, Palmer et al., 2007) The population attributable risk suggested that $7.9 \%$ of the risk for dementia is attributable to anxiety assuming that anxiety and dementia are causally related.

The sensitivity analysis with only adjusted relative risks ( $\mathrm{N}=3 ; 4,387$ subjects) revealed a RR of 1.68, but was not significant ([95\% CI 0.94-3.02], $\mathrm{z}=1.75, \mathrm{p}=.081$ ). There was significant heterogeneity across studies $\left(\mathrm{I}^{2}=87.5 \%, \mathrm{Q}=16.00, \mathrm{df}=2, \mathrm{p}<.001\right)$, which was again explained by stronger associations in studies with older adults and in studies with clinician rated anxiety scales. Meta-regression also showed that the methodological quality 
Figure 3: Box-plot predictive value of anxiety for incident dementia in the community

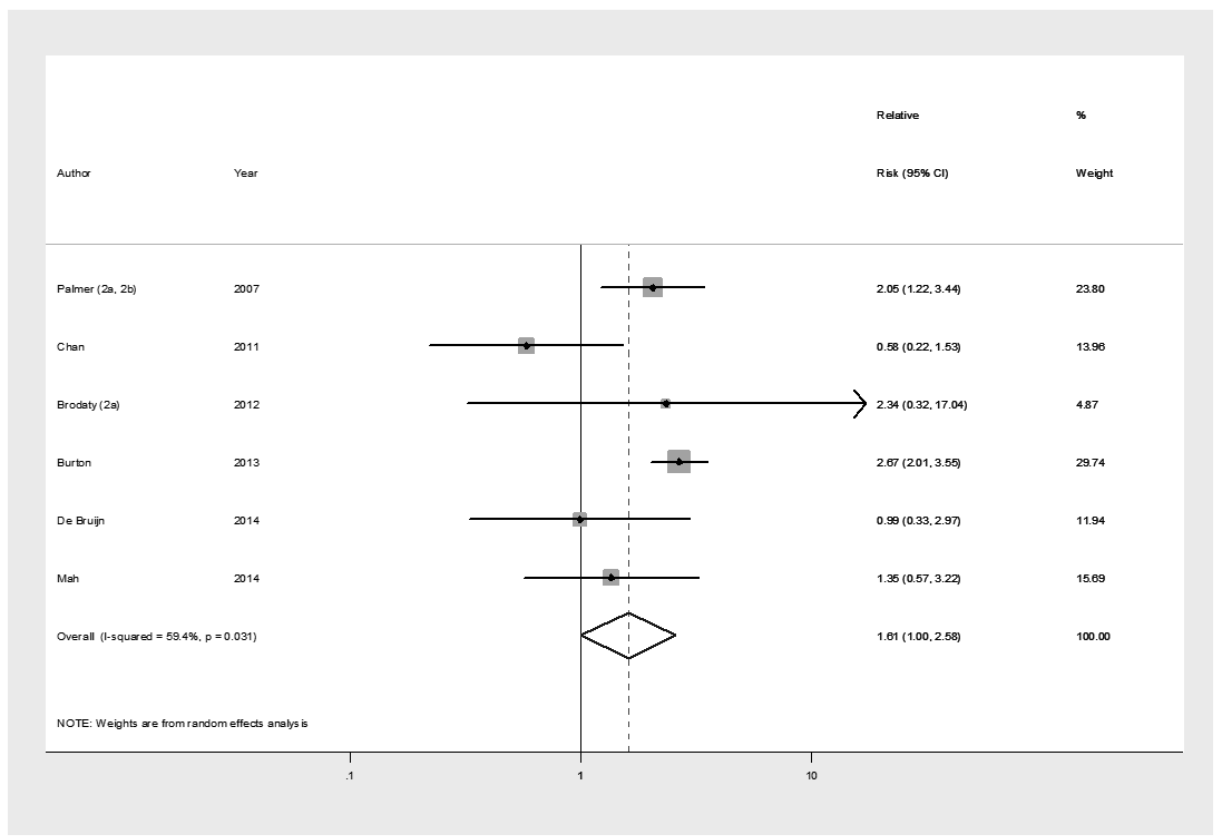

caused some heterogeneity, but these differences were marginal with scores of 0.70 and 0.69 and therefore disregarded.

Finally, a subgroup analysis was conducted on the three studies (3,744 subjects) that had included a specific sample of persons fulfilling MCI criteria at baseline. The methodological quality varied between $0.69-0.87$, with an average of 0.78 . Sample sizes ranged from 47 (Palmer et al., 2007) to 376 subjects (Mah et al., 2015) with a follow-up duration between two (Teng et al., 2007) and 3.4 years.(Palmer et al., 2007) The meta-analysis showed a RR of 1.35, which did not reach statistical significance ([95\% CI 0.84-2.15], $\mathrm{z}=1.24, \mathrm{p}=.213$ ). The test for heterogeneity in this meta-analysis was not significant $\left(\mathrm{I}^{2}=37.2 \%, \mathrm{Q}=5.33, \mathrm{df}=\right.$ $2, \mathrm{p}=.132$ ). A sensitivity analysis with only adjusted relative risks was not possible, since there was only one study with an adjusted measurement (RR 1.35 [95\% CI 1.11-1.64], z= 3.04, $\mathrm{p}<0.01$ ).(Mah et al., 2015)

\section{Objective 2. Conversion to dementia in memory-clinics}

There were six studies ( $\mathrm{N}=2,589$ subjects) examining the conversion rate from MCI to dementia in clinical samples. The methodological quality of the included studies had an average of 0.77 (range $0.59-0.86$ ). The largest study consisted of 1,821 subjects (Rosenberg 
et al., 2013). The sample sizes of the other studies ranged between 51 and 263 subjects. The follow-up duration varied for the other studies between 1.5 and 5.4 years.

The meta-analysis showed a non-significant RR of 1.21 ([95\% CI 0.90-1.63], $\mathrm{z}=1.28$, $\mathrm{p}=.200$ ) (see figure 4$)$. There was significant heterogeneity across studies $\left(\mathrm{I}^{2}=56.7 \%, \mathrm{Q}=\right.$ $11.54, \mathrm{df}=5, \mathrm{p}=.042$ ). The heterogeneity was caused by the use of a clinician based anxiety scale in one study (Ramakers et al., 2010), with the studies who did not use a clinician based anxiety scale reporting a greater effect. The only study with a clinician based anxiety scale showed a negative association $(\mathrm{RR}=0.64,[95 \%$ CI $0.40-1.02], \mathrm{z}=1.86, \mathrm{p}=0.063)$, while the other five studies showed a significant positive finding $(\mathrm{RR}=1.30$, [95\% CI 1.301.63], $\left.\mathrm{z}=2.22, \mathrm{p}=0.027 ; \mathrm{I}^{2}=27.1 \%, \mathrm{Q}=5.48, \mathrm{df}=4, \mathrm{p}<0.241\right)$.

Figure 4: Box-plot predictive value of anxiety for dementia in clinical MCI samples

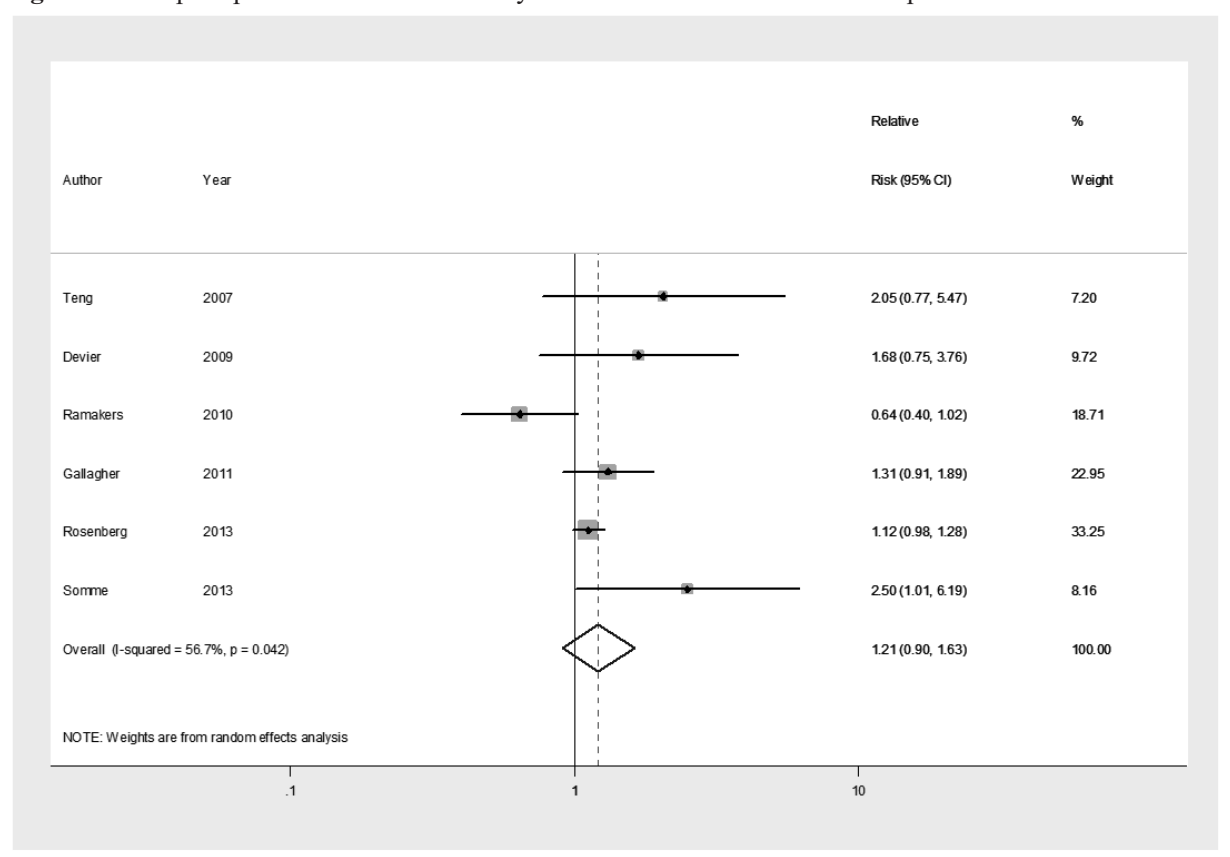

The sensitivity analysis with only adjusted measurements consisted of four studies $(\mathrm{N}=2,364$ subjects) and revealed a non-significant $\mathrm{RR}$ of 1.16 ([95\% CI $0.75-1.81], \mathrm{z}=$ $0.65, \mathrm{p}=.512)$. The test for heterogeneity was significant $\left(\mathrm{I}^{2}=68 \%, \mathrm{Q}=9.38, \mathrm{df}=3, \mathrm{p}=.025\right)$. Again the heterogeneity was caused by the use of clinician based anxiety scales, but also by mean differences of the MMSE between studies. The effect of anxiety was greater in studies with a lower MMSE at baseline with a RR of 1.47 for the studies with lower scores on the MMSE ([95\% CI 0.70-3.09], $\mathrm{z}=1.01, \mathrm{p}<0.0311 ; \mathrm{I}^{2}=66.1 \%, \mathrm{Q}=2.95, \mathrm{df}=1, \mathrm{p}=0.086$ ) versus a RR of 0.98 for the studies with a higher score on the MMSE ([95\% CI 0.38-2.50], $\left.\mathrm{z}=0.05, \mathrm{p}<0.964 ; \mathrm{I}^{2}=75.6 \%, \mathrm{Q}=4.11, \mathrm{df}=1, \mathrm{p}=0.043\right)$. 


\section{Evidence for publication bias}

There were no suggestions of possible publication bias across all studies of the different objectives with p-values ranging between 0.46 and 0.88 on Egger's regression intercept (see appendix figure 1-3). Also, inspection of funnel plots did not suggest major publication bias.

\section{DISCUSSION}

\section{Main findings}

The meta-analysis showed that anxiety is associated with a higher risk for incident cognitive impairment and possibly for incident dementia in community samples. The association of anxiety and conversion to dementia seems to be greater in the group of 80 years and older. Findings with respect to decline on individual cognitive domains in the community were too heterogeneous to be pooled in a meta-analysis. We only found some suggestions that anxiety predicts rate of decline on executive functioning, but this is inconclusive. In clinical MCI samples, however, we did not find an association between anxiety and conversion to dementia. Respectively $6.5 \%$ and $7.9 \%$ of the overall risk for incident cognitive impairment and dementia in the community was attributable to anxiety.

\section{Anxiety as a predictor for decline on individual cognitive domains}

Whether anxiety is associated with accelerated cognitive decline, in other words cognitive aging, remains equivocal. Only one of the seven studies showed a significant decline on visual learning and memory.[12] Since this was a relative small study $(\mathrm{N}=178)$ with a short duration of follow-up, a chance finding cannot be excluded. Furthermore, no association was found in the domains of speed of information processing, attention, language, verbal fluency and visuospatial functioning.

In cross-sectional studies severe anxiety showed a negative association with attention and worsened cognitive performance.(Bierman et al., 2008b) Our systematic review shows, however, that anxiety does not predict a deterioration of attention over time, which has been tested in four longitudinal studies. None of the studies adjusted their cognitive assessment at follow-up for the change in anxiety levels over time. Therefore, these null-results might be explained by improvement of anxiety symptoms even in case of some mild deterioration in cognitive functioning. This might explain the difference with studies looking at incident cognitive impairment and dementia.

Interestingly, three of the five studies showed a significant decline due to anxiety on executive functioning. The decline on executive functioning was not observed in two large studies, i.e. Okereke et al and Bierman et al.(Bierman et al., 2008a, Okereke and 
Grodstein, 2013) Two explanations can be put forward for the negative finding in the study by Okereke et al.(Okereke and Grodstein, 2013) First, they assessed phobic anxiety, while it might be possible that only generalized anxieties are predictive for cognitive decline. Second, they used a global instrument for cognitive screening (TICS), which is less specific and sensitive for change compared to specific tests for executive functioning.(Castanho et al., 2014, Okereke and Grodstein, 2013) The study of Bierman et al is interesting as it had a good methodological quality and assessed cognitive decline over the longest period (nine years).(Bierman et al., 2008a) The other studies had a follow-up duration between 1.5-5.8 years. This might suggest that anxiety is a prodromal expression of the underlying neurodegenerative process and that it is less likely causally related. The study of Bunce et al with a follow-up duration of twelve years did not assess executive functioning.(Bunce et al., 2012)

\section{Anxiety as a predictor for incident cognitive impairment and dementia in the community}

We can conclude that anxiety is a predictor for incident cognitive impairment and probably for dementia in the community. While the sensitivity analysis for dementia in the community based on adjusted relative risks only $(\mathrm{N}=3)$ showed a non-significant positive finding, the RR was of similar magnitude as in the total sample analysis, but the confidence interval became wide due to one large non-significant study having an individual RR of 0.99.(de Bruijn et al., 2014) The other two studies did individually find a positive significant association.(Burton et al., 2013, Mah et al., 2015) The same problem occurred when we selected the studies with baseline samples that explicitly fulfilled the criteria for MCI with one negative non-significant study (Chan et al., 2011) and two studies with a positive significant association.(Mah et al., 2015, Palmer et al., 2007) The only study with an adjusted relative risk showed a positive significant association.(Mah et al., 2015) In summary, replication studies with rigorous methodology are warranted to confirm our finding that anxiety is a predictor for cognitive impairment and dementia in the community.

Whether the association between anxiety and cognition is a result of reverse causality or not, remains uncertain, especially acknowledging the fact that we did not find a consistent association on cognitive aging. Therefore, anxiety could be a prodromal symptom of dementia, caused by an unknown third factor also causing the dementia, or a causal factor itself. As a prodromal symptom, anxious feelings emerge when older adults become aware of (maybe still subtle) problems in their cognitive functioning. They are often afraid to develop dementia in the future. In later stages of the neurodegenerative process anxiety levels usually decrease as a consequence of the decline in the cognitive functioning, which is also necessary to comprehend that you have difficulties in daily functioning.(Wetzels et al., 2010) Anxiety due to the cognitive decline would emerge in late-life, since the risk for dementia also becomes more likely. Indeed, the results of the meta-regression analyses 
showing the highest impact among the oldest old is in line with the hypothesis of anxiety as a prodromal sign of dementia. It is possible that in the subgroup of younger participants cognitive changes are more often transient and secondary to underlying psychopathology, while in the older subgroup they are more often due to neurodegenerative processes. Since the studies in the oldest old also differed by use of clinician-rated anxiety scales, results may also be explained by more reliably assessment of anxiety, as older patients generally tend to underreport anxiety symptoms using self-report questionnaires.(Hendriks et al., 2010)

Nonetheless, anxiety has also been proposed as a causal factor influencing the neuropathological processes leading to cognitive decline and dementia. Potential hypothesis for a causal pathway for anxiety include: a) hypercortisolism, b) cardiovascular disease, c) low-grade inflammation, d) Brain Derived Neurotrophic Factor (BDNF) suppression and e) the cognitive reserves. According to the hypothesis about hypercortisolaemia, anxiety will lead to stress and therefore to higher levels of cortisol. As for cortisol levels, these have been shown to be higher in patients with late-life generalized anxiety disorder compared with healthy controls and to relate to symptom severity as well as a poorer outcome on neuropsychological tests (Mantella et al., 2008, Rosnick et al., 2013) It has been suggested that cortisol-induced overstimulation of glucocorticoid receptors in the medial temporal lobe leads to hippocampus atrophy.(Sapolsky, 2000, Erickson et al., 2003) In animal models, high levels of cortisol administration also led to an increase of amyloid formation and tau accumulation.(Green et al., 2006) Both processes are seen in the pathology of Alzheimer's disease. There are studies that show that anxiety is related with coronary artery disease and stroke.(Sheps and Sheffield, 2001, Lambiase et al., 2014, Batelaan et al., 2016) The mental stress as a result of anxiety triggers physiological reactions like an increased heart rate, blood pressure, vasoconstriction and platelet activity, which are all associated with cardiovascular disease and could lead to vascular dementia. (Sheps and Sheffield, 2001, Tully et al., 2013) Another hypothesis suggest a role for inflammation because increased levels of cytokines such as IL-6 and TNF have been found in stress-related disorders, including anxiety disorders.(Furtado and Katzman, 2015) These cytokines are associated with negative effects on cognitive functioning.(Reichenberg et al., 2001) Anxiety disorders have also been associated with decreased levels of BDNF or with BDNF polymorphism's. (Domingos da Silveira da Luz et al., 2013) BDNF is essential for synaptic plasticity, necessary for learning and memory, and neuronal repair. In Alzheimer's' disease and MCI the levels of BDNF are decreased.(Teixeira et al., 2010) Another possible explanation for a causal pathway might be the finding that less cognitive reserves increases the risk for dementia. (Stern, 2012) Anxiety disorders often have an enduring course throughout life and are frequently accompanied with avoidance behavior. The avoidance behavior could lead to lowered cognitive reserves due to less mental and social stimulation. Assuming that anxiety is indeed causally related to incident cognitive impairment and dementia, the excessive risk 
in the general population that can be attributed to being exposed to anxiety is modest, with percentages of $6.5 \%$ and $7.9 \%$ for cognitive impairment and dementia, respectively. These PARs are in between those for other recognized risk factors, like midlife hypertension (global PAR 5.1\%) and depression (global PAR 7.9\%).(Norton et al., 2014)

\section{Anxiety was not predictive for conversion from MCI to dementia in clinical samples}

In the clinical MCI samples, in which the patients were recruited at memory clinics, no significant associations were found for anxiety as a risk factor for conversion to dementia. Anxiety might thus not be a strong predictor in MCI patients seen by clinicians already seeking help and receiving medical attention. This finding highlights that people should be cautious with interpreting results from clinical samples, as they often cannot be generalized to the general population. It is possible that this finding is a result of referral bias. In clinical samples there is likely an overrepresentation of transient cognitive impairments that are caused by symptoms of psychopathology instead of an underlying neurodegenerative process.(Kessler et al., 2014, Ramakers et al., 2010) We hypothesize that transient cognitive impairments due to primary psychopathology are more easily noted with clinician-based anxiety scales instead of self-report questionnaires. This could explain the potentially protecting effect that was shown in the only study with a clinician-based anxiety scale. (Ramakers et al., 2010)

\section{Strengths and limitations}

The study has some important strengths. Different outcomes and settings have been taken into account to give the most comprehensive account of the current evidence base possible at this moment. Since we separated community and clinical studies, we minimized the risk of results being driven by referral bias in the clinical samples. Some methodological issues however warrant further discussion. First, due to the small number of studies influencing the statistical power, we could not limit our meta-analysis to studies reporting fully adjusted relative risks only. Meta-regression analyses, however, showed that the presence or absence of an adjusted relative risk was never an explanation for heterogeneity across studies and sensitivity analyses restricted to studies who had an adjusted relative risk did not yield a different strength of the associations found. Second, different measurements have been used by the different authors to ascertain anxiety symptoms. Some anxiety scales only assessed one feature of the multidimensional symptoms of anxiety, e.g. Penn State Worrying Questionnaire (PSWQ). The number of studies were too low to look whether the results were driven by a specific subtype of anxiety. Two studies are interesting with respect to heterogeneity in anxiety measures. First, it has been reported that anxiety disorders are particularly related to cognitive decline in males, whereas very mild anxiety levels with cognitive decline in females.(Potvin et al., 2011a) Secondly, another study only identified 
Godot syndrome (fear of upcoming events) to be predictive of dementia and not fear of being left alone or other anxieties.(Gallagher et al., 2011) In addition to the different measurements, there were also scales not validated for the subitems of anxiety. These scales, like the Neuropsychiatric Inventory (NPI) or the Hamilton Depression Scale (HAMD) are validated scales, but not specifically designed for measuring anxiety.

Furthermore, anxiety- and depressive symptoms often occur together. Depression has already been identified as a risk factor for dementia in people with MCI.(Cooper et al., 2015) In the original articles only five studies corrected for depressive symptoms. It however did not change the essence of their outcome. Three studies found a positive significant association between anxiety and conversion to dementia with and without adjustment for the depressive symptoms.(Burton et al., 2013, Gallagher et al., 2011, Mah et al., 2015) The two other studies had non-significant results, one for a positive association and one for a negative association.(de Bruijn et al., 2014, Devier et al., 2009) Both outcomes did not differ greatly after adjustment for the depressive symptoms. This suggests that anxiety is a risk factor for dementia independent of possible comorbid depressive symptomatology.

In this meta-analysis we have only investigated anxiety as a possible risk factor for cognitive decline and dementia. It should be noted that other neuropsychiatric symptoms have been mentioned as possible risk factors for dementia, most notably depression and apathy. Depression is also associated with dementia as stated before.(Cooper et al., 2015) Results on apathy as a risk factor are ambiguous with a meta-analysis showing a non-significant association.(Cooper et al., 2015) It is important for future studies to investigate whether these neuropsychiatric symptoms are all independent risk factors or whether they are an expression of a latent underlying variable.

\section{Conclusion}

Anxiety is associated with a higher risk for incident cognitive impairment and, probably, for dementia in the community. Future studies should focus on the causality of the association by including potentially mediating mechanisms for this association. Irrespective of the association is causal or not, it is important for the clinician to be aware of anxiety as a possible predictor for dementia, especially when the anxiety emerges at late life. Late-life anxiety disorders have a low incidence rate, since $95^{\text {th }}$ percentile of all anxiety complaints have already been exposed at the age of 51 years and $99^{\text {th }}$ percentile at 65 years.(Kessler et al., 2005) When treating the anxiety complaints it should be considered, that the anxiety in the presence of an underlying neurodegenerative process will possibly respond better to the structuring of daily life instead of cognitive behavioural therapy. Exposure in vivo could potentially increase the anxiety complaints. Further research is needed to examine the association between anxiety and conversion to dementia with adjustment for the confounding variables. 


\section{REFERENCES}

ALTMAN, D. G. 2001. Systematic reviews of evaluations of prognostic variables. BMJ, 323, 224-8.

APOSTOlOVA, L. G. \& CUMMINGS, J. L. 2008. Neuropsychiatric manifestations in mild cognitive impairment: a systematic review of the literature. Dement Geriatr Cogn Disord, 25, 115-126.

BATELAAN, N. M., SELDENRIJK, A., BOT, M., VAN BALKOM, A. J. \& PENNINX, B. W. 2016. Anxiety and new onset of cardiovascular disease: critical review and meta-analysis. Br J Psychiatry, 208, 223-231.

BEAUDREAU, S. A. \& O'HARA, R. 2008. Late-life anxiety and cognitive impairment: a review. Am $J$ Geriatr Psychiatry, 16, 790-803.

BIERMAN, E. J., COMIJS, H. C., RIJMEN, F., JONKER, C. \& BEEKMAN, A. T. 2008a. Anxiety symptoms and cognitive performance in later life: results from the longitudinal aging study Amsterdam. Aging Ment Health, 12, 517-523.

BIERMAN, E. J., COMIJS, H. C., RIJMEN, F., JONKER, C. \& BEEKMAN, A. T. 2008b. Anxiety symptoms and cognitive performance in later life: results from the longitudinal aging study Amsterdam. Aging Ment Health, 12, 517-23.

BRODATY, H., HEFFERNAN, M., DRAPER, B., REPPERMUND, S., KOCHAN, N. A., SLAVIN, M. J., TROLLOR, J. N. \& SACHDEV, P. S. 2012. Neuropsychiatric symptoms in older people with and without cognitive impairment. J Alzheimers Dis, 31, 411-420.

BUNCE, D., BATTERHAM, P. J., MACKINNON, A. J. \& CHRISTENSEN, H. 2012. Depression, anxiety and cognition in community-dwelling adults aged 70 years and over. $J$ Psychiatr Res, 46, 1662-1666.

BURTON, C., CAMPBELl, P., JORDAN, K., STRAUSS, V. \& MALLEN, C. 2013. The association of anxiety and depression with future dementia diagnosis: a case-control study in primary care. Fam Pract, 30, 25-30.

CASTANHO, T., S., AMORIM, L., ZIHL, J., PALHA, J. A., SOUSA, N. \& SANTOS, N. C. 2014. Telephone-based screening tools for mild cognitive impairment and dementia in aging studies: a review of validated instruments. Front Aging Neuroscience, 6.

CHAN, W. C., LAM, L. C., TAM, C. W., LUI, V. W., LEUNG, G. T., LEE, A. T., CHAN, S. S., FUNG, A. W., CHIU, H. F. \& CHAN, W. M. 2011. Neuropsychiatric symptoms are associated with increased risks of progression to dementia: a 2-year prospective study of 321 Chinese older persons with mild cognitive impairment. Age Ageing, 40, 30-35.

COOPER, C., SOMMERLAD, A., LYKeTSOS, C. G. \& LIVINGSTON, G. 2015. Modifiable Predictors of Dementia in Mild Cognitive Impairment: A Systematic Review and Meta-Analysis. Am J Psychiatry, 172, 323-334.

DE BRUIJN, R. F., DIREK, N., MIRZA, S. S., HOFMAN, A., KOUdSTAAL, P. J., TIEMEIER, H. \& IKRAM, M. A. 2014. Anxiety is not associated with the risk of dementia or cognitive decline: the Rotterdam Study. Am J Geriatr Psychiatry, 22, 1382-1390.

DEVIER, D. J., PELTON, G. H., TABERT, M. H., LIU, X., CUASAY, K., EISENSTADT, R., MARDER, K., STERN, Y. \& DEVANAND, D. P. 2009. The impact of anxiety on conversion from mild cognitive impairment to Alzheimer's disease. Int J Geriatr Psychiatry, 24, 1335-1342.

DOMINGOS DA SILVEIRA DA LUZ, A. C., PEREIRA DIAS, G., DO NASCIMENTO BEVILAQUA, M. C., COCKS, G., GARDINO, P. F., THURET, S. \& NARDI, A. E. 2013. Translational findings on brain-derived neurotrophic factor and anxiety: contributions from basic research to clinical practice. Neuropsychobiology, 68, 129-38.

ERICKSON, K., DREVETS, W. \& SCHULKIN, J. 2003. Glucocorticoid regulation of diverse cognitive functions in normal and pathological emotional states. Neurosci Biobehav Rev, 27, 233-46. 
FURTADO, M. \& KATZMAN, M. A. 2015. Neuroinflammatory pathways in anxiety, posttraumatic stress, and obsessive compulsive disorders. Psychiatry Res, 229, 37-48.

GAllagher, D., COEN, R., KILROY, D., BELINSKI, K., BRUCE, I., COAKLEY, D., WALSH, B., CUNNINGHAM, C. \& LAWLOR, B. A. 2011. Anxiety and behavioural disturbance as markers of prodromal Alzheimer's disease in patients with mild cognitive impairment. Int J Geriatr Psychiatry, 26, 166-172.

GAO, Y., HUANG, C., ZHAO, K., MA, L., QIU, X., ZHANG, L., XIU, Y., CHEN, L., LU, W., HUANG, C., TANG, Y. \& XIAO, Q. 2013. Depression as a risk factor for dementia and mild cognitive impairment: a meta-analysis of longitudinal studies. Int J Geriatr Psychiatry, 28, 441-449.

GEDA, Y. E., ROBERTS, R. O., MIELKE, M. M., KNOPMAN, D. S., CHRISTIANSON, T. J., PANKRATZ, V. S., BOEVE, B. F., SOCHOR, O., TANGALOS, E. G., R.C., P. \& ROCCA, W. A. 2014. Baseline neuropsychiatric symptoms and the risk of incident mild cognitive impairment: a population-based study. Am J Psychiatry, 171, 572-581.

GEDA, Y. E., SMith, G. E., KNOPMAN, D. S., BOEVE, B. F., TANGAlOS, E. G., IVNIK, R. J., MRAZEK, D. A., EDLAND, S. D. \& PETERSEN, R. C. 2004. De novo genesis of neuropsychiatric symptoms in mild cognitive impairment (MCI). Int Psychogeriatr, 16, 51-60.

GREEN, K. N., BILlingS, L. M., ROOZENDAAL, B., MCGAUGH, J. L. \& LAFERLA, F. M. 2006. Glucocorticoids increase amyloid-beta and tau pathology in a mouse model of Alzheimer's disease. J Neurosci 26, 9047-9056.

HAYDEN, J. A., COTE, P. \& BOMBARDIER, C. 2006. Evaluation of the quality of prognosis studies in systematic reviews. Ann Intern Med, 144, 427-37.

HENDRIKS, G. J., KEIJSERS, G. P. J., KAMPMAN, M., OUDE VOSHAAR, R. C. \& HOOGDUIN, C. A. L. 2010. Agorophobic cognitions in old and young patients with panic disorder. Am J Geriatr Psychiatry, 18, 1155-1158.

KESSLER, E. M., SÜDHOF, J. K. \& FRÖHLICH, L. 2014. "Dementia worry” in memory clinic patients not diagnosed with organic mental disorder. Int Psychogeriatr, 26, 1049-1051.

KESSler, R. C., BERGlund, P., DEMler, O., JIN, R., MERIKANGAS, K. R. \& WALTERS, E. E. 2005. Lifetime prevalence and age-of-onset distributions of DSM-IV disorders in the National Comorbidity Survey Replication. Arch Gen Psychiatry, 62, 593-602.

LAMBIASE, M. J., KUBZANSKY, L. D. \& THURSTON, R. C. 2014. Prospective study of anxiety and incident stroke. Stroke., 45, 438-443.

LARSON, E. B., YAFFE, K. \& LANGA, K. M. 2013. New insights into the dementia epidemic. $N$ Engl $J$ Med, 369 2275-7.

LEVIN, M. L. 1953. The occurrence of lung cancer in man. Acta Unio Int Contra Cancrum, 9, 531-541.

MAH, L., BINNS, M. A. \& STEFFENS, D. C. 2015. Anxiety symptoms in amnestic mild cognitive impairment are associated with medial temporal atrophy and predict conversion to Alzheimer disease. Am J Geriatr Psychiatry, 23, 466-476.

MANTELlA, R. C., BUTTERS, M. A., AMICO, J. A., MAZUMDAR, S., ROLLMAN, B. L., BEGLEY, A. E., REYNOLDS, C. F. \& LENZE, E. J. 2008. Salivary cortisol is associated with diagnosis and severity of late-life generalized anxiety disorder. Psychoneuroendocrinology, 33, 773-781.

NORTON, S., MATTHEWS, F. E., BARNES, D. E., YAFFE, K. \& BRAYNE, C. 2014. Potential for primary prevention of Alzheimer's disease: an analysis of population-based data. Lancet Neurol, 13, 788-794.

OKEREKE, O. I. \& GRODSTEIN, F. 2013. Phobic anxiety and cognitive performance over 4 years among community-dwelling older women in the Nurses' Health Study. Am J Geriatr Psychiatry, 21, 1125 1134. 
PALMER, K., BERGER, A. K., MONASTERO, R., WINBLAD, B., BÄCKMAN, L. \& FRATIGLIONI, L. 2007. Predictors of progression from mild cognitive impairment to Alzheimer disease. Neurology, 68, 1596-602.

PETERSEN, R. C., STEVEnS, J. C., GANGUli, M., TANGAlos, E. G., CUMMINGS, J. L. \& DEKOSKY, S. T. 2001. Practice parameter: early detection of dementia: mild cognitive impairment (an evidencebased review). Report of the Quality Standards Subcommittee of the American Academy of Neurology. Neurology, 56, 1133-42.

PIETRZAK, R. H., MARUFF, P., WOODWARD, M., FREDRICKSON, J., FREDRICKSON, A., KRYSTAL, J. H., SOUTHWICK, S. M. \& DARBY, D. 2012. Mild worry symptoms predict decline in learning and memory in healthy older adults: a 2-year prospective cohort study. Am J Geriatr Psychiatry, 20, 266-275.

PIETRZAK, R. H., SCOTT, J. C., NEUMEISTER, A., LIM, Y. Y., AMES, D., Ellis, K. A., HARRINGTON, K., LAUTENSCHLAGER, N. T., SZOEKE, C., MARTINS, R. N., MASTERS, C. L., VILLEMAGNE, V. L., ROWE, C. C. \& MARUFF, P. 2014. Anxiety symptoms, cerebral amyloid burden and memory decline in healthy older adults without dementia: 3-year prospective cohort study. Br J Psychiatry, 204, 400-401.

POTVIN, O., FORGET, H., GRENIER, S., PRÉVILlE, M. \& HUDON, C. 2011a. Anxiety, depresAnxiety, depression, and 1-year incident cognitive impairment in community-dwelling older adults. $J \mathrm{Am}$ Geriatr Soc, 59, 1421-1428.

POTVIN, O., HUDON, C., DION, M., GRENIER, S. \& PRÉVILLE, M. 2011b. Anxiety disorders, depressive episodes and cognitive impairment no dementia in community-dwelling older men and women. Int J Geriatr Psychiatry, 26, 1080-1088.

RAMAKERS, I. H., VISSER, P. J., AALTEN, P., KESTER, A., JOLLES, J. \& VERHEY, F. R. 2010. Affective symptoms as predictors of Alzheimer's disease in subjects with mild cognitive impairment: a 10-year follow-up study. Psychol Med, 40, 1193-1201.

REICHENBERG, A., YIRMIYA, R., SCHUld, A., KRAUS, T., HAACK, M., MORAG, A. \& POLLMÄCHER, T. 2001. Cytokine-associated emotional and cognitive disturbances in humans. Arch Gen Psychiatry, 58, 445-452.

RosenberG, P. B., Mielke, M. M., APPleby, B. S., OH, E. S., GEDA, Y. E. \& LYKeTSOS, C. G. 2013. The association of neuropsychiatric symptoms in MCI with incident dementia and Alzheimer disease. Am J Geriatr Psychiatry, 21, 685-695.

ROSNICK, C. B., RAWSON, K. S., BUTTERS, M. A. \& LENZE, E. J. 2013. Association of cortisol with neuropsychological assessment in older adults with generalized anxiety disorder. Aging Ment Health, 17, 432-440.

SAPOLSKY, R. M. 2000. Glucocorticoids and hippocampal atrophy in neuropsychiatric disorders. Arch Gen Psychiatry, 57, 925-935.

SHEPS, D. S. \& SHEFFIELD, D. 2001. Depression, anxiety, and the cardiovascular system: the cardiologist's perspective. J Clin Psychiatry, 62 Suppl 8, 12-6; discussion 17-8.

STERN, Y. 2012. Cognitive reserve in ageing and Alzheimer's disease. Lancet Neurol, 11, 1006-1012.

TEIXEIRA, A. L., BARBOSA, I. G., DINIZ, B. S. \& KUMMER, A. 2010. Circulating levels of brainderived neurotrophic factor: correlation with mood, cognition and motor function. Biomark Med, 4, 871-87.

TENG, E., LU, P. H. \& CUMMINGS, J. L. 2007. Neuropsychiatric symptoms are associated with progression from mild cognitive impairment to Alzheimer's disease. Dement Geriatr Cogn Disord, 24, 253-259. 
Chapter 2

TULLY, P. J., COSH, S. M. \& BAUNE, B. T. 2013. A review of the affects of worry and generalized anxiety disorder upon cardiovascular health and coronary heart disease. Psychol Health Med. , 18, 627-644.

WADSWORTH, L. P., LORIUS, N., DONOVAN, N. J., LOCASCIO, J. J., RENTZ, D. M., JOHNSON, K. A., SPERLING, R. A. \& MARShALL, G. A. 2012. Neuropsychiatric symptoms and global functional impairment along the Alzheimer's continuum. Dement Geriatr Cogn Disord, 34, 96-111.

WETZELS, R., ZUIDEMA, S., JANSEN, I., VERHEY, F. \& KOOPMANS, R. 2010. Course of neuropsychiatric symptoms in residents with dementia in long-term care institutions: a systematic review. Int Psychogeriatr, 22, 1040-53. 
Appendix table 1: Neuropsychological tests per study

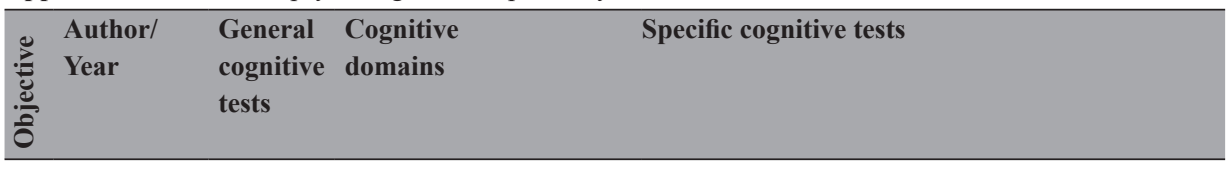

Objective 1. Anxiety and rate of cognitive decline in the community

\begin{tabular}{|c|c|c|c|c|}
\hline 1 & $\begin{array}{l}\text { Bierman, } \\
2008\end{array}$ & MMSE & $\begin{array}{l}\text { Fluid intelligence } \\
\text { Memory } \\
\text { Processing speed }\end{array}$ & $\begin{array}{l}\text { Two sub-sets of } 12 \text { items (A\&B) from Raven's } \\
\text { Coloured Progressive Matrices. AVLT (auditory } \\
\text { verbal learning test) learning score, delayed recall, } \\
\text { retention. } \\
\text { Adjusted version coding task. }\end{array}$ \\
\hline 1 & $\begin{array}{l}\text { Brodaty, } \\
2012\end{array}$ & & $\begin{array}{l}\text { Memory } \\
\text { Attention/processing } \\
\text { speed } \\
\text { Language } \\
\text { Visuospatial } \\
\text { Executive functioning }\end{array}$ & $\begin{array}{l}\text { Logical memory story A delayed, RAVLT (total trail } \\
1-5 \text {, short delayed, long delayed), BVRT recogni- } \\
\text { tion. } \\
\text { Digit symbol coding, TMT-A. } \\
\text { Boston naming test, animal fluency. } \\
\text { Block design. } \\
\text { COWAT, TMT-B. }\end{array}$ \\
\hline 1 & $\begin{array}{l}\text { Bunce, } \\
2012\end{array}$ & MMSE & $\begin{array}{l}\text { Memory } \\
\text { Processing speed } \\
\text { Verbal Fluency }\end{array}$ & $\begin{array}{l}\text { Testing word, face, name, adress recall, figure } \\
\text { reproduction. } \\
\text { Symbol Letter Modalities Test. } \\
\text { Number of animals in } 30 \mathrm{sec} \text {. }\end{array}$ \\
\hline 1 & $\begin{array}{l}\text { De Bruijn, } \\
2014\end{array}$ & & $\begin{array}{l}\text { Memory } \\
\text { Attention/ processing } \\
\text { speed } \\
\text { Verbal fluency } \\
\text { Executive functioning }\end{array}$ & $\begin{array}{l}\text { 15-Word Learning Test based on Rey's recall of } \\
\text { words. } \\
\text { Stroop Test, Letter-Digit Substitution Task. } \\
\text { Verbal Fluency Test. } \\
\text { Stroop Test. }\end{array}$ \\
\hline 1 & $\begin{array}{l}\text { Okereke, } \\
2013\end{array}$ & TICS & n.a. & a. \\
\hline 1 & $\begin{array}{l}\text { Pietrzak, } \\
2012\end{array}$ & & $\begin{array}{l}\text { Memory } \\
\text { Visual attention } \\
\text { Psychomotor speed }\end{array}$ & $\begin{array}{l}\text { One-card learning (OCL), Continuous Paired Asso- } \\
\text { ciate Learning Test (CPAL), One-Back test (OBK), } \\
\text { International Shopping List Test. } \\
\text { Identification task (IDN). } \\
\text { Detection task (DET). }\end{array}$ \\
\hline 1 & $\begin{array}{l}\text { Pietrzak, } \\
2014\end{array}$ & & $\begin{array}{l}\text { Attention } \\
\text { Language } \\
\text { Visuospatial } \\
\text { Executive functioning }\end{array}$ & $\begin{array}{l}\text { California Verbal Learning Test - Second Edition } \\
\text { (CVLT-II) delayed recall, Rey Complex Figure Test } \\
\text { (RCFT) } 30 \text { min delayed recall tests, logical memory } \\
\text { delayed recall, CVLT-II delayed recall, CVLT-II d' } \\
\text { measures, RCFT } 3 \text { and 30min delayed recall, RCFT } \\
\text { recognition tests. } \\
\text { Digit Span, Stroop Dots, Digit Symbol Coding. } \\
\text { D-KEFS Category Fluency (Animals/Boys' } \\
\text { Names), Boston Naming tests. } \\
\text { RCFT copy, Clock Drawing. } \\
\text { Stroop Colors/Dots, Letter Fluency (FAS) and } \\
\text { Category Switching (Fruit/Furniture) tests from } \\
\text { the Delis-Kaplan Executive Function System (D- } \\
\text { KEFS). }\end{array}$ \\
\hline
\end{tabular}




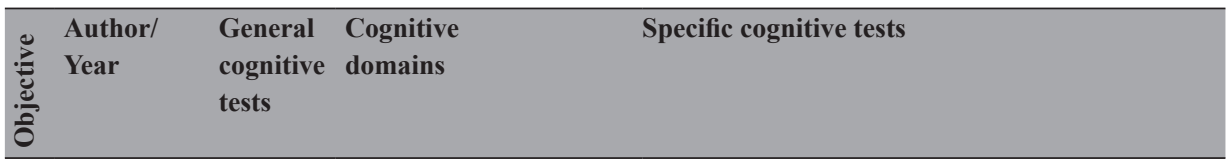

Objective 1. Anxiety and risk for incident cognitive impairment in the community

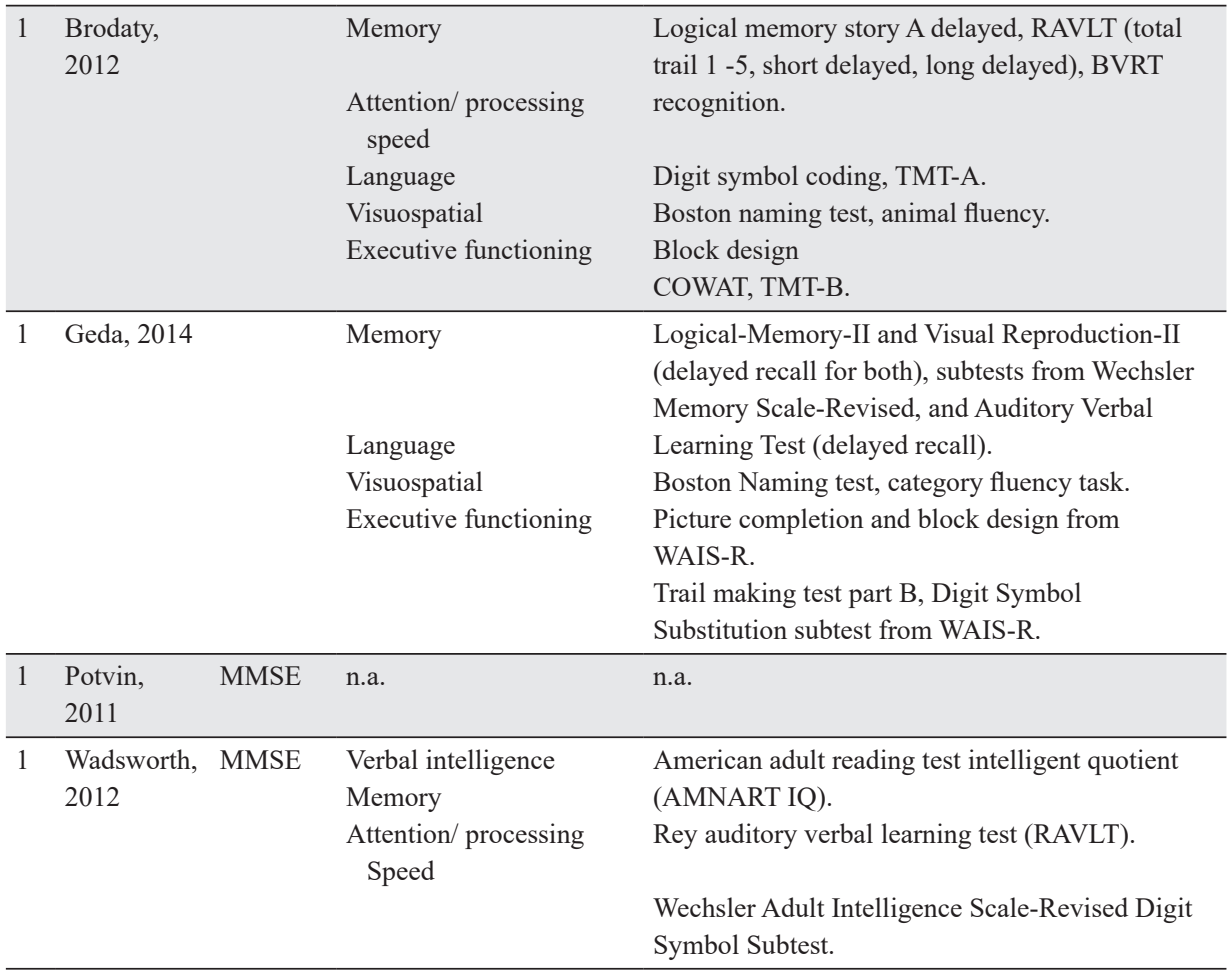




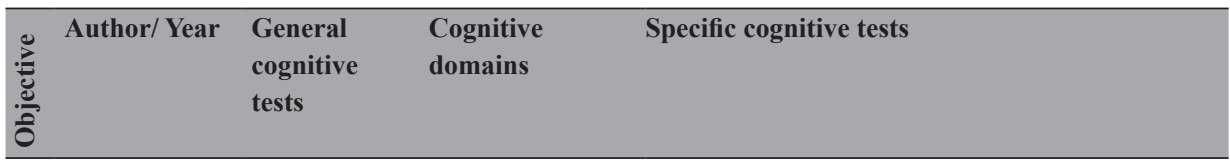

Objective 1. Anxiety and risk for incident dementia in the community

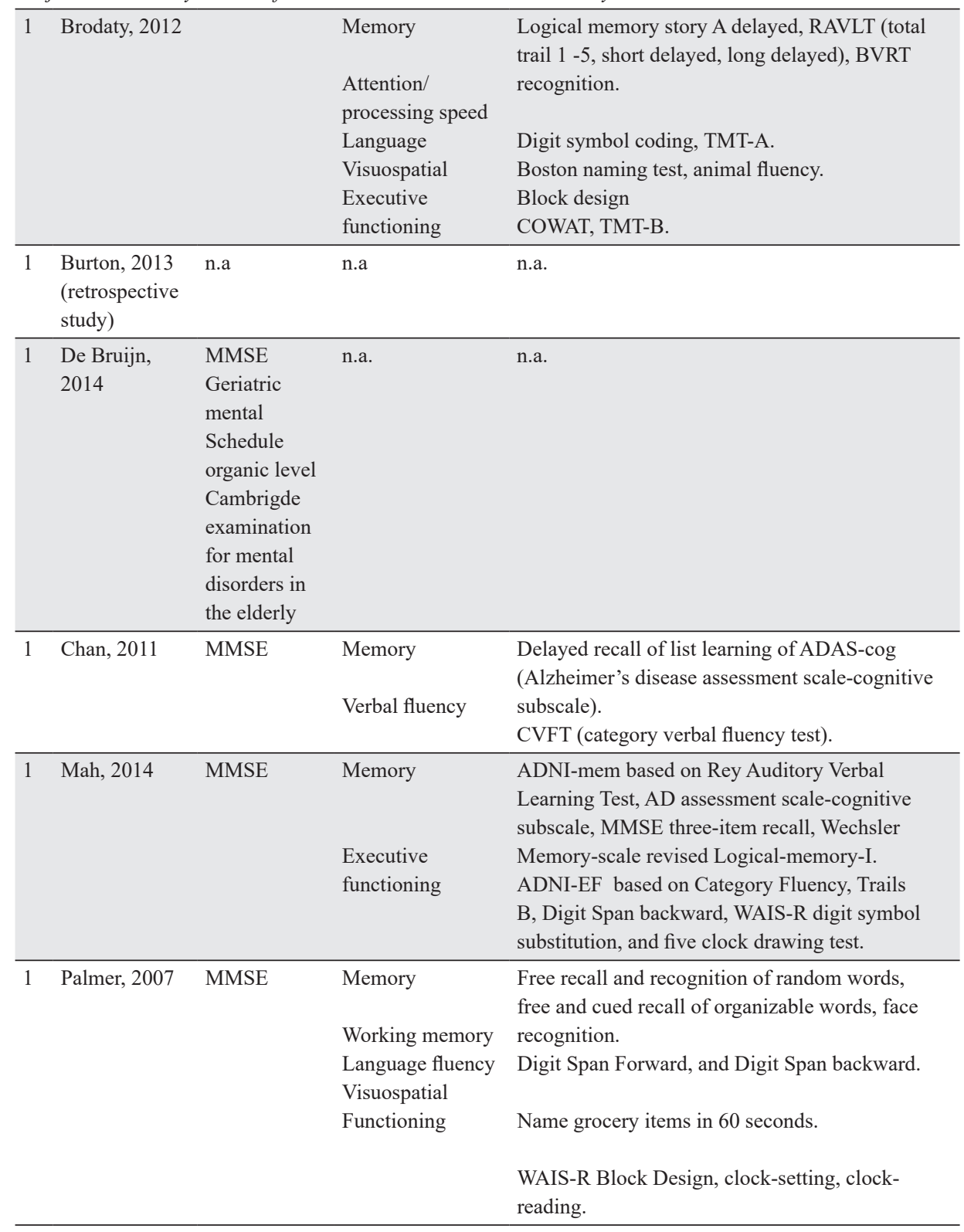




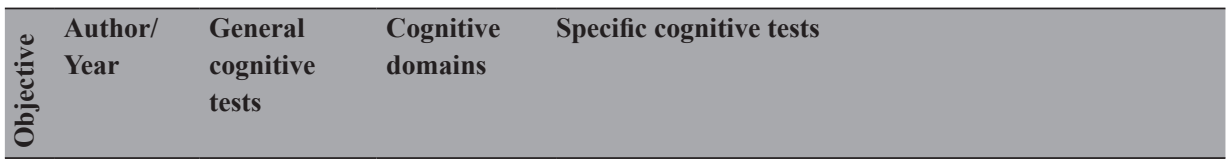

Objective 2. Conversion to dementia in memory-clinics

\begin{tabular}{|c|c|c|c|c|}
\hline 2 & \multicolumn{2}{|l|}{$\begin{array}{l}\text { Devier, } \\
2009\end{array}$} & $\begin{array}{l}\text { Visuospatial } \\
\text { functioning } \\
\text { Executive } \\
\text { functioning }\end{array}$ & $\begin{array}{l}\text { 12-item, 6-trial SRT with total immediate recall, delayed } \\
\text { recall, and the percent savings from immediate to delayed } \\
\text { recall, WMS-VR subtest, multiple-choice version of the } \\
\text { Benton Visual Retention Test. } \\
\text { The digit span subtest from the WMS (forward plus } \\
\text { reverse digits) and cancellation tests that featured a } \\
\text { diamond-shaped stimulus (cancellation-shape) and a } \\
\text { group of letters (cancellation-letter). } \\
\text { 15-item version of the BNT (total spontaneous } \\
\text { responses), the ANT (60-second trial), and the repetition } \\
\text { of high-frequency phrases and complex ideational } \\
\text { material subtests of the Boston Diagnostic Aphasia } \\
\text { Evaluation (BDAE repetition and BDAE comprehension, } \\
\text { respectively). } \\
\text { Block design and object assembly subtests of the } \\
\text { WAIS-R, the 5-item Rosen Drawing Test, and the } \\
\text { matching subtest of the Benton Visual Retention Test. } \\
\text { Similarities subtest of the WAIS-R, the identities and } \\
\text { oddities subtest of the Mattis Dementia Rating Scale } \\
\text { (Mattis identities and oddities), the CFL version of the } \\
\text { Controlled Oral Word Association Test (COWAT-CFL) } \\
\text { and WAIS-R Digit Symbol }\end{array}$ \\
\hline 2 & $\begin{array}{l}\text { Gallagher, } \\
2011\end{array}$ & $\begin{array}{l}\text { MMSE } \\
\text { CAM-COG }\end{array}$ & n.a. & n.a. \\
\hline 2 & $\begin{array}{l}\text { Ramakers, } \\
2010\end{array}$ & MMSE & $\begin{array}{l}\text { Intelligence } \\
\text { Memory } \\
\text { Processing } \\
\text { speed } \\
\text { Fluency } \\
\text { Executive } \\
\text { functioning }\end{array}$ & $\begin{array}{l}\text { Groninger Intelligence Test } \\
\text { 15-word learning test } \\
\text { Stroop test, trail making test } \\
\text { One minute fluency animals } \\
\text { Stroop 3, trail making test- part B }\end{array}$ \\
\hline 2 & $\begin{array}{l}\text { Rosenberg, } \\
2013\end{array}$ & MMSE & $\begin{array}{l}\text { Memory } \\
\text { Attention } \\
\text { Psychomotor } \\
\text { speed } \\
\text { Fluency } \\
\text { Executive } \\
\text { functioning }\end{array}$ & $\begin{array}{l}\text { Wechsler Memory-scale revised Logical Memory IA } \\
\text { immediate, WMS-R Logical Memory IIA-Delayed. } \\
\text { Digit Span Forward and Backward. } \\
\text { WAIS-R Digit symbol, Trail making test Part A. } \\
\text { Category fluency, Boston Naming Test. } \\
\text { Trail making test B. }\end{array}$ \\
\hline 2 & $\begin{array}{l}\text { Somme, } \\
2013\end{array}$ & MSE & Memory & ew York Logical Memory Test. \\
\hline
\end{tabular}




\begin{tabular}{|c|c|c|c|c|}
\hline 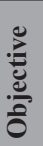 & $\begin{array}{l}\text { Author/ } \\
\text { Year }\end{array}$ & $\begin{array}{l}\text { General } \\
\text { cognitive } \\
\text { tests }\end{array}$ & $\begin{array}{l}\text { Cognitive } \\
\text { domains }\end{array}$ & Specific cognitive tests \\
\hline 2 & Teng, 2007 & & $\begin{array}{l}\text { Memory } \\
\text { Attention/ } \\
\text { processing } \\
\text { speed } \\
\text { Language } \\
\text { Visuospatial } \\
\text { functioning } \\
\text { Executive } \\
\text { functioning }\end{array}$ & $\begin{array}{l}\text { WMS-R/III Logical-Memory-II, WMS-R/III Visual } \\
\text { Reproduction II, California Verbal Learning Test I/II } \\
\text { long delay free recall, Rey complex figure test: 3-minute } \\
\text { delayed recall. } \\
\text { WAIS-III digit span, digit symbol, Trail making test part } \\
\text { A. } \\
\text { Bostin naming test, category fluency animals. } \\
\text { WAIS-III picture completion, block design, Rey complex } \\
\text { figure test copy. } \\
\text { Controlled Orals Word association test, Stroop-test color } \\
\text { word interference, Trail making test part B, Wisconsin } \\
\text { card sorting test. }\end{array}$ \\
\hline
\end{tabular}


Appendix figure 1: Funnel plot for meta-analysis anxiety and risk for incident cognitive impairment in the community

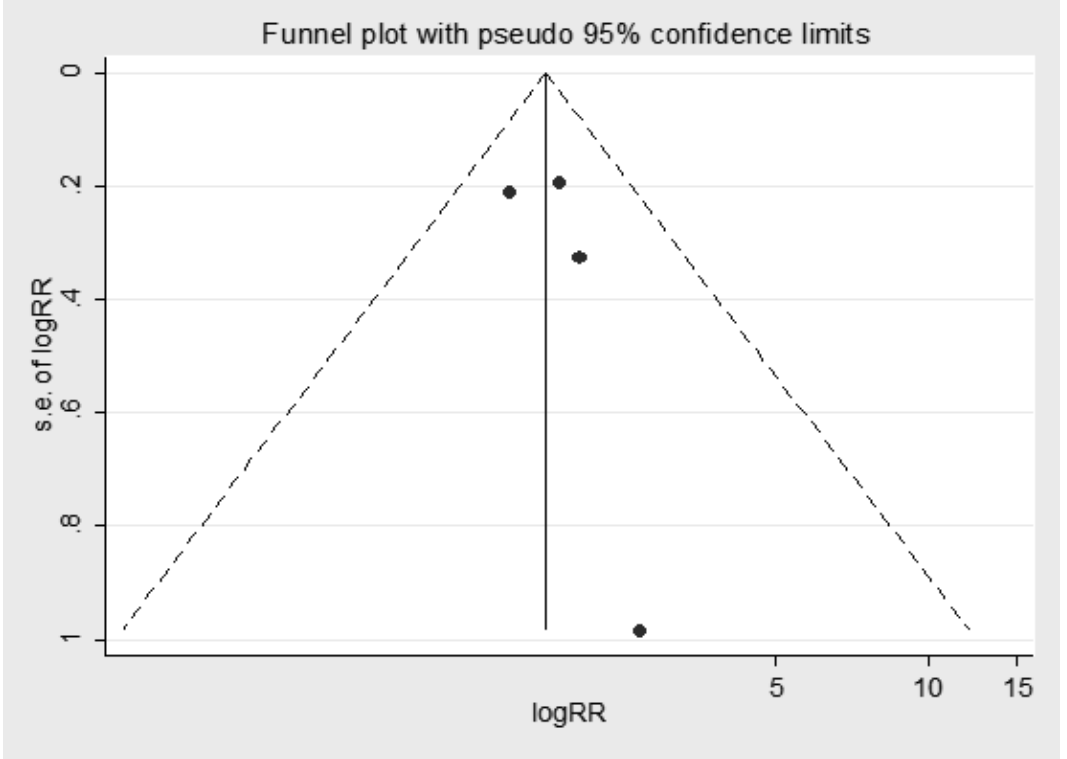

$\mathrm{P}=0.47$ for Egger's regression intercept

Appendix figure 2: Funnel plot for meta-analysis anxiety and risk for incident dementia in the community

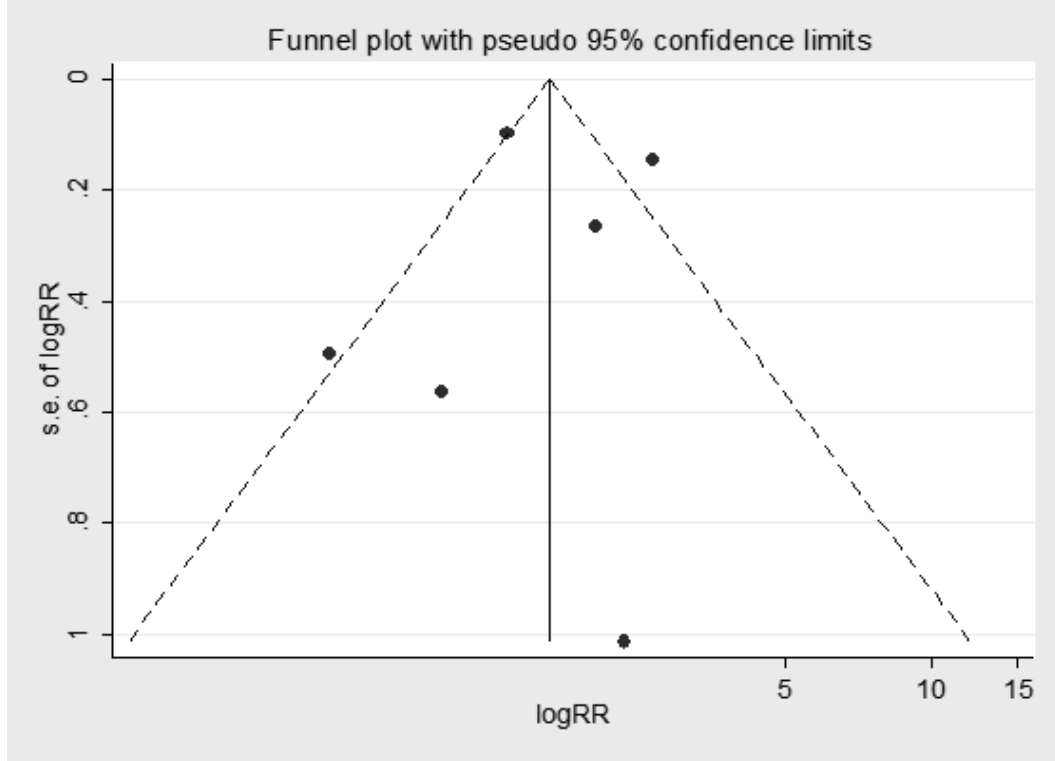

$\mathrm{P}=0.88$ for Egger's regression intercept 
Appendix figure 3: Funnel plot for meta-analysis anxiety and risk for conversion to dementia in memoryclinics

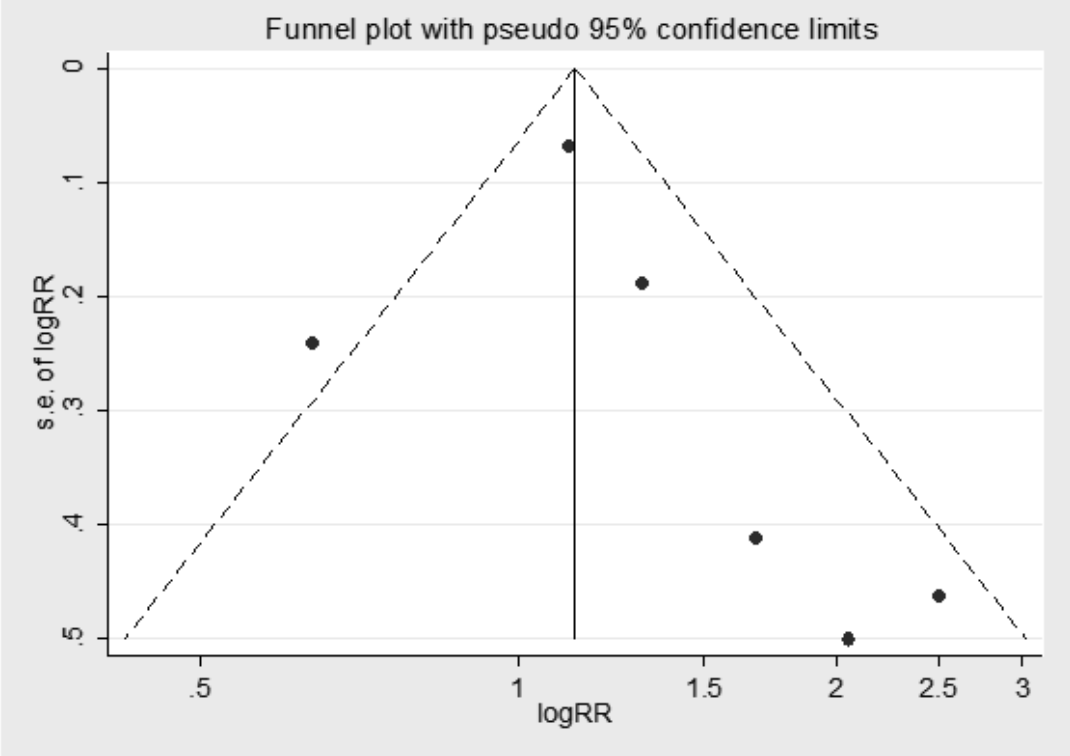

$\mathrm{P}=0.46$ for Egger's regression intercept 



\section{Chapter 3}

\section{Anxiety disorders and \\ figural fluency: a measure of executive function}




\section{ABSTRACT}

Background - Anxiety possibly interferes with executive functioning, although most studies rely on anxiety symptoms or lack control for comorbid depression. The objective of the present study is to examine the association between executive functioning and (individual) anxiety disorders with and without controlling for depression.

Method - Generalized anxiety disorder (GAD), panic disorder with and without agoraphobia, agoraphobia, social phobia, as well as depressive disorder according to DSM-IV criteria were assessed with the Mini International Neuropsychiatric Interview in 82,360 community-dwelling people participating in the Lifelines cohort. Figural fluency as a measure of executive functioning was assessed with the Ruff Figural Fluency Test (RFTT). Linear regression analyses with the RFFT score as the dependent variable and psychiatric diagnosis as independent variables (dummies) were performed, adjusted for potential confounders. Multivariate results are presented with and without adjustment for depression.

Results - Presence of any anxiety disorder was associated with worse performance on the RFFT ( $\mathrm{B}=-0.78, \mathrm{SE}=0.32, \mathrm{p}=.015)$, independent of depression. No dose-response relationship with the number of anxiety disorders was found.

Only agoraphobia and generalized anxiety disorder were significantly associated with the RFFT score in the multivariate models. Agoraphobia remained significant when further adjusted for depressive disorder $(\mathrm{B}=-1.14, \mathrm{SE}=0.41, \mathrm{p}<.01)$, while $\mathrm{GAD} \operatorname{did} \operatorname{not}(\mathrm{B}=0.013$, $\mathrm{SE}=0.431, \mathrm{p}=.975)$.

Limitations - Executive function was tested by only one measure, namely figural fluency. Conclusion - Agoraphobia is associated with worse executive functioning. Treatment of agoraphobia could be influenced by the executive dysfunction which clinicians should be aware of when regular treatment fails. 


\section{INTRODUCTION}

Anxiety disorders are among the most common psychiatric disorders with a pooled lifetime prevalence rate of $16.6 \%$ (ranging between 3,8 and 25\%). (Remes et al., 2016) Higher anxiety levels are associated with poorer cognitive functioning (Forsell et al., 2003, Lyketsos et al., 2002, Beaudreau and O'Hara, 2008), although negative and even opposite findings have also been reported.(Biringer et al., 2005, Bierman et al., 2008) Eysenks processing efficiency theory hypothesizes that anxiety particularly influences executive functioning, as anxiety interferes by preempting some of the processing and storage resources of the working memory system.(Eysenck and Calvo, 1992) Executive functions are high-order cognitive processes that encompass skills necessary for purposeful, goal-directed behavior and are essential to the ability to respond to novel and unfamiliar situations.(Izaks et al., 2011, Lezak et al., 2004, Strauss et al., 2006). Executive dysfunction negatively interferes with both pharmacotherapy as well as cognitive behavioral therapy (CBT) for affective disorders. (Alexopoulos, 2005, Mohlman, 2005) This is clinically relevant, as problem-solving therapy adapted for executive dysfunction for example showed more improvement of depressive symptoms and problem solving skills in late-life depression.(Alexopoulos et al., 2008) In anxiety disorders, an executive function training program could improve intrusive thoughts that occur due to poor executive function of inhibitory control.(Bomyea and Amir, 2011)

A review study has shown that most studies examining the association between poor executive performance and anxiety rely on anxiety symptom severity measures instead of anxiety disorders.(Beaudreau and O'Hara, 2008) One study that has investigated this association by lumping all anxiety disorders together and indeed found an association between the presence of anxiety disorders and worse executive functioning in younger adults. (Airaksinen et al., 2005) Studies focussing on specific anxiety disorders, however, have found contradicting results. Of the four studies devoted to generalized anxiety disorder (GAD), two out of three studies in older adults found an association between GAD and worse executive functioning (Butters et al., 2011a, Price and Mohlman, 2007), while the only study in younger adults did not (Airaksinen et al., 2005, Mantella et al., 2007). Also for panic disorder and social phobia the results are not congruent, with for each diagnosis one study showing worse executive functioning (Airaksinen et al., 2005, Cohen et al., 1996) and two studies which did not replicate this finding.(Airaksinen et al., 2005, Asmundson et al., 1994-1995, Gladsjob et al., 1998) These studies were all conducted in younger adults. These inconsistent results may be explained by differences in methodology. First, the use of different cognitive tests for measuring executive functioning, e.g. trail-making test B (Airaksinen et al., 2005, Gladsjob et al., 1998, Mantella et al., 2007), Stroop colour and word test (Price and Mohlman, 2007), and the Delis-Kaplan executive function system. (Butters et al., 2011b) Secondly, some studies did not correct for depression. (Gladsjob et al., 1998, Price and Mohlman, 2007). Depression may easily confound results, as anxiety 
symptoms and depressive symptoms have both unique but also overlapping relationships with cognitive functioning [18]. Thirdly, differences in the mean age of the population studied, as older adults with an anxiety disorder may be more vulnerable to poor executive functioning, due to decreased cognitive reserves compared to younger adults.(Deptula et al., 1993) Finally, the sex-difference may explain some inconsistencies as some studies found a greater impact of clinically relevant anxiety symptoms on cognitive functioning for men.(Wetherell et al., 2002, Potvin et al., 2011)

To our knowledge this is the first study to investigate the association between different anxiety disorders measured with a semi-structured interview and executive functioning in a large population-based sample of younger and older adults. It enables us to investigate this association adjusted for all relevant confounders, including depressive disorder, as well as to test potential moderation by age and sex.

\section{METHODS}

\section{Study population}

We used the baseline data of the Lifelines population based cohort study, which included 167,729 subjects.(Stolk et al., 2008, Scholtens et al., 2014) Lifelines is a facility that is open for all researchers (see www.lifelines.net). This observational study recruited subjects and completed the baseline measurements between 2006 and 2013 in the northern provinces of the Netherlands (Groningen, Friesland, Drenthe). Random selected general practitioners invited all their listed patients between 25 and 50 years of age. When a patient was willing to participate, the family members were also asked to participate including their partner, parents, parents in law and children, leading to a three-generation study. Subjects could also register themselves at the Lifelines website. Exclusion criteria for the Lifelines study were: a) severe mental or physical illness, b) not able to visit the general practitioner, c) not able to fill in the questionnaires, and d) insufficient understanding of the Dutch language. Pregnant women were not excluded, but rescheduled for measurements until 6 months after pregnancy or 3 months after breast feeding. In participants aged 65 years or older the Mini Mental State Examination (MMSE) was administered. When scored lower than 26, the participants received a shorter test-battery, excluding the Mini International Neuropsychiatric Interview (MINI) and the Ruff Figural Fluency Test (RFFT). Additional exclusion criteria for the present analyses were: a) age below 18 years, b) MMSE below 26, c) no baseline measurement for the MINI or the RFFT, d) self-reported diagnosis of neurological disorders (Parkinson's disease, stroke, epilepsy, multiple sclerosis and spasticity) or dementia, and e) use of Hydroxyzine (antihistamine) as a rare anxiolytic not equivalent to benzodiazepines or antidepressants. As a result, we included 82.360 subjects in the present analyses (see figure 1). 
Figure 1: Flow diagram of the selected subjects*

\begin{tabular}{|c|c|}
\hline $\begin{array}{l}\text { Lifelines study: } \\
\mathrm{N}=167.729\end{array}$ & $\begin{array}{l}\text { Total sample in lifelines: } \\
\mathrm{N}=167.729\end{array}$ \\
\hline$\downarrow$ & \multirow{2}{*}{$\begin{array}{l}\text { No MINI excluded } \\
\text { (automatically excludes } \\
\text { MMSE }<26 \text { ) }\end{array}$} \\
\hline $\begin{array}{l}\text { MINI version 2/ 3: } \\
\mathrm{N}=125.988\end{array}$ & \\
\hline & \multirow[t]{2}{*}{ No RFFT excluded } \\
\hline $\begin{array}{l}\text { RFFT: } \\
\mathrm{N}=84.907\end{array}$ & \\
\hline$\downarrow$ & $\begin{array}{l}\text { Schizophrenia, bipolar } \\
\text { disorder and OCD excluded }\end{array}$ \\
\hline $\begin{array}{l}\text { No severe mental } \\
\text { illness: } \\
\mathrm{N}=84.236\end{array}$ & \multirow{2}{*}{$\begin{array}{l}\text { PD, MS, stroke, epilepsy, } \\
\text { spasticity and dementia } \\
\text { excluded }\end{array}$} \\
\hline$\downarrow$ & \\
\hline $\begin{array}{l}\text { No neurological } \\
\text { disorders/ dementia: } \\
\mathrm{N}=82.386\end{array}$ & \multirow{3}{*}{ Hydroxyxine excluded } \\
\hline$\downarrow$ & \\
\hline $\begin{array}{l}\text { No Hydroxyzine: } \\
\mathrm{N}=82.360\end{array}$ & \\
\hline$\downarrow$ & \\
\hline $\begin{array}{l}\text { No age below } 18: \\
\mathrm{N}=82.360\end{array}$ & $\begin{array}{l}\text { Total sample in analyses: } \\
\mathrm{N}=82.360\end{array}$ \\
\hline
\end{tabular}

*Abbreviations: MINI, Mini International Neuropsychiatric Interview, RFFT, Ruff's Figural Fluency Test; OCD, obsessive-compulsive disorder; PD, Parkinson's disease; MS, Multiple Sclerosis.

Subjects who met the inclusion criteria received an informed consent form, a self-administered questionnaire on demographics, presence or history of somatic and mental disorders, use of medication, and were invited to the study site. During this visit, a trained research assistant administered the MINI and the RFFT. At the end of this visit, participants received another self-administered questionnaire about alcohol use.

\section{Primary variables}

Anxiety disorders - Anxiety disorders according to DSM-IV criteria were assessed with the MINI. The MINI is a structured interview with a good sensitivity and positive predictive value.(Sheehan et al., 1998) In Lifelines, the sections on GAD, panic disorder with or without agoraphobia, agoraphobia without panic disorder, social phobia, and depressive disorder were administered. During the lifelines baseline assessment, the reference period 
of the MINI was adapted, therefore we have only used the last version assessing current psychopathology.

Executive functioning - Executive functioning was assessed with a figural fluency test: the RFFT. Fluency has been defined as the ability to use one or more strategies that maximize the production responses under constraint of time and restricted search conditions while avoiding response repetition.(Ruff, 1988) Core elements of executive functioning consists of planning and reasoning, mental flexibility, working memory, inhibition, strategy generation and regulation of action in the face of new or unfamiliar tasks. (Lezak et al., 2004, Ross, 2014) The RFFT is considered to be an overall measure of executive functioning comprising these core elements in the process to initiate and sustain mental productivity, apply effective strategies for response and to self-monitor and regulate the response.(Lezak et al., 2004, Ross, 2014) The RFFT was administered to all participants until 01-04-2012, and due to logistical reasons hereafter in a random half of the sample. The RFFT consists of five parts with each part containing 35 five-dot patterns arranged in five columns and seven rows. Each part either uses different distractors or uses different patterns. For each part it required the participants to draw as many unique designs between the dots during 60 seconds. The total number of unique designs was used as the dependent variable in the analyses.(Ruff, 1996, Ruff et al., 1987) The RFFT has a good test-retest reliability and good to excellent interrater reliability (Berning et al., 1998, Ruff et al., 1987, Ross, 2014), and is sensitive to changes in younger and older adults.(Izaks et al., 2011, Ruff et al., 1987) Reference data is available for younger and older adults stratified by age and educational level.(Izaks et al., 2011)

\section{Covariates}

All variables associated with both anxiety disorders as well as cognitive functioning, were considered as potential confounders. Based on the literature, we included age, sex, level of education, psychotropic drug use, alcohol use(Paterniti et al., 1999, Sinforiani et al., 2011), and chronic somatic diseases. Education level was defined into low (no or primary education), medium (lower/ prepatory vocational education to intermediate vocational education/ apprenticeship) and high education (higher secondary education to university) (included as dummy's with low education as reference). Alcohol use was measured with the Food Frequency Questionnaire, and based on the two questions with respect to number of drinks and drinking days, categorized in no use, social use or excessive use. Excessive use was defined as $\geq 5$ units per day, or $\geq 4$ days 3 or more alcohol units. Social use was the reference for the dummies due to the u-shape relationship of alcohol and cognition. Medication use was self-reported and the psychotropic medication included current use of antidepressants, mood stabilizers and antipsychotics, and past year use of tranquilizers. Somatic disease burden was measured as the number of self-reported chronic diseases, i.e. chronic lung disease, cardiac disease, diabetes mellitus, arthrosis/ arthritis or rheumatism, 
cancer, ulcer, chronic intestinal problems and liver disease. Self-report questionnaires for these diseases have been shown to be adequate when compared to the general practitioner information and independent of cognitive impairment.(Kriegsman et al., 1996).

\section{Statistical analysis}

Descriptives are presented for four subgroups, i.e. patients suffering from either 1) an anxiety disorder, 2) anxiety disorder with comorbid depressive disorder, or 3) depressive disorder, and 4) a non-anxious, non-depressed comparison group. Group differences were tested by ANOVA analyses (dimensional variables) and $\mathrm{chi}^{2}$-square tests (categorical variables).

Linear regression analyses with the RFFT score as the dependent variable were conducted, with psychiatric diagnosis as independent variable. First a model with the four diagnostic groups (dummies with the non-anxious non-depressed group as reference) was tested. Second, the association of one anxiety disorder versus two or more comorbid anxiety disorders was evaluated to explore the presence of a dose-response relationship. Third, the relation of individual anxiety disorders and executive functioning was evaluated by examining the presence or absence of either panic disorder with and without agoraphobia (yes/no), agoraphobia without panic disorder (yes/no), social phobia (yes/no) and GAD (yes/no) in one regression model. Results of all analyses are presented bivariately as well as multivariately adjusted for age, sex, education, somatic comorbidity, psychotropic drug use and alcohol use. Comorbidity with depression deserves specific attention. On the one hand, comorbidity between anxiety and depression may represent a more severe state. On the other hand, depression may confound the specific effect of anxiety on executive functioning. Therefore, results with and without adjustment for depressive disorder will be presented for all analyses. Furthermore, interaction of psychiatric diagnoses with either age or sex were tested in all models. If significant, stratified analyses are performed for either different age groups or sex. The analyses were conducted with SPSS 22 for windows. P-values $<.05$ were considered significant.

\section{RESULTS}

\section{Baseline comparisons}

As shown in table 1, all socio-demographic and clinical characteristics differed between the diagnostic groups. The mean age of the group with anxiety and depressive disorders was significantly lower compared to the other diagnostic groups. The post-hoc analyses showed that the non-anxious non-depressed group consisted of fewer females, were more highly educated, had less somatic comorbidity, used less psychotropic drugs and more alcohol compared to subjects with depression and/or anxiety. 
Chapter 3

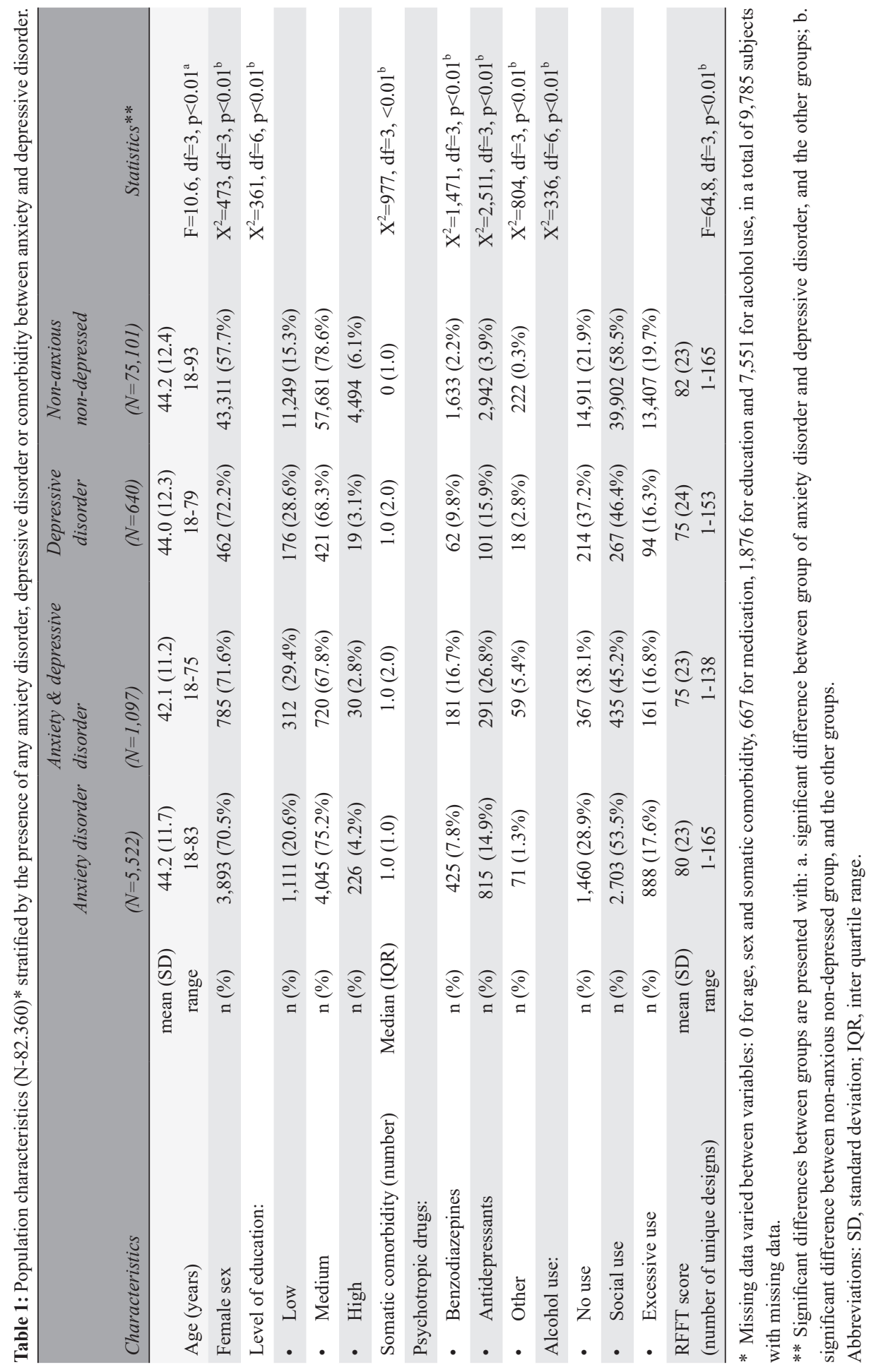




\section{Association between any anxiety disorder and RFFT}

In both, the unadjusted and adjusted models, subjects with any anxiety disorders and/or depression scored worse on the RFFT compared to non-anxious non-depressed subjects. Subjects with comorbid anxiety and depression had the lowest score on the RFFT (see table 2).

Table 2: Association of any anxiety disorder and other diagnostic groups with the RFFT sum score* (with nonanxious non-depressed controls as reference group) using linear regression

\begin{tabular}{lcccc}
\hline & B & S.E. & Beta & P-value \\
\hline Unadjusted $(\mathrm{n}=72,575)^{* *}$ & & & & \\
Constant & 81.98 & 0.089 & & \\
Anxiety disorder $(\mathrm{n}=5,522)$ & -2.14 & 0.341 & -0.023 & $<0.01^{* * *}$ \\
Anxiety and depressive disorder $(\mathrm{n}=1,097)$ & -6.51 & 0.761 & -0.032 & $<0.01^{* * *}$ \\
Depressive disorder $(\mathrm{n}=640)$ & -6.97 & 0.987 & -0.026 & $<0.01^{* * *}$ \\
Adjusted**** $(\mathrm{n}=72,575)$ & & & & \\
Constant & 89.96 & 0.481 & & \\
Anxiety disorder $(\mathrm{n}=5,522)$ & -0.78 & 0.316 & -0.008 & $0.015^{* * *}$ \\
Anxiety and depressive disorder $(\mathrm{n}=1,097)$ & -4.13 & 0.707 & -0.020 & $<0.01^{* * *}$ \\
Depressive disorder $(\mathrm{n}=640)$ & -4.00 & 0.904 & -0.015 & $<0.01^{* * *}$ \\
\hline
\end{tabular}

* RFFT, Ruff's Figural Fluency test.

** 9,785 subjects had missing data for covariates, leaving 72,575 subjects for analyses.

*** Significant.

**** Adjusted for: age, sex, education, somatic comorbidity, psychotropic drug use and alcohol use.

The presence of any anxiety disorder as well as of depression neither significantly interacted with age nor sex. The presence of comorbid anxiety and depressive disorder, however, had a significant interaction with sex $(\mathrm{P}=0.016)$, but not with age $(\mathrm{p}=0.059)$. Stratified analyses showed that the association of a comorbid anxiety and depressive disorder with the RFFT score was larger in females than in males: $\mathrm{B}=-7.77(\mathrm{SE}=0.90, \mathrm{p}<0.01)$ versus $\mathrm{B}=-3.25$ $(\mathrm{SE}=1.44, \mathrm{p}=0.024)$ in the unadjusted analyses and $\mathrm{B}=-5.29, \mathrm{SE}=0.83, \mathrm{p}<0.01$ versus $\mathrm{B}=-$ $0.42, \mathrm{SE}=1.33, \mathrm{p}=0.751$ ) in the adjusted analyses.

\section{Dose-response associations of anxiety disorders on RFFT}

No dose-response relationship was found. The presence of only one anxiety disorder was significantly associated with a lower performance on the RFFT (see table 3). The presence of two or more comorbid anxiety disorders was also associated with a lower performance on the RFFT, but this association disappeared after adjustment for a comorbid depressive disorder. 
Table 3: Results for one anxiety disorder or comorbid anxiety disorders (more than one) compared to nonanxious non-depressed controls on the RFFT *

\begin{tabular}{lcccc}
\hline & B & S.E. & Beta & P-value \\
\hline Unadjusted $(\mathrm{n}=72,575)$ & & & & \\
Constant & 81.92 & 0.089 & & \\
One anxiety disorder $(\mathrm{n}=5,545)$ & -2.76 & 0.341 & -0.030 & $<0.01^{* * *}$ \\
Two or more anxiety disorders $(\mathrm{n}=1,074)$ & -2.86 & 0.764 & -0.14 & $<0.01^{* * *}$ \\
\hline Adjusted without depression** $(\mathrm{n}=72,575)$ & & & & \\
Constant & 89.85 & 0.481 & & \\
One anxiety disorder $(\mathrm{n}=5,545)$ & -1.16 & 0.316 & -0.013 & $<0.01^{* * *}$ \\
Two or more anxiety disorders $(\mathrm{n}=1,074)$ & -1.62 & 0.707 & -0.008 & $=0.022^{* * *}$ \\
Adjusted with depression** $(\mathrm{n}=72,575)$ & & & & \\
Constant & 89.96 & 0.481 & & \\
One anxiety disorder $(\mathrm{n}=5,545)$ & -0.76 & 0.323 & -0.008 & $=0.019^{* * *}$ \\
Two or more anxiety disorders $(\mathrm{n}=1,074) * *$ & -0.55 & 0.727 & -0.003 & $=0.452$ \\
\hline
\end{tabular}

* RFFT, Ruff's Figural Fluency test.

** Adjusted for age, sex, education, somatic comorbidity, psychotropic drug use, alcohol use and optionally for depression.

*** Significant.

\section{Association of individual anxiety disorders with RFFT}

Of the 6,619 subjects suffering from an anxiety disorder, agoraphobia and GAD were most prevalent (see table 4). The multivariate analyses showed that only agoraphobia and GAD were significantly associated with the RFFT score. However, after adjustment for depression, only agoraphobia had a significant association with the RFFT (adjusted B=-1.18, $\mathrm{SE}=0.41, \mathrm{p}<0.01)$ (see table 4).

Agoraphobia comorbid to panic disorder $(\mathrm{n}=229)$ however was not associated with worse executive functioning (adjusted $\mathrm{B}=-0.19, \mathrm{SE}=1.56, \mathrm{p}=0.90$ ) and had an effect size comparably to panic disorder without agoraphobia.

Since agoraphobia was the most prevalent anxiety disorder and comorbid to many other anxiety disorders, a post-hoc analysis was performed to examine the association between any anxiety disorders, excluding agoraphobia. This revealed that the prior significant association of any anxiety disorder was driven by agoraphobia and not by a shared factor underlying the individual anxiety disorders as this analysis did not yield a significant association (adjusted $\mathrm{B}=-0.51, \mathrm{SE}=0.46, \mathrm{p}=0.26$ ). 
Table 4: Influence of the individual anxiety disorders (present versus absent) on the RFFT *

\begin{tabular}{|c|c|c|c|c|}
\hline & B & S.E. & Beta & $\mathrm{P}$-value \\
\hline \multicolumn{5}{|l|}{ Unadjusted $(\mathrm{n}=72,575) * *$} \\
\hline Constant & 81.91 & 0.089 & & \\
\hline Panic disorder $(\mathrm{n}=514)$ & 1.11 & 1.102 & 0.004 & $=0.315$ \\
\hline Agoraphobia $(n=3,360)$ & -4.51 & 0.445 & -0.039 & $<0.001 * * *$ \\
\hline $\operatorname{GAD}(\mathrm{n}=3,371)$ & -0.86 & 0.445 & -0.007 & $=0.053$ \\
\hline Social phobia $(\mathrm{n}=693)$ & 0.09 & 0.973 & 0.000 & $=0.927$ \\
\hline \multicolumn{5}{|c|}{ Adjusted without depression $* * * *(n=72,575)$} \\
\hline Constant & 89.84 & 0.481 & & \\
\hline Panic disorder $(\mathrm{n}=514)$ & 0.29 & 1.009 & 0.001 & $=0.778$ \\
\hline Agoraphobia $(n=3,360)$ & -1.28 & 0.410 & -0.011 & $=0.002 * * *$ \\
\hline $\operatorname{GAD}(n=3,371)$ & -0.83 & 0.411 & -0.007 & $=0.042 * * *$ \\
\hline Social phobia $(n=693)$ & -1.13 & 0.889 & -0.004 & $=0.203$ \\
\hline \multicolumn{5}{|c|}{ Adjusted with depression $* * * *(n=72,575)$} \\
\hline Constant & 89.92 & 0.481 & & \\
\hline Panic disorder $(\mathrm{n}=514)$ & 0.80 & 1.012 & 0.003 & $=0.793$ \\
\hline Agoraphobia $(n=3,360)$ & -1.18 & 0.410 & -0.010 & $=0.004 * * *$ \\
\hline $\operatorname{GAD}(\mathrm{n}=3,371)$ & 0.013 & 0.431 & 0.000 & $=0.975$ \\
\hline Social phobia $(n=693)$ & -0.65 & 0.892 & -0.003 & $=0.464$ \\
\hline
\end{tabular}

*RFFT, Ruff's Figural Fluency test.

** 9,785 subjects had missing data for covariates, leaving 72,575 subjects for analyses.

*** Significant.

**** Adjusted for age, sex, education, somatic comorbidity, psychotropic drug use, alcohol use, other anxiety disorders and optionally for depression.

\section{DISCUSSION}

\section{Main findings}

In the present study, presence of any anxiety disorder was associated with worse executive functioning, even in the absence of depression. This effect was driven by agoraphobia. The impact of anxiety disorders, however, was less than that of depressive disorders. Patients suffering from anxiety disorders scored on average 2 unique designs less on the RFFT, while patients suffering from depressive disorder only or comorbid depressive and anxiety disorders scored 7 and 6.5 unique designs less on the RFFT, respectively. Comorbid between separate anxiety disorders was not associated with worse executive function compared to only one anxiety disorder. After adjustment for depression, only agoraphobia remained associated with executive dysfunction. GAD was associated with worse executive functioning, replicating previous findings, but this was fully explained by comorbid depressive disorder. These associations were not moderated by age. Only among subjects 
with comorbid anxiety and depression the association with worse RFFT scores was larger in females than in males.

\section{Anxiety disorders and executive functioning}

In our study anxiety disorders were associated with worse executive function. This result is a replication of one prior study investigating anxiety disorders in younger adults.(Airaksinen et al., 2005) This community-based case-control study ( $\mathrm{n}=287)$ also showed that anxiety disorders $(n=112)$ were associated with worse executive functioning measured with the trail-making test part B, independent of depressive disorder, psychotropic drug use or alcohol use disorders. Our effect of anxiety disorders however was driven by the specific effects of agoraphobia. In the study of Araiksinen only three subjects with only agoraphobia were identified, indicating a different cause of the significant finding.

In our study only agoraphobia remained significant after adjustment for depression and the other individual anxiety disorders. By our knowledge this is the first study that suggests that specific features of agoraphobia are associated with worsened executive functioning. The strength of the association between agoraphobia and executive function should be noted. The effect-sizes were small $(\mathrm{B}=-0.78$ for anxiety disorders, and $\mathrm{B}=-1.14$ for agoraphobia). For better interpretation, we should compare these effects to a decline in executive functioning across the lifespan. When age is categorized in three groups (18-44, 45-64, $\geq 65$ ), the oldest age groups has worst executive functioning. Compared to either the youngest age group and the middle age group, both effect sizes were much larger compared to the impact of anxiety disorders $(\mathrm{B}=-22.5, \mathrm{SE}=0.34, \mathrm{p}<0.01$ and $\mathrm{B}=-6.5, \mathrm{SE}=0.17, \mathrm{p}<0.01$, respectively). It is also noteworthy that among all persons with an anxiety disorder in our sample, persons with agoraphobia without panic disorder and GAD were most prevalent (both $42 \%$ ), while in a clinical setting agoraphobia without panic disorder comprises only $0-31 \%$ of the patients with an anxiety disorder.(Wittchen et al., 2010) The same review has also shown that in the community $46-85 \%$ of the population with agoraphobia does not even have a comorbid diagnosis of panic disorder.(Wittchen et al., 2010) The prevalence rates in our study therefore are possibly explained by its setting in the community.

Previous studies have hardly focused on agoraphobia, but six studies (five studies in adults and one study in older adults) did investigate other individual anxiety disorders. To date, some smaller studies (up to 88 patients) have yielded conflicting results in younger adults (Asmundson et al., 1994-1995, Cohen et al., 1996, Gladsjob et al., 1998, Boldrini et al., 2005). Of the two smaller studies that included social phobia, only one found an association with worse executive functioning.(Asmundson et al., 1994-1995, Cohen et al., 1996) Of the three smaller studies that investigated the association between executive functioning and panic disorder with or without agoraphobia, none found a worse association (Asmundson et al., 1994-1995, Gladsjob et al., 1998, Boldrini et al., 2005). These conflicting results can be 
explained by low sample sizes, acknowledging the small effect-sizes we found in our study. Two studies however merit further discussion.

The study of Araiksinen also investigated the effect of the individual anxiety disorders in younger adults and found a significant association for the group of panic disorder with or without agoraphobia and agoraphobia together $(\mathrm{N}=33$ of which 3 subjects with only agoraphobia), but not for social phobia, specific phobia and OCD. Nonetheless, this last association was lost after adjustment for alcohol disorders according to the DSM-IV criteria. No significant association of GAD on executive functioning was found, but there were only 7 subjects identified with GAD in a population sample of 1,093 subjects.(Airaksinen et al., 2005) It is possible that the small numbers of the individual anxiety disorders in combination with the small beta's of the anxiety disorders in our study may explain the differences with our results.

Interestingly, one case-control study focused specifically on older GAD patients (60 years or older). Adjusted for depression and lorazepam usage, GAD was significantly associated with lower scores on the letter-number sequencing test of the Wechsler Adult Intelligence Scale and the Delis-Kaplan Executive Function System (D-KEFS) sorting test (N=197). (Butters et al., 2011b) Possibly, the higher risk for (early) underlying neurodegenerative diseases in this older sample may explain the difference with our findings. Our recent meta-analysis has identified late-life anxiety as a risk factor for cognitive impairment and dementia, which was more likely a prodromal symptom of the underlying neurodegenerative process instead of a causal factor.(Gulpers et al., 2016) In our cross-sectional study, however, the strength of the associations was not moderated by age. Another explanation for the absence of an association between GAD and executive function might be that GAD is specifically associated with memory and not with executive function. A systematic review concluded that anxiety was more strongly associated with memory problems compared to other cognitive domains. (Beaudreau and O'Hara, 2008) However, only one study included patients with GAD whereas all other studies were based on anxiety symptoms only.(Beaudreau and O'Hara, 2008) There are no clear explanations why GAD would have a greater effect on memory than on executive function. Nonetheless, worrying and rumination in GAD are associated with hyperactivity of the dorsolateral region of the prefrontal cortex (Mathew, 2004), while other anxiety disorders as panic disorder or phobias are suggested to give underactivity in this area.(Berkowitz et al., 2007) Since these brain areas are strongly involved in executive function, this might partly explain the differential effect of GAD compared with other anxiety disorders on neurocognitive domains.

Several mechanisms may explain the association between agoraphobia and executive dysfunction. First of all, both phenomenons might have a similar underlying cause. An example of a potentially underlying factor causing both phenomenons is Alzheimer's disease. Alzheimer's disease leading to executive dysfunction(Kirova, 2015) has been associated with atrophy of the amygdala(Klein-Koerkamp, 2014). The amygdala plays an important 
role within the neuronal anxiety circuits, and anxiety has been associated with Alzheimer's disease cerebral fluid markers.(Ramakers et al., 2013)

Nonetheless, both phenomenons may also be risk factors for each other. First, as described in the introduction, agoraphobia may interfere with the working memory system by preempting some of the processing and storage resources.(Eysenck and Calvo, 1992) Although no prospective studies have monitored executive functioning in patients with agoraphobia, a study among GAD patients showed that cognitive functioning improved after treatment. (Butters et al., 2011b) . It should however be noted that agoraphobia is the only diagnosis of the anxiety disorders that only requires a behavioral component, and not a cognitive component like worrying that potentially negatively interferes with the working memory system. Therefore, the explanation that agoraphobia may interfere with the working system is less likely for our findings. Secondly, subjects with premorbid problems in executive functioning could be more prone to develop anxiety disorders. Executive functions like planning and organizing are necessary for purposeful, goal-directed activities.(Spielberg et al., 2013) Problems in executive functioning could therefore lead to avoidance of activities and thus agoraphobia. Executive dysfunctioning prior to the onset of agoraphobia could either be a trait characteristic or acquired due to an early neurodegenerative disorder. Since the association of agoraphobia in our cohort was similar in all age groups, a trait characteristics seems more likely than an underlying neurodegenerative process

According to differences between sexes we noted that among subjects with comorbid anxiety and depression the association with worse RFFT scores was larger in females than in males. Females are in general more vulnerable for anxiety and depression with higher prevalence rates compared to men.(Steel et al., 2014) This may have increased the variance and statistical power among females. Moreover, it may also be possible that the severity of the symptoms was worse in the female group.

\section{Strengths and limitations}

The study has some important strengths. The study is conducted in a large sample with a diagnostic interview to assess DSM-IV anxiety disorders.(Klijs, 2015) This enabled us to investigate individual anxiety disorders with smaller prevalence rates in the community, as well as comorbid groups.

Some methodological limitations need to be considered. First, our cross-sectional study design cannot answer the direction of the association between agoraphobia and worsened executive functioning. Second, the study only incorporated the RFFT as indicator of executive functioning, measuring figural fluency. Executive functioning contains several high-order cognitive processes, as working memory, planning, inhibition, fluency and shifting-attention.(Lezak et al., 2004, Bryan and Luszcz, 2000, Miyake and Friedman, 2012) A battery of separate tests for specific aspects of executive functioning might have given more in-depth information, as well as adding a test for shifting attention (like the 
trail-making-test part B) not covered by the RFFT. Nonetheless, strengths of the RFFT include that it comprises most core elements of executive functioning in one estimate, is well-validated, has norm-data available for younger and older adults, and is sensitive to changes due to alcohol use or dementia.(Fama et al., 1998, Izaks et al., 2011, Ruff et al., 1987, Zinn et al., 2004). Third, measurements for other cognitive domains have not been implemented in the study design, which limits the opportunity to test our hypothesis that anxiety disorders specifically affect executive functioning. A simple test addressing attention or processing speed might have been relevant as speed of information processing may interfere with the RFFT in the amount of unique designs that people can draw within 60 seconds.

\section{Conclusion}

In our study we found an association between anxiety disorders and executive dysfunction, which was driven by agoraphobia. Future longitudinal studies should examine whether subtle impairment of frontal structures underlying these executive dysfunction results in agoraphobic behavior (patients withdraw themselves from activities when experiencing decline in executive functioning) or agoraphobia itself give rise to subtle decline of executive functioning (loosing brain capacity due to inactivity). Treatment of agoraphobia could be influenced by the executive dysfunction which clinicians should be aware of when regular treatment fails. 


\section{REFERENCES}

AIRAKSINEN, E., LARSSON, M. \& FORSELL, Y. 2005. Neuropsychological functions in anxiety disorders in population-based samples: evidence of episodic memory dysfunction. Journal of Psychiatric Research, 39, 207-214.

ALEXOPOULOS, G. S. 2005. Depression in the elderly. Lancet, 365, 1961-1970.

ALEXOPOUlOS, G. S., RAUE, P. J., KANELlOPOUlOS, D., MACKIN, S. \& AREAN, P. A. 2008. Problem solving therapy for the depression-executive dysfunction syndrome of late life. Int $J$ Geriatr Psychiatry, 23, 782-788.

ASMUNDSON, G. J., STEIN, M. B., LARSEN, D. K. \& WALKER, J. R. 1994-1995. Neurocognitive function in panic disorder and social phobia patients. Anxiety, 1, 201-207.

BEAUDREAU, S. \& O'HARA, R. 2008. Late-life anxiety and cognitive impairment: a review. Am J Geriatr Psychiatry, 16, 790-803.

BERKOWITZ, R. L., COPLAN, J. D., REDDY, D. P. \& J.M., G. 2007. The human dimension: how the prefrontal cortex modulates the subcortical fear response. Rev Neurosci, 18, 191-207.

BERNING, L. C., WEED, N. C. \& ALOIA, M. S. 1998. Interrater reliability of the Ruff Figural Fluency Test. Assessment, 5, 181-186.

BIERMAN, E. J., COMIJS, H. C., RIJMEN, F., JONKER, C. \& BEEKMAN, A. T. 2008. Anxiety symptoms and cognitive performance in later life: results from the longitudinal aging study Amsterdam. Aging Ment Health, 12, 517-523.

BIRINGER, E., MYKLETUN, A. \& DAHL, A. A. 2005. The association between depression, anxiety, and cognitive function in the elderly general population--the Hordaland Health Study. Int $J$ Geriatr Psychiatry, 20, 989-997.

BOLDRINI, M., DEL PACE, L., PLACIDI, G. P., KEILP, J., ELLIS, S. P., SIGNORI, S., PLACIDI, G. F. \& CAPPA, S. F. 2005. Selective cognitive deficits in obsessive-compulsive disorder compared to panic disorder with agoraphobia. Acta Psychiatr Scand, 111, 150-158.

BOMYEA, J. \& AMIR, N. 2011. The Effect of an Executive Functioning Training Program on Working Memory Capacity and Intrusive Thoughts. Cognit Ther Res, 35, 529-535.

BRYAN, J. \& LUSZCZ, M. A. 2000. Measurement of executive function: considerations for detecting adult age differences. $J$ Clin Exp Neuropsychol, 22, 40-55.

BUTTERS, M. A., BHALLA, R. K. \& ANDREESCU, C. 2011a. Changes in neuropsychological functioning following treatment for late-life generalised anxiety disorder. Br J Psychiatry, 199, 211-218.

BUTTERS, M. A., BHALlA, R. K., ANDREESCU, C., WETHERELL, J. L., MANTELLA, R., BEGLEY, A. E. \& LENZE, E. J. 2011b. Changes in neuropsychological functioning following treatment for late-life generalised anxiety disorder. The British Journal of Psychiatry, 199, 211-218.

COHEN, L. J., HOLLANDER, E., DECARIA, C. M., STEIN, D. J., SIMEON, D., LIEBOWITZ, M. R. \& ARONOWITZ, B. R. 1996. Specificity of neuropsychological impairment in obsessive-compulsive disorder: a comparison with social phobic and normal control subjects. J Neuropsychiatry Clin Neurosci, 8, 82-85.

DEPTULA, D., SINGH, R. \& POMARA, N. 1993. Aging, emotional states, and memory. Am J Psychiatry $150,429-434$.

EYSENCK, M. W. \& CALVO, M. G. 1992. Anxiety and performance: The processing efficiency theory. Cognition \& Emotion, 6, 409-434.

FAMA, R., SULLIVAN, E. V., SHEAR, P. K., GAHN-WEINER, D. A. \& YESAVAGE, J. A. 1998. Fluency performance patterns in Alzheimer's disease and Parkinson's disease. Clin Neuropsychol, 12, $487-$ 499. 
FORSELL, Y., PALMER, K. \& FRATIGLIONI, L. 2003. Psychiatric symptoms/syndromes in elderly persons with mild cognitive impairment: data from a cross-sectional study. Acta Neurol Scand Suppl, 179, 25-28.

GLADSJOB, J. A., RAPAPORTA, M. H., MCKINNEY, R. \& LUCASC, J. A. 1998. A neuropsychological study of panic disorder: Negative findings. Journal of Affective Disorders 49.

GULPERS, B., RAMAKERS, I., HAMEL, R., KOHLER, S., OUDE VOSHAAR, R. \& VERHEY, F. 2016. Anxiety as a predictor for cognitive decline and dementie: a review and meta-analysis. The American Journal of Geriatric Psychiatry, 24, 823-842.

IZAKS, G. J., JOOSTEN, H., KOERTS, J., GANSEVOORT, R. T. \& SLAETS, J. P. 2011. Reference Data for the Ruff Figural Fluency Test: Stratified by Age and Educational Level. PLoS ONE, 6, e17045.

KIROVA, A. M. B., R.B.; LAGALWAR, S. 2015. Working memory and executive function decline across normal aging, mild cognitive impairment, and Alzheimer's disease. Biomed Res Int.

KLEIN-KOERKAMP, Y. H., R.A.; RAMDEEN, K.T.; MOREAUD, O; KEIGNART, S; KRAINIK, A; HAMMERS, A; BACIU, M; HOT, P. 2014. Amygdalar atrophy in early Alzheimer's disease. Curr Alzheimer Res, 11, 239-252.

KLIJS, B. S., S.; MANDEMAKERS, J.J.; SNIEDER, H.; STOLK, R.P.; SMIDT, N. 2015. Representativeness of the LifeLines Cohort Study. PLoS One, 10.

KRIEGSMAN, D. M., PENNINX, B. W., VAN EIJK, J. T., BOEKE, A. J. \& DEEG, D. J. 1996. Self-reports and general practitioner information on the presence of chronic diseases in community dwelling elderly. A study on the accuracy of patients' self-reports and on determinants of inaccuracy. $J$ Clin Epidemiol, 49, 1407-1417.

LEZAK, M. D., HOWIESON, D. B. \& LORING, D. W. 2004. Neuropsychologic assessment. New York: Oxford University Press.

LYKETSOS, C. G., LOPEZ, O., JONES, B., FITZPATRICK, A. L., BREITNER, J. \& DEKOSKY, S. 2002. Prevalence of neuropsychiatric symptoms in dementia and mild cognitive impairment: results from the cardiovascular health study. JAMA, 288.

MANTElla, R. C., BUtTers, M. A., DEW, M. A., MUlSANT, B. H., BEGLEY, A. E., TRACEY, B., SHEAR, M. K., REYNOLDS, C. F. \& LENZE, E. J. 2007. Cognitive impairment in late-life generalized anxiety disorder. Am J Geriatr Psychiatry, 15, 673-679.

MATHEW, S. J. M., X.; COPLAN, J.D.; SMITH, E.L.; SACKEIM, H.A.; GORMAN, J.M.; SHUNGU, D.C. 2004. Dorsolateral prefrontal cortical pathology in generalized anxiety disorder: a proton magnetic resonance spectroscopic imaging study. Am J Psychiatry, 161, 1119-1121.

MIYAKE, A. \& FRIEDMAN, N. P. 2012. The Nature and Organization of Individual Differences in Executive Functions: Four General Conclusions. Curr Dir Psychol Sci., 21, 8-14.

MOHLMAN, J. 2005. Does executive dysfunction affect treatment outcome in late-life mood and anxiety disorders? J Geriatr Psychiatry Neurol, 18, 97-108.

PATERNITI, S., DUfOUIL, C., BISSERBE, J. C. \& ALPEROVITCH, A. 1999. Anxiety, depression, psychotropic drug use and cognitive impairment. Psychol Med, 29, 421-428.

POTVIN, O., FORGET, H., S., G., PREVILLE, M. \& HUDON, C. 2011. Anxiety, Depression, and 1-Year Incident Cognitive Impairment in Community-Dwelling Older Adults. J Am Geriatr Soc 59, 14211428.

PRICE, R. B. \& MOHLMAN, J. 2007. Inhibitory control and symptom severity in late life generalized anxiety disorder. Behav Res Ther, 45, 2628-2639.

RAMAKERS, I. H., VERHEY, F. R., SCHELTENS, P., HAMPEL, H., SOININEN, H., AALTEN, P., RIKKERT, M. O., VERBEEK, M. M., SPIRU, L., BLENNOW, K., TROJANOWSKI, J. Q., SHAW, L. 
M., VISSER, P. J. \& INVESTIGATORS., A. S. D. N. I. A. D. 2013. Anxiety is related to Alzheimer cerebrospinal fluid markers in subjects with mild cognitive impairment. Psychol Med, 43, 911-910.

REMES, O., BRAYNE, C., VAN DER LINDE, R. \& LAFORTUNE, L. 2016. A systematic review of reviews on the prevalence of anxiety disorders in adult populations. Brain Behav, 6.

ROSS, T. P. 2014. The Reliability and Convergent and Divergent Validity of the Ruff Figural Fluency Test in Healthy Young Adults. Archives of Clinical Neuropsychology, 29, 806-817.

RUFF, R. M. 1988. Ruff Figural Fluency Test professional manual. Odessa, FL: Psychological Assessment Resources.

RUFF, R. M. 1996. RFFT: Ruff Figural Fluency Test: Professional manual. Lutz: Psychological Assessment Resources.

RUFF, R. M., LIGHT, R. H. \& EVANS, R. W. 1987. The Ruff Figural Fluency Test: A normative study with adults. Dev Neuropsychol, 3, 37-51.

SCHOLTENS, S., SMIDT, N., SWERTZ, M. A., BAKKER, S. J., DOTINGA, A., VONK, J. M. \& AL., E. 2014. Cohort Profile: LifeLines, a three-generation cohort study and biobank. Int J Epidemiol, 44, 1172-1180.

SHEEHAN, D. V., LECRUBIER, Y., SHEEHAN, K. H., AMORIM, P., JANAVS, J., WEILlER, E., HERGUETA, T., BAKER, R. \& DUNBAR, G. C. 1998. The Mini-International Neuropsychiatric Interview (M.I.N.I.): the development and validation of a structured diagnostic psychiatric interview for DSM-IV and ICD-10. The Journal of clinical psychiatry, 59, 22-33.

SINFORIANI, E., ZUCCHELLA, C., PASOTTI, C., CASONI, F., BINI, P. \& COSTA, A. 2011. The effects of alcohol on cognition in the elderly: from protection to neurodegeneration. Funct Neurol, 26, 103-106.

SPIELBERG, J. M., HELLER, W. \& MILLER, G. A. 2013. Hierarchical brain networks active in approach and avoidance goal pursuit. Front Hum Neurosci, 17, 284.

STEEL, Z., MARNANE, C., IRANPOUR, C., CheY, T., JACKSON, J. W., PATEL, V. \& SilOVE, D. 2014. The global prevalence of common mental disorders: a systematic review and meta-analysis 1980-2013. Int J Epidemiol, 43, 476-493.

STOLK, R. P., ROSMAlEN, J. G. M., POSTMA, D. S., DE BOER, R. A., NAVIS, G., SLAETS, J. P. J., ORMEL, J. \& WOLFFENBUTTEL, B. H. R. 2008. Universal risk factors for multifactorial diseases: LifeLines a three-generation population-based study. Eur J Epidemiol, 23, 67-74.

STRAUSS, E., SHERMAN, E. M. S. \& SPREEN, O. 2006. A compendium of neuropsychological tests. New York: Oxford University Press.

WETHERELL, J. L., REYNOLDS, C. A., GATZ, M. \& PEDERSEN, N. L. 2002. Anxiety, Cognitive Performance, and Cognitive Decline in Normal Aging. Journal of Gerontology, 57B, 246-255.

WITTCHEN, H. U., GLOSTER, A. T., BEESDO-BAUM, K., FAVA, G. A. \& CRASKE, M. G. 2010. Agoraphobia: a review of the diagnostic classificatory position and criteria. Depress Anxiety., 27, 113-133.

ZINN, S., STEIN, R. \& SWARTZWELDER, H. S. 2004. Executive functioning early in abstinence from alcohol. Alcohol Clin Exp Res, 28, 1338-1346. 



\title{
Chapter 4
}

\section{Anxiety as a risk factor for cognitive decline: a twelve year follow-up cohort study}

\author{
Based on: \\ Gulpers BJA \\ Oude Voshaar RC \\ van Boxtel MPJ \\ Verhey FRJ \\ Köhler S.
}


Chapter 4

\section{ABSTRACT}

Background - Anxiety might be a risk factor for cognitive decline, but previous studies had a short follow-up, small sample sizes or studied general or single cognitive domain functioning.

Method - Anxiety symptoms were assessed with the Symptom Check List-90 in a general population subsample of 918 participants of the Maastricht Aging Study aged 50 years or older. Anxiety was analysed both dichotomously (highest versus lower quartiles as a group), and continuously. Neuropsychological tests measured executive function, memory, speed of information processing and verbal fluency. Linear mixed models were conducted with anxiety symptoms as predictor and change in cognitive scores as outcome. Differences of the associations by age and gender were studied with three-way interactions.

Results - Higher anxiety symptoms were significantly associated with more decline in verbal memory in those aged 65 years and older (delayed recall $\mathrm{X}^{2}=9.30, \mathrm{df}=2, \mathrm{p}=0.01$; immediate recall $\left(\chi^{2}=11.81, \mathrm{df}=2, \mathrm{p}=.003\right)$. There were sex differences on executive functioning $(\chi 2=6.63, \mathrm{df}=2, \mathrm{p}=.036)$, fluency $(\chi 2=6.89, \mathrm{df}=2, \mathrm{p}=.032)$ and processing speed $\left(\chi^{2}=8.83, \mathrm{df}=2, \mathrm{p}=.012\right)$, with lower performance in women over time.

Conclusion - Anxiety symptoms were associated with a decline of verbal memory in older adults and with poorer performance in non-amnestic domains in women, in participants without cognitive impairments at baseline. Adequate treatment of anxiety symptoms could beneficially influence the risk for developing neurodegenerative diseases. Further research is needed to elucidate whether this association is causal. 


\section{INTRODUCTION}

Anxiety in the community is a risk factor for cognitive impairment, and possibly for dementia,(Gulpers et al., 2016) but research to date about the association between anxiety symptoms and specific cognitive functioning has been equivocal. In cross-sectional studies, larger effect sizes were found on memory problems compared to other cognitive domains. (Beaudreau and O'Hara, 2008) A recent cross-sectional study in a large sample with younger and older adults $(\mathrm{N}=82,360)$ showed a significant association between anxiety disorders and reduced executive function, but the authors did not find an effect of age on the association. A stronger association in the older age group is to be expected when neurodegeneration is assumed to be the underlying mechanism.(Gulpers et al.) Indeed, our systematic review showed that anxiety might be associated with decline in executive function.(Gulpers et al., 2016) In contrast, the evidence from longitudinal studies for an association between anxiety and memory decline is scarce, with only one out of seven studies showing a significant decline on memory.(Gulpers et al., 2016)

Interpretation of previous studies in this field is difficult as conflicting results are at least partly explained by methodological differences like variability in duration of follow-up, residual confounding, and different anxiety measures.(Gulpers et al., 2016) In our metaanalysis, we showed that the impact of anxiety on cognitive decline is strongest in the oldest adults (80 years or older), which seems to suggest that anxiety is a prodromal symptom of dementia.[1] As the asymptomatic and prodromal phase of Alzheimer's disease may span two decades or even more(Villemagne et al., 2013), studies with a long follow-up duration is required for more definitive answers. To date, only one longitudinal study on individual cognitive domains had a follow-up of more than ten years(Bunce and al., 2012), with the majority of studies having a follow-up of less than five years.(Gulpers et al., 2016) In addition, adjustment for relevant confounders is important as different covariates have already been associated with the risk for cognitive decline, e.g. age and education. (Anstey and Christensen, 2000, Larson et al., 1992) Insufficient adjustment for confounders could lead to an overestimation of the effect of anxiety. Previous studies generally did not study potential heterogeneity by age or sex. Older adults have less cognitive reserve, which is associated with a higher risk for cognitive decline.(Stern, 2012) In females, prevalence of Alzheimer's disease is higher than in men which is not only explained by females living longer, suggesting that female gender may be another risk factor.(Mielke et al., 2014) Finally, depression is often comorbid to anxiety and is also associated with a higher risk for cognitive decline(Cooper et al., 2015), but few studies accounted for their correlation. Anxiety disorders comorbid to major depression may further accelerate cognitive decline in older adults compared to those with major depression only.(DeLuca et al., 2005)

Taken together, prospective studies with assessment of multiple cognitive domains, longer follow-up duration, adequate control for confounding and comorbid depression are needed. 
In this population study, we therefore investigate the crude and adjusted associations with 12 years of follow-up between anxiety and cognitive decline on 1. executive function (as the current literature suggests an association with anxiety), and more exploratively, 2. on memory, speed of information processing and fluency. Also interactions of anxiety with age and gender were investigated.

\section{METHODS}

\section{Study sample}

The Maastricht Aging Study (MAAS) comprises 1,823 participants to study the determinants of cognitive aging.(Jolles et al., 1995) Participants were recruited from the Registration Network Family Practices (Registratienet Huisartspraktijken, RNH), a data base managed by the Department of General Practice of Maastricht University.(Metsemakers et al., 1992) A total of 10,396 participants were sampled from the RNH database. There were 4,490 participants willing to participate, others did not want to participate or did not respond to the invitation. After checking the exclusion criteria (see below) 4,189 participants were suitable to participate. Of this group 1,823 participants (43.5\%) were randomly selected and stratified by age (twelve age groups between 24-81 years), gender and level of occupational activity (high/low) (see Figure 1). During a 12-year follow-up, adults of 50 years and older were tested every 3 years.

Exclusion criteria defined in the RNH database were: coma (only active), cerebrovascular pathology, any tumor of the nervous system, congenital malformations of the nervous system, multiple sclerosis, parkinsonism, epilepsy (all types), dementia, organic psychosis (other than dementia), schizophrenia, affective psychosis, and mental retardation. In addition, before participation in the test program all participants were screened in a semi-structured interview to update RNH exclusion criteria and to check for the following exclusion criteria not coded in the RNH data base: history of transient ischemic attacks (TIA), brain surgery, hemodialysis for renal failure, electroconvulsive therapy, and regular use of psychotropic drugs. Finally, a score below 24 on the Mini-Mental State Examination (MMSE) led to exclusion from the study at baseline. Additional exclusion criteria for the current study were: age below 50 years, and no baseline data for the Symptom Check List-90 (SCL-90). We included 918 participants in the present analyses.

\section{Baseline measurements}

Anxiety - Anxiety was measured with the anxiety subscale of the SCL-90.(Arrindell and Ettema, 1986) It comprised ten questions with a five-point Likert-scale rating the degree of a specific anxiety symptom. The total score was calculated by adding up the individual 
Figure 1: Flowdiagram of the selected participants

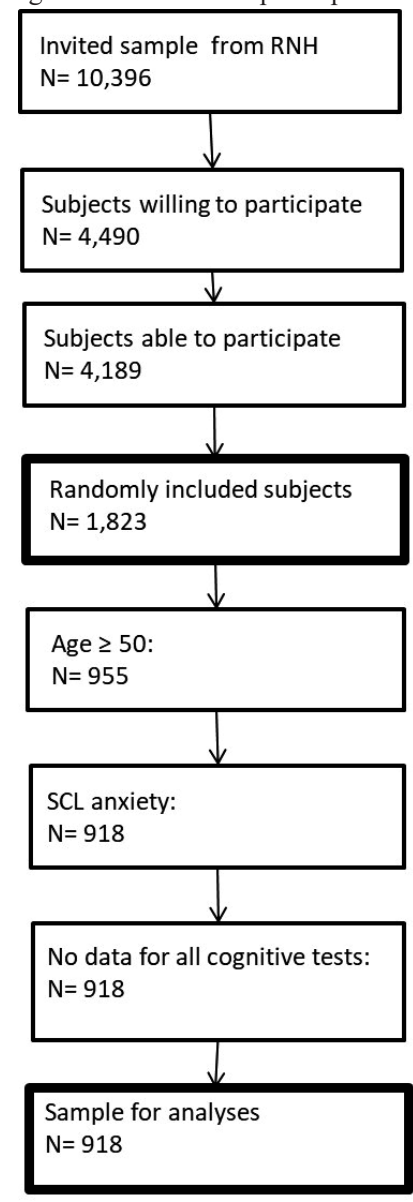

Exclusion criteria for the

study were applied

Age below 50 excluded.

No baseline data for SCL anxiety excluded

No baseline data for all cognitive tests excluded

scores per question (range 10-50). Anxiety was used both dichotomously (high anxiety yes/ no, defined by being in the highest quartile) and continuously (anxiety symptom score).

Depression - Depression was measured with the depression subscale of the SCL-90 and comprised of 16 questions using the same five-point severity scale as for anxiety. The individual scores were added up to calculate the total score, which corresponds with the scoring of the anxiety subscale (range 16-80). Depressive symptoms were used dichotomously (high depressive symptoms yes/no, defined by being in the highest quartile), and continuously (depressive symptom score) as a covariate in the analyses of anxiety as primary predictor.

Covariates - Age, sex, educational level and alcohol use were considered as covariates based on their asssociations with both anxiety and cognitive decline. Educational level was based on self-report data and defined in eight categories ranging from primary education (1) to an university degree (8). For analyses education level was recoded in three levels: 
low (level 1-2), medium (level 3-5) and high (level 6-8) (included as dummy variables with low education as reference). Alcohol use was measured by asking about the amount of drinking days in a week, and the number of drinks. Alcohol use was categorized in no use, social use or excessive use. Excessive use was defined as $\geq 5$ units per day, or $\geq 4$ days 3 or more alcohol units. Social use was defined as $<5$ units per day, or $<4$ days 3 or more alchol units. Social use was the reference for the dummy's due to the u-shape relationship of alcohol and cognition. The use of psychotropic medication was also self-reported by naming all used medication at baseline and every follow-up.

\section{Outcome}

Primary outcome - Executive function was the primary outcome variable using the Concept Shifting Test (CST) and the Stroop Colored Word Test (SCWT).

The CST(Van der Elst et al., 2006a) measures cognitive flexibility and is a modification of the Trail Making Test(Vink and Jolles, 1985). It consists of three sheets (A, B and C) with on each test sheet 16 small circles. In these circles, the test items (numbers [A], letters [B], or both [C]) appear in a fixed random order. Participants are requested to cross out the items in the right order, alternating digits and numbers in the CST-C condition. The time to complete the tasks is recorded. The shifting score was calculated by subtracting the average time of completing CST-A and CST-B from the time to complete CST-C.

The SCWT measures response inhibition. It involves three cards which display hundred stimuli each: color names (card 1), colored patches (card 2) and color names printed in incongruously colored ink (card 3).(Houx and Jolles, 1993, Van der Elst et al., 2006c) Participants need to read the color names (card 1), name the colored patches (card 2) and for card three they name the incongruously color of the color names. The SCWT score was calculated by subtracting the average time of completing card 1 and 2, from the time of completing card $3 \mathrm{C}$.

Secondary outcome - Memory, speed of information processing and fluency were considered as secondary outcome measurements. Memory was measured with the immediate and delayed recall of the Verbal Learning Test (VLT), where 15 non-related monosyllabic words were successively presented.(Brand and Jolles, 1985, Van der Elst et al., 2005) For the immediate recall participants were asked to recall as many words as possible, and this procedure was subsequently repeated five times. The immediate recall score was calculated by summing the correctly named words over five trials. After 20 minutes the delayed recall was tested (one trial) scoring the amount of the correctly named words.

Speed of information processing was tested with the Letter-Digit Substitution Test (LDST).(van der Elst et al., 2006b) Participants were instructed to match digits to letters, according to a key of letter/digit combinations at the top of the sheet, as quickly as possible within 90 seconds. 
Fluency was measured with a subtest of the Groningen Intelligence Test (GIT) by asking the respondent to name as many animals as possible within one minute.(Luteijn and van der Ploeg, 1983)

\section{Statistical analysis}

Group differences between the two subgroups (high anxiety and low anxiety), were tested by independent $\mathrm{t}$-tests (dimensional variables) and $\chi^{2}$ tests (categorical variables).

Linear mixed models were conducted for the longitudinal data with the dichotomous variable of the high anxiety group or the dimensional score of anxiety symptoms at baseline and time as the independent variables and the outcome on the specific neuropsychological tests as the dependent variable. The analyses were adjusted for age, sex, educational level, alcohol and for the highest quartile on the depression subscale of the SCL-90 (yes/no) in the analyses for high anxiety, and depressive symptoms continuous for anxiety symptoms continuous. No adjustment for psychotropic drug use took place in the primary analyses, since regular psychotropic drug use was already an exclusion criterion at baseline. The model included random effects for intercept and slope with an unstructured covariance structure, as this gave the best model fit according to likelihood ratio testing. Differences in rate of change in cognition over time as a function of baseline anxiety (dichotomous and continuous) was tested by including the anxiety by time (3-levels: baseline, 6 and 12 years) interaction term in the model, using the Wald $\chi^{2}$ test as a test of homogeneity of effects. In addition, three-way interaction terms tested effect moderation by age and gender on the outcome of cognitive changes over time. If significant, stratified analyses were run for different age-groups ( $<65$ years and $\geq 65$ years), and for males and females separately. The same approach was used for the dichotomous depression variable as predictor. Analyses were conducted in SPSS v22.0 and Stata15, with an alpha-level of 0.05 in two-sided tests. For three-level interactions, stratified analyses were done also for $\mathrm{p}<.10$, given the low power of such tests.

To explore clinical significance by calculating a standardized effect size (Cohen's d), we followed the recommendation by Feingold $(2009,2013)$ and used the fixed effect of the groupXtime interaction in the nominator and the SD of the cognition score at baseline, so that: $d=$ b_interaction / SD_baseline_raw.(Feingold, 2009, Feingold, 2013) For anxiety symptoms, this was done for a 10-point change to get clinically meaningful results. An effect of 0.2 reflects a small effect, 0.5 a medium, and 0.8 a large effect. 


\section{RESULTS}

\section{Baseline comparisons}

At baseline, there were significant differences between the participants with high anxiety symptoms and participants with low anxiety symptoms, with the former more often being female and lower educated. They used less alcohol and had higher mean scores for depression (see table 1).

Table 1: Baseline characteristics and difference between participants with high and low anxiety symptoms.

\begin{tabular}{lccc}
\hline Characteristics* & $\begin{array}{c}\text { High anxiety } \\
\text { symptoms }\end{array}$ & $\begin{array}{c}\text { Low anxiety } \\
\text { symptoms }\end{array}$ & Statistics \\
& $(\mathrm{N}=233)$ & $(\mathrm{N}=685)$ & \\
\hline Socio-demographics/ confounders: & & & \\
\hline Age in years, mean (SD) range & $65.0(8.6) 50-82$ & $64.2(8.9) 50-82$ & $\mathrm{t}=1.28, \mathrm{df}=916, \mathrm{p}=0.202$ \\
\hline Female gender, $\mathrm{n}(\%)$ & $139(59.7 \%)$ & $307(44.8 \%)$ & $\mathrm{X}^{2}=14,7, \mathrm{df}=1, \mathrm{p}<0.01$ \\
\hline Level of education, $\mathrm{n}(\%)$ & & & \\
\hline Low & $135(57.9 \%)$ & $313(45.7 \%)$ & \\
\hline Medium & $68(29.2 \%)$ & $258(37.7 \%)$ & $\mathrm{X}^{2}=10.4, \mathrm{df}=2, \mathrm{p}=0.005$ \\
\hline High & $30(25.4 \%)$ & $114(16.6 \%)$ & \\
\hline Alcohol use, $\mathrm{n}(\%) * *$ & & & \\
\hline No use & $69(30.9 \%)$ & $116(17.6 \%)$ & \\
\hline Social use & $101(45.3 \%)$ & $347(52.6 \%)$ & $\mathrm{X}^{2}=18.1, \mathrm{df}=2, \mathrm{p}<0.01$ \\
\hline Excessive use & $53(23.8 \%)$ & $197(29.8 \%)$ & \\
\hline Psychopathology, mean (SD) range & & & \\
\hline SCL-90 anxiety & $18(5) 14-42$ & $11(1) 10-13$ & $\mathrm{t}=-20.6, \mathrm{df}=238, \mathrm{p}<0.01$ \\
\hline SCL-90 depression & $27(9) 16-62$ & $19(3) 16-36$ & $\mathrm{t}=-13.6, \mathrm{df}=250, \mathrm{p}<0.01$ \\
\hline
\end{tabular}

Abbreviations: SD, standard deviation; SCL, Symptom Checklist.

* Missing data varied between variables : 35 missings alcohol use, 8 missings SCL-90 depression, 0 missings for the other variables.

** Alcohol use: no use 0 alcohol units per day; social use $<5$ units per day, or $<4$ days 3 or more alchol units; excessive use $\geq 5$ units per day, or $\geq 4$ days 3 or more alcohol units.

\section{High versus low anxiety symptoms}

In the analyses testing difference in rate of change among those with high versus low anxiety symptoms adjusted for age, gender, education and alcohol, none of the primary or secondary cognitive outcomes revealed significant main effects. Analyses with adjustment for comorbid high depressive symptoms yielded similar results. Effect moderation by age group ( $<65$ years vs $\geq 65$ years) was not significant. There was, however, a significant difference between men and women for change in verbal fluency (overall $\chi^{2}=8.10, \mathrm{df}=$ $2, p=.017)$. In analyses stratified by gender, men with high anxiety experienced a nonsignificant improvement over time $\left(\chi^{2}=4.62\right.$, df $\left.2, p=.099\right)$, while women with high 
anxiety experienced a non-significant decline $\left(\chi^{2}=5.90, \mathrm{df}=2, \mathrm{p}=.052\right)$. This remained virtually unchanged after adjusting for comorbid high depressive symptoms.

\section{Severity of anxiety symptoms}

Using continuous anxiety symptoms as predictor adjusted for age, gender, education and alcohol use showed that rate of decline in WLT delayed recall was faster with increasing anxiety symptom levels in the total sample (cohen's $d$ after 6 years and 12 years; -0.19 and 0.02) (see table 2).

Table 2: Anxiety symptoms at baseline, related to cognitive decline over 12 years, without adjustment of depressive symptoms.

\begin{tabular}{|c|c|c|c|c|c|c|c|c|}
\hline \multirow[b]{3}{*}{ Parameter } & \multicolumn{8}{|c|}{ Time } \\
\hline & \multicolumn{2}{|c|}{ Baseline } & \multicolumn{2}{|c|}{$\begin{array}{c}\text { Change from } \\
\text { baseline to } \\
6 \text { year FU }\end{array}$} & \multicolumn{2}{|c|}{$\begin{array}{l}\text { Change from } \\
\text { baseline to } \\
12 \text { year FU }\end{array}$} & \multicolumn{2}{|c|}{$\begin{array}{l}\text { Anxiety } \\
\text { symptoms } \\
\text { x time* }\end{array}$} \\
\hline & Difference & $95 \% \mathrm{CI}$ & Difference & $95 \% \mathrm{CI}$ & Difference & $95 \% \mathrm{CI}$ & $\mathrm{X}^{2}$ & $\mathrm{P}$ \\
\hline CST interference score & 0.002 & $\begin{array}{c}-0.003 \text { to } \\
0.006\end{array}$ & 0.003 & $\begin{array}{l}-0.004 \\
\text { to } 0.010\end{array}$ & -0.001 & $\begin{array}{l}-0.010 \\
\text { to } 0.009\end{array}$ & 1.06 & 0.590 \\
\hline $\begin{array}{l}\text { Stroop interference } \\
\text { score }\end{array}$ & 0.004 & $\begin{array}{c}-0.002 \text { to } \\
0.011\end{array}$ & -0.001 & $\begin{array}{l}-0.008 \\
\text { to } 0.006\end{array}$ & 0.000 & $\begin{array}{l}-0.009 \\
\text { to } 0.010\end{array}$ & 0.18 & 0.913 \\
\hline WLT immediate recall & -0.083 & $\begin{array}{c}-0.220 \text { to } \\
0.055\end{array}$ & -0.147 & $\begin{array}{l}-0.299 \\
\text { to } 0.004\end{array}$ & -0.003 & $\begin{array}{l}-0.180 \\
\text { to } 0.173\end{array}$ & 4.41 & 0.110 \\
\hline WLT delayed recall & -0.021 & $\begin{array}{c}-0.065 \text { to } \\
0.023\end{array}$ & -0.056 & $\begin{array}{c}-0.106 \\
\text { to } \\
-0.006\end{array}$ & 0.005 & $\begin{array}{l}-0.055 \\
\text { to } 0.065\end{array}$ & 6.60 & 0.037 \\
\hline LDST & -0.072 & $\begin{array}{c}-0.203 \text { to } \\
0.059\end{array}$ & -0.093 & $\begin{array}{l}-0.211 \\
\text { to } 0.025\end{array}$ & -0.004 & $\begin{array}{l}-0.158 \\
\text { to } 0.150\end{array}$ & 3.19 & 0.203 \\
\hline Fluency & -0.046 & $\begin{array}{c}-0.135 \text { to } \\
0.042\end{array}$ & 0.018 & $\begin{array}{l}-0.073 \\
\text { to } 0.110\end{array}$ & 0.114 & $\begin{array}{c}0.005 \text { to } \\
0.223\end{array}$ & 4.56 & 0.102 \\
\hline
\end{tabular}

Abbreviations: FU: follow-up; 95\% CI: 95\% confidence interval; CST: concept shifting test; WLT: word learning test; LDST: letter digit substation test.

All analyses adjusted for age, gender, education and alcohol use. Scores for CST interference score and Stroop interference score were log-transformed.

* Test of interaction between high anxiety (yes/no) and time (baseline, 6 years and 12 years follow-up) with $2 \mathrm{df}$.

The three-way-interaction with age for the WLT delayed recall warranted further inspection $\left(\chi^{2}=5.17, \mathrm{df}=2, \mathrm{p}=.076\right)$. Age-stratified analyses showed that higher anxiety levels was associated with faster decline in the older age group only $\left(\chi^{2}=9.30, \mathrm{df}=2, \mathrm{p}=.010\right)$ (cohen's $d$ after 6 and 12 years; -0.48 and -0.18) (see table 3). For WLT immediate recall, no overall effect was found, but the three-way interaction of anxiety symptoms by time by age group was significant $\left(\chi^{2}=9.15, \mathrm{df}=2, \mathrm{p}=.010\right)$. Age-stratified analyses showed that increasing anxiety symptoms were associated with faster decline in the older age group 
only $\left(\chi^{2}=11.81, \mathrm{df}=2, \mathrm{p}=.003\right)$ (cohen's $\mathrm{d}$ after 6 and 12 years; -0.53 and -0.28$)$ (see table 3).

Table 3: Anxiety symptoms in younger and older adults related to verbal memory over 12 years, without adjustment for high depressive symptoms.

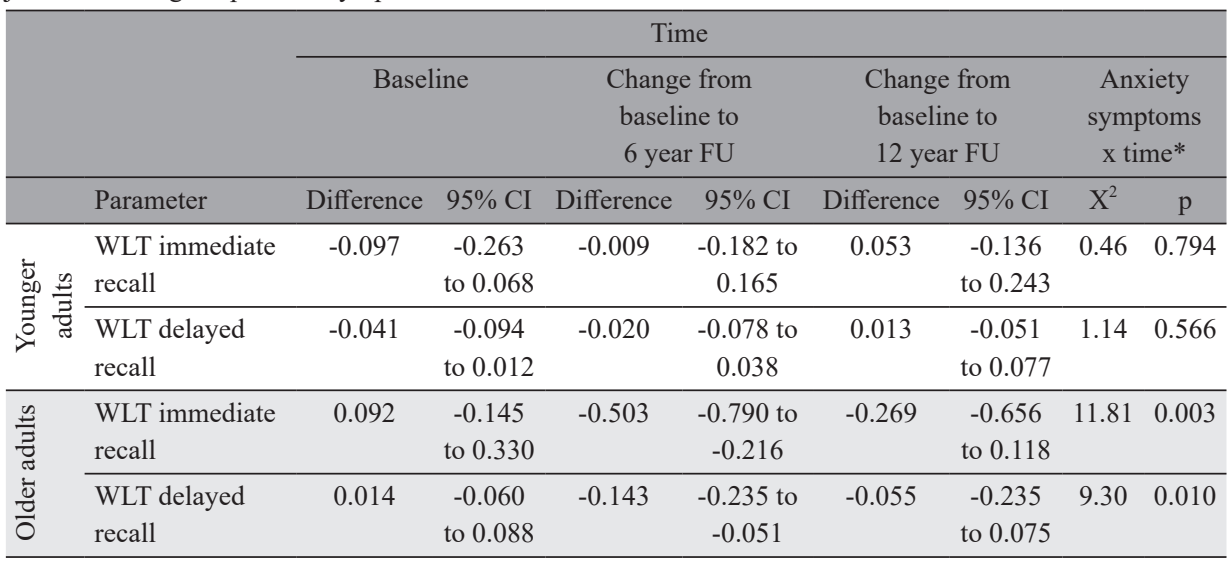

Abbreviations: FU: follow-up; 95\% CI: 95\% confidence interval; WLT: word learning test.

All analyses adjusted for age, gender, education and alcohol use.

* Test of interaction between anxiety symptoms and time (baseline, 6 years and 12 years follow-up) with $2 \mathrm{df}$.

Some notable gender difference were observed, too, with worse cognitive trajectories in women compared with men. For CST interference (interaction with gender: $\chi 2=6.63, \mathrm{df}=$ $2, \mathrm{p}=.036)$, stratified analyses suggested a non-significant improvement in men $(\chi 2=3.08$, $\mathrm{df}=2, \mathrm{p}=.215)$ and non-significant decline in women $(\chi 2=5.93, \mathrm{df}=2, \mathrm{p}=.052)($ Table 4). For LDST (interaction with gender: $\chi^{2}=6.54, \mathrm{df}=2, \mathrm{p}=.038$ ) and fluency interaction with gender $\left(\chi^{2}=6.89, \mathrm{df}=2, \mathrm{p}=.032\right)$, stratified analyses showed that anxiety symptoms predicted faster decline on the LDST in women only $\left(\chi^{2}=8.83, \mathrm{df}=2, \mathrm{p}=.012\right)$ (cohen's $\mathrm{d}$ after 6 and 12 years; -0.20 and -0.05), wheras fluency scores improved significantly in men with more severe baseline anxiety symptoms $\left(\chi^{2}=8.75, \mathrm{df}=2, \mathrm{p}=.013\right.$ ) (cohen's d after 6 and 12 years; 0.28 and 0.49$)$, but not in women $\left(\chi^{2}=2.80, \mathrm{df}=2, \mathrm{p}=.246\right)$ (see table 4 ). All associations persisted after additional adjustment for depressive symptoms.

\section{High versus low depressive symptoms}

In the total sample, high depressive symptoms were not significantly associated with rate of change in primary or secondary cognitive outcomes before or after adjustment for comorbid high anxiety symptoms. Significant effect moderation by age for CST interference $(\chi 2=6.87, \mathrm{df}=2, \mathrm{p}=.032)$ and WLT delayed recall $(\chi 2=7.78, \mathrm{df}=2, \mathrm{p}=.020))$ were observed: a faster decline in those with high versus low depressive symptoms was observed in older participants for both the CST $(\chi 2=6.23, \mathrm{df}=2, \mathrm{p}=.044)$ (cohen's d after 6 and 12 years; 0.100 and -0.813$)$ and the WLT delayed recall $(\chi 2=9.40, \mathrm{df}=2, \mathrm{p}=.009)$ (cohen's 
d after 6 and 12 years; -0.398 and -0.206). No interactions with gender were observed. All associations persisted after additional adjustment for high anxiety symptoms.

Table 4: Anxiety symptoms in males and femald related to CST, fluency and the LDST over 12 years, without adjustment for high depressive symptoms.

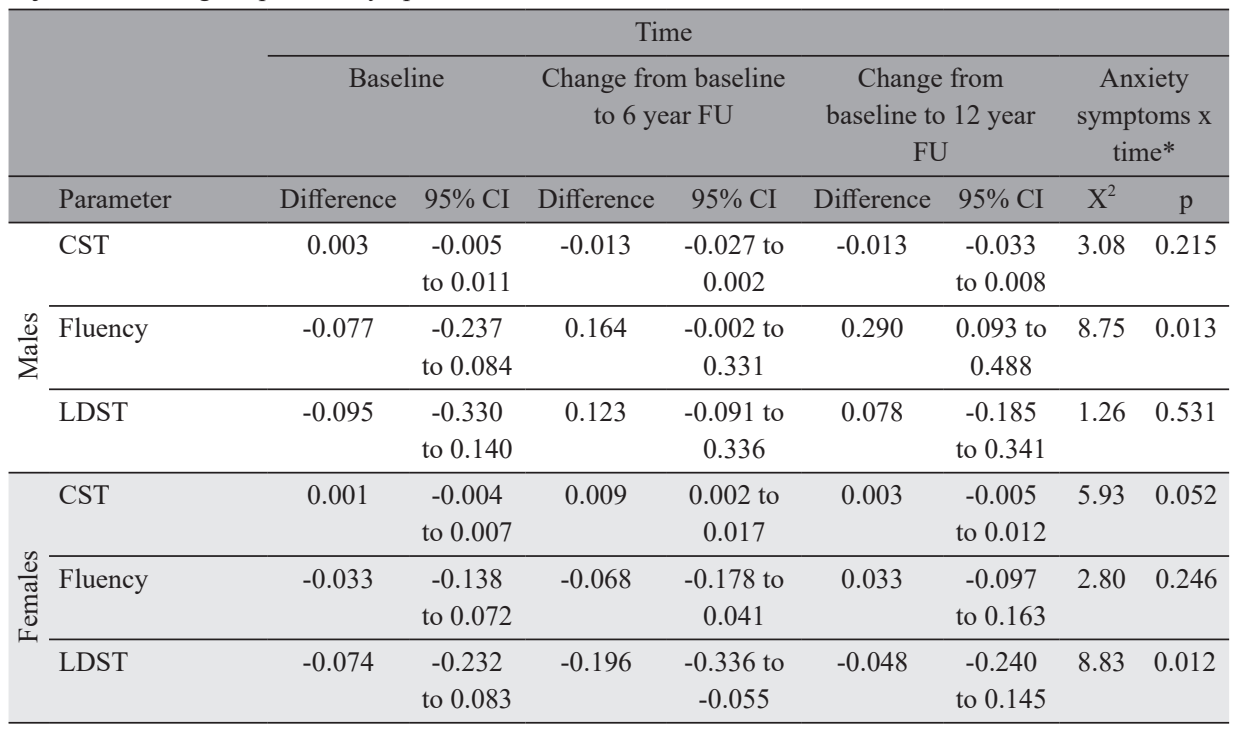

Abbreviations: FU: follow-up; 95\% CI: 95\% confidence interval; CST: concept shifting test; LDST: letter digit substation test

All analyses adjusted for age, gender, education and alcohol use.

* Test of interaction between anxiety symptoms and time (baseline, 6 years and 12 years follow-up) with $2 \mathrm{df}$.

\section{DISCUSSION}

\section{Main findings}

In contrast to our hypothesis, higher anxiety symptoms did not predict a faster decline in executive functioning over time. Nonetheless, impact of anxiety on the course of executive functioning over time differed significantly between both sexes, with increasing anxiety symptoms predicting a worse cognitive trajectory in women compared to men. A similar sex-specific effect was found for processing speed and verbal fluency. In contrast, faster decline in verbal memory (immediate and delayed recall) was associated with higher anxiety symptoms irrespective of sex but was more pronounced in the older age group. Also only in older adults with high depressive symptoms a faster decline on executive functioning and verbal memory (delayed recall) was found compared with older adults with low depressive symptoms. 
Chapter 4

\section{Anxiety and cognition}

We found no significant association in the total population between anxiety and executive functioning. There was, however, a significant difference between sexes, with women with increasing levels of anxiety showing a faster deterioration of executive functioning over time. Previous research showed conflicting results, with some studies reporting a significant deterioration of executive functioning over time,(de Bruijn et al., 2014, Pietrzak et al., 2014, Brodaty et al., 2012, Kassem et al., 2017, Pietrzak et al., 2015) while others did not. (Pietrzak et al., 2012, Okereke and Grodstein, 2013) Inconsistent findings in the literature may be explained by different components of executive functioning. In MAAS, we tested response inhibition and cognitive flexibility. A previous study in a sample restricted to women with phobic anxiety for example only tested verbal fluency and working memory as a measure of executive functioning, and did not find any decline over time.(Okereke and Grodstein, 2013) Furthermore, previous studies did not study potential sex differences in executive functions.(Brodaty et al., 2012, de Bruijn et al., 2014, Kassem et al., 2017, Pietrzak et al., 2012, Pietrzak et al., 2014, Pietrzak et al., 2015) However, our results suggest a specific effect on cognitive flexibility in women only. The stronger association in women might be due to a more severe (Kessler et al., 2005, Yonkers et al., 2003) or more chronic anxiety phenotype.(de Beurs et al., 2000) Indeed, women in MAAS have a higher prevalence of anxiety symptoms $\left(X^{2}=14.7, d f=1, p<0.01\right)$, and a higher severity of anxiety symptoms $(\mathrm{t}=-4.73, \mathrm{df}=772, \mathrm{p}<0.01)$, though they do not differ significantly in chronicity of anxiety symptoms compared with men $\left(\mathrm{X}^{2}=3.39, \mathrm{df}=1, \mathrm{p}=0.07\right)$. Previous research has also shown an increased risk for coronary heart disease in women with anxiety symptoms.(Nabi et al., 2010) Since the vascular disease burden could potentially mediate the association between anxiety and deterioration of executive function, this may explain these sex-specific findings as well. The higher prevalence and higher severity of anxiety symptoms in women in our sample might also explain the differences between sexes according to the outcome on processing speed and fluency over time.(Kessler et al., 2005, Yonkers et al., 2003, de Beurs et al., 2000) Processing speed and executive function, too, are often affected with cerebrovascular damage(Vasquez and Zakzanis, 2015). Further reserch on these sex differences, including the role of differences in vascular burden is needed.

For the immediate and delayed recall of verbal memory, older participants ( $>65$ years) with increasing levels of anxiety symptoms had a significant greater decline than older participants with less anxiety symptoms. This association was not found in the younger adults (50-65 years), suggesting that anxiety symptoms in late life can be a prodromal symptom of dementia. Deficits of verbal memory are considered a marker for Alzheimer's disease, as memory deficits (especially delayed recall) are almost always present in an early phase.(Cummings, 2004) Previous longitudinal studies on the impact of anxiety on memory decline were largely negative (Brodaty et al., 2012, de Bruijn et al., 2014, Okereke and Grodstein, 2013, Pietrzak et al., 2012, Pietrzak et al., 2014, Bunce et al., 2012a), with 
only one study finding a significant association (Palmer et al., 2007). Whether late-life anxiety could be prodromal or causally related to neurodegeneration remains unclear. Anxiety and cognitive dysfunction could also be caused by an unknown third factor. A recent meta-analysis found suggestions for anxiety as a prodromal symptom of neurodegenerative diseases, since the associations were the strongest in the oldest of 80 years and older. Anxiety could then be a consequence of diminished cognitive capacities which are only experienced on a subjective level. These people may benefit from structuring of daily life. In our study the older participants (65+ years) had a mean age of 72 years and therefore had a lower a-priori chance of underlying neuropathology compared to the group of 80 years and older in the meta-analysis.(Gulpers et al., 2016) There are also different pathways that could explain the rol of anxiety as a causal factor for neurodegeneration. According to the hypothesis about hypercortisolaemia (Mantella et al., 2008), prolonged exposure to anxiety-related stress will lead to chronic hypothalamic-pituitaryadrenal (HPA) dysregulation and therefore to higher levels of cortisol.(Gulpers et al., 2016) It has been suggested that cortisol-induced overstimulation of glucocorticoid receptors of glutamatergic neurons in the medial temporal lobe leads to hippocampus atrophy and to cognitive dysfunction. (Sapolsky, 2000, Erickson et al., 2003, Gulpers et al., 2016, Lupien et al., 2005) Other possible mechanisms are cardiovascular disease (as stated above) (Lambiase et al., 2014), low-grade inflammation (Furtado and Katzman, 2015, Reichenberg et al., 2001), brain derived neurotrophic factor (BDNF) suppression (Teixeira et al., 2010) and diminished cognitive reserves.(Stern, 2012).

In line with previous studies, high depressive symptoms were also associated with a decline on the delayed recall of verbal memory, but also of executive functioning in the older age group.(Riddle et al., 2017) In our study, the impact of high depressive symptoms on verbal memory and executive functioning was higher than the impact of high anxiety levels. Results from research comparing the effect of anxiety and depression on cognitive decline in the same study sample are contradictory. Some previous studies also found smaller effect sizes (albeit non-significant) for anxiety compared to depression on cognitive decline(Biringer et al., 2005, Bunce et al., 2012b), while others found stronger effect sizes for anxiety.(Burtona et al., 2013, Potvin et al., 2011) To establish the clinical significance of our results cohen's d effect sizes were calculated. For anxiety symptoms these effect sizes ranged between small and medium effect sizes, for high depressive symptoms it ranged between small and large effect sizes.

\section{Strengths and limitations}

A particular strength of this study is the longitudinal design with one of the longest followup. A limitation of the study is that we included a healthy population from the community with low scores on the symptom dimensions of the SCL-90. Therefore, participants with 
more severe levels of anxiety were more likely to be excluded, limiting the generalizability of our findings to this group. The average score of 18 in the anxious group is relatively low for a psychiatric population and could have led to an underestimation of the association between anxiety and cognition. Another limitation is the use of the self-report measures for anxiety and depression, which may have lead to exposure misclassification. Importantly, such misclassifiaton is probably non-differential i.e. unlikely to be affected by someone's subsequent course of cognition. Further, in our data no information was available according to age of onset of anxiety symptoms or history of anxiety disorder, which could have been relevant to differentiate between a prodromal symptom, or a causal factor of neurodegenerative disease. Next, factor-analysis shows high correlation between anxiety and depression.(Strauman and Wetzler, 1992) It makes it difficult to exclusively evaluate anxiety symptoms or depressive symptoms. Correcting for the other affective domain as a confounder is conservative, but can lead to overcorrection. As there is also overlap in the clinical presentation of depression and anxiety, this problem will likely persist with other measurements. A final limitation is the possibility that changes over time in the severity of anxiety symptoms has influenced our outcome.

\section{Conclusion}

In our study, anxiety symptoms predicted decline in executive functioning over time in women and decline in verbal memory in the older age group (65+ years). Further longitudinal research is needed to fully understand the heterogeneuous relationship between anxiety and cognition including potentially mediating mechanisms. Adequate treatment of anxiety symptoms could potentially beneficially influence the risk for developing neurodegenerative disease. 


\section{REFERENCES}

ANSTEY, K. \& CHRISTENSEN, H. 2000. Education, activity, health, blood pressure and apolipoprotein E as predictors of cognitive change in old age: a review. Gerontology, 46, 163-177.

ARRINDELL, W. A. \& ETTEMA, J. H. M. 1986. SCL-90. Een multidimensionale psychopathologie indicator [SCL-90. A multidimensional psychopathology indicator]. Lisse, the Netherlands: Swets Test Publisher.

BEAUDREAU, S. \& O'HARA, R. 2008. Late-life anxiety and cognitive impairment: a review. Am J Geriatr Psychiatry, 16, 790-803.

BIRINGER, E., MYKLETUn, A., DAHL, A. A., SMITH, A. D., ENGEDAL, K., NYGAARD, H. A. \& LUND, A. 2005. The association between depression, anxiety, and cognitive function in the elderly general population - the Hordaland Health Study. Int J Geriatr Psychiatry., 20, 989-997.

BRAND, N. \& JOLLES, J. 1985. Learning and retrieval rate of words presented auditory and visually. Journal of General Psychology, 112, 201-210.

BRODATY, H., HEFFERNANA, M., DRAPERA, B., REPPERMUND, S., KOCHAN, N. A., SLAVINA, M. J., TROLLORB, J. N. \& SACHDEVA, P. S. 2012. Neuropsychiatric Symptoms in Older People with and Without Cognitive Impairment. Journal of Alzheimer's disease, 31, 411-420.

BUNCE, D. \& AL., E. 2012. Depression, anxiety and cognition in community-dwelling adults aged 70 years and over. $J$ Psychiatr Res, 46, 1662-1666.

BUNCE, D., BATTERHAM, P. J., MACKINNON, A. J. \& CHRISTENSEN, H. 2012a. Depression, anxiety and cognition in community-dwelling adults aged 70 years and over. J Psychiatr Res, 46, 1662-1666.

BUNCE, D., BATTERHAMB, P. J., MACKINNON, A. J. \& CHRISTENSEN, H. 2012b. Depression, anxiety and cognition in community-dwelling adults aged 70 years and over. Journal of Psychiatric Research., 46, 1662-1666.

BURTONA, C., CAMPBElla, P., JORDANA, K., STRAUSSA, V. \& MALLENA, C. 2013. The association of anxiety and depression with future dementia diagnosis: a case-control study in primary care. Family Practice., 30, 25-30.

COOPER, C., SOMMERLAD, A., LYKETSOS, C. G. \& LIVINGSTON, G. 2015. Modifiable Predictors of Dementia in Mild Cognitive Impairment: A Systematic Review and Meta-Analysis. Am J Psychiatry, 172, 323-334.

CUMMINGS, J. L. 2004. Alzheimer's disease. N Engl J Med., 351, 56-67.

DE BEURS, E., BEEKMAN, A. T., DEEG, D. J., VAN DYCK, R. \& VAN TILBURG, W. 2000. Predictors of change in anxiety symptoms of older persons: results from the Longitudinal Aging Study Amsterdam. Psychol Med., 30, 515-527.

DE BRUIJN, R. F., DIREK, N., MIRZA, S. S., HOFMAN, A., KOUdSTAAL, P. J., TIEMEIER, H. \& IKRAM, M. A. 2014. Anxiety is not associated with the risk of dementia or cognitive decline: the Rotterdam Study. Am J Geriatr Psychiatry, 22, 1382-1390.

DELUCA, A. K., LENZE, E. J. \& MULSANT, B. H. 2005. Comorbid anxiety disorder in late life depression: association with memory decline over four years. Int J Geriatr Psychiatry, 20, 848-854.

ERICKSON, K., DREVETS, W. \& SCHULKIN, J. 2003. Glucocorticoid regulation of diverse cognitive functions in normal and pathological emotional states. Neurosci Biobehav Rev, 27, 233-46.

FEINGOLD, A. 2009. Effect sizes for growth-modeling analysis for controlled clinical trials in the same metric as for classical analysis. Psychological Methods, 14, 43-53.

FEINGOLD, A. 2013. A regression framework for effect size assessments in longitudinal modeling of group differences. Reviews of General Psychology 17, 111-121. 
FURTADO, M. \& KATZMAN, M. A. 2015. Neuroinflammatory pathways in anxiety, posttraumatic stress, and obsessive compulsive disorders. Psychiatry Res, 229, 37-48.

GULPERS, B., LUGTENBURG, A., ZUIDERSMA, M., VERHEY, F. \& VOSHAAR, R. O. Anxiety disorders and executive function.

GULPERS, B., RAMAKERS, I., HAMEL, R., KOHLER, S., OUDE VOSHAAR, R. \& VERHEY, F. 2016. Anxiety as a predictor for cognitive decline and dementie: a review and meta-analysis. The American Journal of Geriatric Psychiatry, 24, 823-842.

HOUX, P. J. \& JOLLES, J. 1993. Age-related decline of psychomotor speed: effects of age, brain health, sex, and education. Percept Mot Skills, 76, 195-211.

JOLlES, J., HOUX, P. J., VAN BOXTEL, M. P. J., PONDS, R. W. H. M. \& EDS. 1995. Maastricht Aging Study: Determinants of Cognitive Aging. Maastricht, Neuropsych Publishers.

KASSEM, A. M., GANGULI, M., YAFFE, K., HANLON, J. T., LOPEZ, O. L., WILSON, J. W., CAULEY, J. A., FRACTURES, T. O. \& GROUP, I. M. M. S. R. 2017. Anxiety symptoms and risk of cognitive decline in older community-dwelling men. International Psychogeriatrics, 29, 1137-1145.

KESSlER, R. C., BERGlund, P., DEMLER, O., JIN, R., MERIKANGAS, K. R. \& WALTERS, E. E. 2005. Lifetime Prevalence and Age-of-Onset Distributions of DSM-IV Disorders in the National Comorbidity Survey Replication. Arch Gen Psychiatry, 62, 593-602.

LAMBIASE, M. J., KUBZANSKY, L. D. \& THURSTON, R. C. 2014. Prospective study of anxiety and incident stroke. Stroke, 45, 438-443.

LARSON, E. B., KUKULL, W. A. \& KATZMAN, R. L. 1992. Cognitive impairment: dementia and Alzheimer's disease. Annu Rev Public Health, 13.

LUPIEN, S. J., FIOCCO, A., WAN, N., MAHEU, F., LORD, C., SCHRAMEK, T. \& TU, M. T. 2005. Stress hormones and human memory function across the lifespan. Psychoneuroendocrinology, 30, 225-242.

LUTEIJN, F. \& VAN DER PLOEG, F. A. E. 1983. Handleiding Groninger Intelligentietest (GIT) [Manual Groningen Intelligence Test]. Lisse, the Netherlands: Swets and Zeitlinger.

MANTEllA, R. C., BUTTERS, M. A., AMICO, J. A., MAZUMDAR, S., ROLLMAN, B. L., BEGLEY, A. E., REYNOLDS, C. F. \& LENZE, E. J. 2008. Salivary cortisol is associated with diagnosis and severity of late-life generalized anxiety disorder. Psychoneuroendocrinology, 33, 773-781.

METSEMAKERS, J. F., HÖPPENER, P., KNOTTNERUS, J. A., KOCKEN, R. J. \& LiMONARD, C. B. 1992. Computerized health information in The Netherlands: a registration network of family practices. Br J Gen Pract 42, 102-106.

MIELKE, M. M., VEMURI, P. \& ROCCA, W. A. 2014. Clinical epidemiology of Alzheimer's disease: assessing sex and gender differences. Clin Epidemiol, 8, 37-48.

NABI, H., HAll, M., KOSKenVUO, M., SINGH-MANOUX, A., OKSANEN, T., SUOMINEN, S., KIVIMÄKI, M. \& VAHTERA, J. 2010. Psychological and Somatic Symptoms of Anxiety and Risk of Coronary Heart Disease: The Health and Social Support Prospective Cohort Study. BIOL PSYCHIATRY, 67, 378-385.

OKEREKE, O. I. \& GRODSTEIN, F. 2013. Phobic anxiety and cognitive performance over 4 years among community-dwelling older women in the Nurses' Health Study. Am J Geriatr Psychiatry, 21, 11251134.

PALMER, K., BERGER, A. K., MONASTERO, R., WINBLAD, B., BÄCKMAN, L. \& FRATIGLIONI, L. 2007. Predictors of progression from mild cognitive impairment to Alzheimer disease. Neurology, 68, 1596-602.

PIETRZAK, R. H., MARUFF, P., WOODWARD, M., FREDRICKSON, J., FREDRICKSON, A., KRYSTAL, J. H., SOUTHWICK, S. M. \& DARBY, D. 2012. Mild worry symptoms predict decline in 
learning and memory in healthy older adults: a 2-year prospective cohort study. Am J Geriatr Psychiatry, 20, 266-275.

PIETRZAK, R. H., SCOTT, J. C., NEUMEISTER, A., LIM, Y. Y., AMES, D., ELLIS, K. A., HARRINGTON, K., LAUTENSCHLAGER, N. T., SZOEKE, C., MARTINS, R. N., MASTERS, C. L., VILLEMAGNE, V. L., ROWE, C. C. \& MARUFF, P. 2014. Anxiety symptoms, cerebral amyloid burden and memory decline in healthy older adults without dementia: 3-year prospective cohort study. Br J Psychiatry, 204, 400-401.

PIETRZAK, R. H., YING LIM, Y., NEUMEISTER, A., AMES, D., ELLIS, K. A., HARRINGTON, K., LAUTENSCHLAGER, N. T., RESTREPO, C., MARTINS, R. N., MASTERS, C. L., VILLEMAGNE, V. L., ROWE, C. C., MARUFF, P. \& FOR THE AUSTRALIAN IMAGING, B., AND LIFESTYLE RESEARCH GROUP 2015. Amyloid- $\beta$, Anxiety, and Cognitive Decline in Preclinical Alzheimer Disease: A Multicenter, Prospective Cohort Study. JAMA Psychiatry, 72, 284-291.

POTVIN, O., FORGET, H., GRENIER, S., PREVILlE, M. \& HUDON, C. 2011. Anxiety, Depression, and 1-Year Incident Cognitive Impairment in Community-Dwelling Older Adults. J Am Geriatr Soc., 59, 1421-1428.

REICHENBERG, A., YIRMIYA, R., SCHUld, A., KRAUS, T., HAACK, M., MORAG, A. \& POLLMÄCHER, T. 2001. Cytokine-associated emotional and cognitive disturbances in humans. Arch Gen Psychiatry, 58, 445-452.

Riddle, M., POTTER, G. G., MCQUOID, D. R., STEFFEnS, D. C., BEYER, J. L. \& TAYLOR, W. D. 2017. Longitudinal Cognitive Outcomes of Clinical Phenotypes of Late-Life Depression. Am J Geriatr Psychiatry, 25, 1123-1134.

SAPOLSKY, R. M. 2000. Glucocorticoids and hippocampal atrophy in neuropsychiatric disorders. Arch Gen Psychiatry, 57, 925-935.

STERN, Y. 2012. Cognitive reserve in ageing and Alzheimer's disease. Lancet Neurol, 11, 1006-1012.

STRAUMAN, T. J. \& WETZLER, S. 1992. The Factor Structure of SCL-90 and MCMI Scale Scores: Within-Measure and Interbattery Analyses. Multivariate Behav Res., 27, 1-20.

TEIXEIRA, A. L., BARBOSA, I. G., DINIZ, B. S. \& KUMMER, A. 2010. Circulating levels of brainderived neurotrophic factor: correlation with mood, cognition and motor function. Biomark Med, 4, 871-87.

VAN DER ELST, W., VAN BOXTEL, M. P., VAN BREUKELEN, G. J. \& JOLLES, J. 2005. Rey's verbal learning test: normative data for 1855 healthy participants aged 24-81 years and the influence of age, sex, education, and mode of presentation. J Int Neuropsychol Soc, 11, 290-302.

VAN DER ELST, W., VAN BOXTEL, M. P., VAN BREUKELEN, G. J. \& JOLLES, J. 2006a. The Concept Shifting Test: adult normative data. Psychol Assess., 18, 424-432.

VAN DER ELST, W., VAN BOXTEL, M. P., VAN BREUKELEN, G. J. \& JOLLES, J. 2006b. The Letter Digit Substitution Test: normative data for 1,858 healthy participants aged 24-81 from the Maastricht Aging Study (MAAS): influence of age, education, and sex. J Clin Exp Neuropsychol, 28, 998-1009.

VAN DER ELST, W., VAN BOXTEL, M. P., VAN BREUKELEN, G. J. \& JOLLES, J. 2006c. The Stroop color-word test: influence of age, sex, and education; and normative data for a large sample across the adult age range. Assessment, 13, 62-79.

VASQUEZ, B. P. \& ZAKZANIS, K. K. 2015. The neuropsychological profile of vascular cognitive impairment not demented: a meta-analysis. J Neuropsychol., 9, 109-136.

Villemagne, V. L., BURnham, S., BOURGEAT, P., BroWn, B., Ellis, K. A., SAlVAdo, O., SZOEKE, C., MACAULAY, S. L., MARTINS, R., MARUFF, P., AMES, D., ROWE, C. C., MASTERS, C. L. \& GROUP., A. I. B. A. L. A. R. 2013. Amyloid $\beta$ deposition, neurodegeneration, and 
Chapter 4

cognitive decline in sporadic Alzheimer's disease: a prospective cohort study. Lancet Neurol, 12, 357-367.

VINK, M. \& JOLLES, J. 1985. A new version of the Trail-Making Test as an information processing task. J Clin Neuropsychol, 7.

YONKERS, K. A., BRUCE, S. E., DYCK, I. R. \& KELLER, M. B. 2003. Chronicity, relapse, and illness-course of panic disorder, social phobia, and generalized anxiety disorder: findings in men and women from 8 years of follow-up. Depress Anxiety, 17, 173-179. 



\section{Chapter 5}

\section{Personality and negative \\ life-events predicts course of anxiety in older adults with late-life depression}


Chapter 5

\begin{abstract}
Objective - Studies on remission of depression often ignore the course of comorbid anxiety disorders or anxiety symptoms. We explored the predictors of complete remission (no depression nor anxiety diagnoses on follow-up) and of the course of comorbid anxiety symptoms. Additionally, we tested the hypothesis that the course of anxiety disorders and symptoms in depression is explained by negative life-events and especially in the presence of high neuroticism or a low sense of mastery.
\end{abstract}

Methods - An observational study of 270 patients ( $\geq 60$ years) diagnosed with major depressive disorder and two-year follow-up data, who participated in the Netherlands Study of Depression in Older persons (NESDO). Socio- demographic, somatic, psychiatric, and treatment variables were first explored as possible predictors. A multiple logistic regression analysis was used to examine their predictive value concerning complete remission. Subsequently, negative life-events, personality and their interaction were tested as potential predictors. Linear Mixed Models were used to assess whether the personality traits modified the effect of early and recent life-events, and time and their interactions on the course of the anxiety symptoms.

Results - A total of 135/270 patients (50.0\%) achieved complete remission. Depressed patients with a comorbid anxiety disorder at baseline achieved significantly less often a complete remission (38/103 (37.0\%) versus 97/167 (58.1\%). The severity of depressive and anxiety symptomatology, the presence of a comorbid anxiety disorder, and a poorer physical health at baseline predicted non-remission. Also, a higher neuroticism level was associated with non-remission. The impact of mastery on complete remission differed significantly between patients with and without childhood trauma. Patients with lower sense of mastery and childhood trauma achieved less often complete remission. In line with our hypothesis, a less favorable course of self-reported anxiety symptoms was associated with more recent negative life-events, but only among patients with a high level of neuroticism or a low level of mastery.

Conclusion - In the face of life-events, maladaptive personality traits may play a central role in the prognosis of late-life depression due to its impact on anxiety. 


\section{INTRODUCTION}

Comorbid anxiety in depression is common(1) and several studies demonstrated the inhibiting effect of comorbid anxiety on treatment results for depression(2). Several problems occur reviewing the studies on remission. First, studies traditionally focus on the one diagnosis of interest, namely depression, while for patients a meaningful remission means a complete remission of both depression and anxiety diagnoses. Second, most studies include participants based on formal DSM diagnoses but evaluate remission based on symptom severity scales. Previous studies, however, show that when it concerns comorbid anxiety in late-life depression it is important to differentiate between the categorical approach (any comorbid anxiety disorder) and the dimensional approach (comorbid anxiety severity)(3-5).

Predictors of complete remission in depressed older adults, that also takes into account the remission state of comorbid anxiety disorders, are to our knowledge unknown. In contrast, predictors of the depressive and anxiety symptom trajectories, separate from another, are relatively well-studied. For the depressive symptoms, these include a greater medical burden, presence of specific depressive symptoms (anhedonia and neurovegetative), smoking, low self-esteem, and interpersonal difficulties $(6,7)$. Few studies have traced the course of anxiety symptoms and its determinants in community-dwelling older adults. A more unfavorable course of anxiety symptoms after 6 years has been associated with female gender and higher levels of neuroticism at baseline $(8,9)$. Only one study focused on the course of anxiety symptoms in depressed older adults. Higher levels of worry and lower levels of cognitive control predicted persistent and severe levels of anxiety symptoms(10).

Increasing health limitations and events involving death and illness of spouses, children, and peers are major sources of stress that come with aging. Exposure to these negative lifeevents (NLE) has a moderate but significant relation with late-life depression $(11,12)$. The association with late-life anxiety is less well studied and more ambiguous $(8,13,14)$. It has long been theorized that personality dimensions may serve as vulnerability factors(15) and moderators(16) in the development and maintenance of affective symptoms by influencing the way in which persons perceive, react to, or cope with significant life events. Studies in adult samples, however, show conflicting results $(17,18)$.

One could hypothesize that personality traits account for the considerable differences in course of comorbid anxiety in the presence of stress. Vasunilashorn argues the importance of distinguishing between perceptions of stress and exposure to stressors when studying the links between stress and health among older adults(19). The destabilizing appraisal of stress and the dysfunctional coping with NLE are closely related to personality traits such as neuroticism, which increases a person's vulnerability to experience negative emotions(20), and sense of mastery(21,22).

For the paucity of data available on complete remission in the case of comorbidity our first objective was to examine predictors of complete remission of late-life depression 
Chapter 5

defined as no depressive nor an anxiety disorder at follow-up. Our second objective was to examine the course of anxiety symptoms over time. Additionally, we tested the hypothesis that the course of anxiety disorders and symptoms is largely explained by negative lifeevents (in contrast to the course of depressive symptoms) and especially in the presence of high neuroticism or a low sense of mastery.

\section{METHODS}

\section{Participants}

Data were used from the Netherlands Study of Depression in Older persons (NESDO). NESDO is a multi-site naturalistic and prospective cohort study including 378 depressed and 132 non-depressed older adults aged 60 through 93 years. The population and methods of the NESDO study have been described in detail elsewhere(23). The study protocol of NESDO has been approved centrally by the ethical review board of the VUMC and all persons gave informed consent after oral and written information. Depressed participants were included when they fulfilled the DSM-IV-TR criteria for major depression ( $\mathrm{N}=359$; 95.0\%) of whom 270 (75.2\%) completed the two-year follow-up assessments(24). Patients who completed the two-year follow-up did not differ from non-completers with respect to any of the variables of interest that are described below.

\section{Measurements}

\section{Psychiatric diagnoses}

Major depressive disorder and anxiety disorders (panic disorder with or without agoraphobia, agoraphobia, social phobia, and generalized anxiety disorder) were diagnosed according to DSM-IV-TR criteria at baseline and at 2-year follow-up with the Composite International Diagnostic Interview (CIDI; WHO version 2.1). The CIDI is a structured clinical interview that is designed for use in research and has a high validity for depressive and anxiety disorders(25).

\section{Symptom severity}

The severity of anxiety symptoms during the 2-year follow-up period was assessed with the Beck Anxiety Inventory (BAI), a 21 item, self-report questionnaire primarily addressing somatic anxiety symptoms(26). The BAI was administered at baseline and repeated at 6-, 12-, 18-, and 24-months follow-up. A score $\geq 19$ was considered as clinically relevant anxiety.

The severity of the depressive symptoms was assessed with the 30-item self-report version of the Inventory of Depressive Symptomatology (IDS-SR)(27). 


\section{Early and recent negative life events}

Early negative life events or childhood trauma, including emotional neglect as well as psychological, physical, and sexual abuse before the age of 16, was assessed using a structured inventory previously used in the Mental Health Survey and Incidence Study(28) and the Netherlands Study of Depression and Anxiety(29). A childhood abuse index was constructed by recoding the frequency scores in (0) never, (1) once, sometimes and (2) regularly, often or very often. These scores were summed up, resulting in a childhood abuse index that ranges from 0 to 8 , with higher scores indicating a higher frequency of childhood abuse(30).

The occurrence of recent negative life-events (NLE), such as the loss of a friend or family member or experiencing serious illness, was assessed using the Brugha questionnaire(31). These events reflect the presence of life stressors during the last six months before the 6-, 12-, 18-, and 24-months follow-up. For the analyses we used a sum score of the total reported negative life-events (NLEburden), since cumulative stress exposure through lifeevents may lead to a 'wear and tear' of the stress system $(32,33)$.

\section{Personality}

The big five personality domains, i.e. neuroticism, extraversion, openness to experience, agreeableness and conscientiousness, were assessed with the 60-item NEO-Five Factor Inventory (NEO-FFI)(34).

Sense of mastery (or locus of control) was assessed with a the 5-item Dutch version of the Pearlin and Schooler Mastery Scale. A higher score on the Mastery Scale indicates a low sense of mastery(35).

\section{Complete remission vs non-remission}

Complete remission was defined as not meeting the DSM-IV-TR criteria of neither a major depressive or dysthymic disorder, nor an anxiety disorder at two-year follow-up. Nonremitted participants still met the criteria of a major depressive or a dysthymic disorder and/or any anxiety disorder, including a panic disorder with or without agoraphobia, agoraphobia, social phobia, and generalized anxiety disorder.

A stricter definition of complete remission was defined as not meeting any of the diagnostic criteria and scoring below the predefined cut-off scores on the depression and anxiety severity scales. For the IDS-SR this meant a score $<18(27,36)$ and for the BAI a score $<19(26)$.

\section{Covariates at baseline}

Socio-demographic characteristics including age, sex and years of education were assessed with standard questions. Clinical variables included age of onset of the depression; the severity of the depressive symptoms (IDS-SR); the presence of a comorbid anxiety disorder 
(yes/no); the number of chronic diseases, assessed with a self-report questionnaire asking whether they currently or previously had any of the following chronic diseases or disease events: cardiac disease (including myocardial infarction), peripheral atherosclerosis, stroke, diabetes mellitus, COPD (asthma, chronic bronchitis or pulmonary emphysema), arthritis (rheumatoid arthritis or osteoarthritis), cancer, or any other chronic disease; the use of any anti-depressive medication (yes/no); and the frequent use ( $>4 /$ week) of benzodiazepines (yes/no), both self-reported and checked by inspection of the medication participants had to bring in.

\section{Statistical analyses}

Chi-square and t-tests were used to test for differences between the non- and completely remitted groups. Next, a multiple logistic regression analysis with complete remission (yes/ no psychiatric diagnoses at follow-up) as the dependent variable, was used to explore the predictive value of all covariates including socio-demographic, psychopathology, somatic and treatment characteristics. These analyses were also repeated with the stricter definition of complete remission.

Subsequently, the personality traits, life-events and their interaction were tested as potential predictors for complete remission (no psychiatric diagnoses at follow-up), adjusted for all the above-mentioned covariates. For interaction terms, stratified analyses, were performed when $\mathrm{p}<0.10(37)$. Dummy variables were then created through median-split for the personality traits (high/low).

We applied Linear Mixed Models (LMM) examining the course of anxiety symptom severity over time. This approach allows for correlated observations over time and handles missing values on different measurements efficiently using maximum likelihood, with data being considered missing at random, conditional on covariates $(38,39)$. First, we fitted a standard model with intercept and a linear effect of time. Next, we added a quadratic slope to explore the best fit with the course of the anxiety symptom severity. To determine which model best fitted the data we used the log-likelihood statistics. In the final models we allowed a random intercept and a random slope for the independent variable time. Both were allowed to vary across the subjects, following a normal distribution. The covariance structure was estimated as heterogeneous first-order autoregressive structure. Using LMM, we assessed whether personality traits modified the effect of early and recent life-events, and time and their interactions on the course of anxiety symptoms. Again, stratified analyses with dummy variables for the personality traits (high/low) and NLE (high/low) were performed when an interaction showed a $\mathrm{p}<0.10$. Data were analyzed using Statistical Package of the Social Sciences (SPSS), version 22.0 (IBM SPSS, Chicago, IL). 


\section{RESULTS}

\section{Descriptives}

Patients who completed the two-year follow-up $(\mathrm{N}=270)$ had, at baseline, a mean age of 70.4 years $(\mathrm{SD}=7.4)$ and consisted of $178(66.0 \%)$ women. The mean years of education was $10.5(\mathrm{SD}=3.4)$. Concerning the severity of the psychiatric state at baseline we looked at depression severity and comorbid anxiety disorders or comorbid anxiety symptoms. The mean depression severity was $30.0(\mathrm{SD}=12.9)$, which can be categorized as a moderate depression. Among the subgroup of the depressed persons, 38.1\% (103 of 270) had one or more comorbid anxiety disorders, with $18.9 \%$ fulfilling the diagnostic criteria for Social Phobia, $13.0 \%$ for Panic disorder with or without Agoraphobia, $8.9 \%$ for Agoraphobia, and 9.6\% for Generalized Anxiety Disorder. Furthermore, 39.0\% (99 of 254) of the depressed patients suffered from clinically relevant anxiety symptoms. The participants had a mean number of chronic diseases of 2.1 ( $\mathrm{SD}=1.5)$. In total, $191(70.7 \%)$ used antidepressant medication, and 107 (39.6\%) frequently used benzodiazepines.

Of the 270 participants, 267 provided information about the occurrence of childhood trauma. $143(53,6 \%)$ reported any childhood trauma. A total of 207 patients provided information about life-events during follow-up. Among those 188 participants (90.8\%) experienced one or more negative life events during these two years $(\mathrm{M}=4.46, \mathrm{SD}=3.58$, range $=1-19)$.

\section{Complete remission vs non-remission}

Table 1 presents the baseline characteristics of the 270 patients, stratified by complete remission status at follow-up. Of these 270 patients, 103 (38.1\%) had a comorbid anxiety disorder at baseline. Depressed patients with a comorbid anxiety disorder at baseline achieved significantly less often a complete remission (38/103 (37.0\%) versus 97/167 (58.1\%), $\left.\mathrm{X}^{2}=11.4, \mathrm{df}=1, \mathrm{p}=.001\right)$. As non-remission can be either the presence of a depressive disorder at follow-up, the presence of any anxiety disorder or both, Figure 1 presents detailed results of (non-)remission at 2-year follow-up. In the 'pure' depression group 19 participants (11.4\%) develop a (comorbid) anxiety disorder during follow-up. 
Figure 1: Diagnostic status at two-year follow-up of depressed older adults with and without comorbid anxiety disorder at baseline

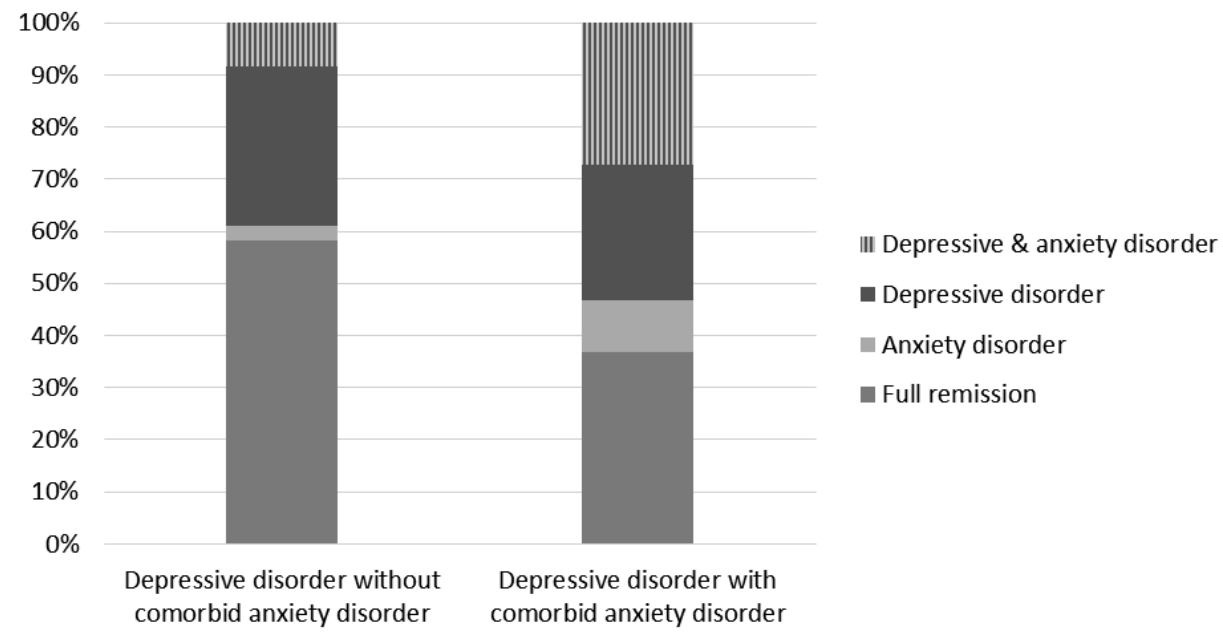

The possible determinants for complete remission were explored, see table 1. Of the 270 participants with diagnostic data at follow-up, 267 provided information about the occurrence of childhood trauma of whom $143(53,6 \%)$ reported any childhood trauma. A total of 207 patients provided information about life-events during follow-up. Among those 188 participants $(90.8 \%)$ experienced one or more negative life events during these two years $(\mathrm{M}=4.46, \mathrm{SD}=3.58$, range $=1-19)$.

In multiple logistic regression analyses including all socio-demographic, psychopathology, somatic and treatment characteristics, only the severity of depressive symptoms $(\mathrm{OR}=1.03$ [95\% CI: $1.00-1.06], \mathrm{p}=.027)$, severity of anxiety symptoms $(\mathrm{OR}=1.04[95 \%$ CI: $1.01-1.07$ ], $\mathrm{p}=.024)$, any anxiety disorder at baseline (OR=2.25 [95\% IC: $1.22-4.18$ ], $\mathrm{p}=.010)$, and the number of chronic diseases $(\mathrm{OR}=1.24$ [95\%CI: $1.01-1.54], \mathrm{p}=.042)$ predicted non-remission significantly.

When we repeat the analyses applying the stricter definition of complete remission (no depressive or anxiety diagnoses at follow-up, nor scores above the predefined cut-off points of the severity measures) $196 / 270(72,6 \%)$ patients were accounted as non-remitted versus $135 / 270(50,0 \%)$ with the first definition of complete remission (no depressive or anxiety diagnoses at follow-up). Results of the multiple logistic regression analyses remained the same, with only age of onset of the depression showing an additional significant association with remission outcome. Participants in the complete remission group had a later age of onset of their depression (data not shown).

Adding the variables of interest (life-events and personality) to the model adjusted for covariates, only neuroticism significantly predicted complete remission (no depressive or anxiety diagnoses at follow-up) $(\mathrm{OR}=1.06$ [95\% CI: $1.00-1.13], \mathrm{p}=.040)$, but not mastery 
Table 1: Determinants of complete remission (neither a depressive nor an anxiety disorder at FU)

\begin{tabular}{|c|c|c|c|c|}
\hline \multirow[b]{2}{*}{ Determinants } & \multicolumn{4}{|c|}{ Outcome at Follow-up } \\
\hline & & $\begin{array}{c}\text { Complete } \\
\text { remission } \\
(n=135)\end{array}$ & $\begin{array}{c}\text { Not } \\
\text { remitted } \\
(n=135)\end{array}$ & Statistics \\
\hline \multicolumn{5}{|l|}{ Socio-demographic } \\
\hline - $\quad$ Age (years) & mean (SD) & $70.3(7.1)$ & $70.6(7.7)$ & $\mathrm{t}=-0.4, \mathrm{df}=268, \mathrm{p}=.699$ \\
\hline - Female sex & $\mathrm{n}(\%)$ & $87(64.4)$ & $91(67.4)$ & $\mathrm{X}^{2}=0.3, \mathrm{df}=1, \mathrm{p}=.608$ \\
\hline - $\quad$ Education (years) & mean (SD) & $10.9(3.2)$ & $10.2(3.6)$ & $\mathrm{t}=1.7, \mathrm{df}=268, \mathrm{p}=.094$ \\
\hline \multicolumn{5}{|l|}{ Psychopathology: } \\
\hline - Age onset depression & mean (SD) & $49.9(19.7)$ & $45.3(20.4)$ & $\mathrm{t}=1.9, \mathrm{df}=258, \mathrm{p}=.065$ \\
\hline - Comorbid anxiety disorder & $\mathrm{n}(\%)$ & $38(28.1)$ & $65(48.1)$ & $\mathrm{X} 2=11.4, \mathrm{df}=1, \mathrm{p}=.001$ \\
\hline - Depression severity (IDS-SR) & mean (SD) & $25.7(11.5)$ & $34.2(12.9)$ & $\mathrm{t}=-5.7, \mathrm{df}=265, \mathrm{p}<.001$ \\
\hline - $\quad$ Anxiety severity (BAI) & mean (SD) & $13.4(9.2)$ & $20.9(11.4)$ & $\mathrm{t}=-5.8, \mathrm{df}=252, \mathrm{p}<.001$ \\
\hline \multicolumn{5}{|l|}{ Somatic morbidity: } \\
\hline - Number of chronic diseases & mean $(\mathrm{SD})$ & $1.7(1.2)$ & $2.5(1.7)$ & $\mathrm{t}=-4.4, \mathrm{df}=267, \mathrm{p}<.001$ \\
\hline \multicolumn{5}{|l|}{ Pharmacological treatment: } \\
\hline - Use of any antidepressant & $\mathrm{n}(\%)$ & $97(72.9)$ & $94(69.6)$ & $\mathrm{X}^{2}=0.4, \mathrm{df}=1, \mathrm{p}=.550$ \\
\hline - Frequent use of benzodiazepine & $\mathrm{n}(\%)$ & $47(34.1)$ & $61(45.2)$ & $\mathrm{X}^{2}=3.5, \mathrm{df}=1, \mathrm{p}=.062$ \\
\hline \multicolumn{5}{|l|}{ Life-events } \\
\hline - $\quad$ NLEburden during FU & mean (SD) & $3.8(3.4)$ & $5.0(3.7)$ & $\mathrm{t}=-2.5, \mathrm{df}=205, \mathrm{p}=.015$ \\
\hline - Childhood Trauma Index & mean $(\mathrm{SD})$ & $0.8(1.1)$ & $1.2(1.2)$ & $\mathrm{t}=-2.4, \mathrm{df}=265, \mathrm{p}=.017$ \\
\hline \multicolumn{5}{|l|}{ Personality: } \\
\hline - Neuroticism & mean $(\mathrm{SD})$ & $36.9(6.0)$ & $41.0(6.5)$ & $\mathrm{t}=-5.3, \mathrm{df}=252, \mathrm{p}<.001$ \\
\hline - Mastery & mean $(\mathrm{SD})$ & $14.4(2.9)$ & $16.0(3.2)$ & $\mathrm{t}=-4.0, \mathrm{df}=248, \mathrm{p}<.001$ \\
\hline
\end{tabular}

IDS-SR: Inventory of Depressive Symptomatology self-report version; BAI: Beck Anxiety Inventory; NLEburden: reported negative life-events during 2-year follow-up.

$(\mathrm{p}=.627)$, NLEburden $(\mathrm{p}=.200)$ or childhood trauma $(\mathrm{p}=.649)$. The only significant interaction was found between the level of mastery and childhood trauma $(\mathrm{p}=.036)$.

Analyses stratified for the presence of childhood trauma revealed that among patients without any childhood trauma, the OR of mastery was 0.93 [95\% CI: $0.79-1.09]$ ( $p=.366$ ), whereas among those with any childhood trauma 1.17 [95\% CI: $0.98-1.40](\mathrm{p}=.078)$ suggesting that a higher score, meaning a lower sense of mastery, is only associated with remission among traumatized depressed patients (albeit not significantly).

\section{Predicting course of anxiety}

Among the 267 patients with BAI data at follow-up, 72 (26.7\%) suffered from clinically relevant anxiety symptoms at the end of this period.

A linear model with an additional quadratic slope factor provided the best representation of the course of the anxiety symptoms $(p<.01)$. The results of the multiple linear mixed 
models analyses that yield significant interaction effects between the personality traits and NLE (recent and childhood trauma) on course of anxiety symptoms over time are shown in table 2. No significant interaction was found with the personality traits of interest and childhood trauma (Neuroticism*Childhood trauma*time: $F(1,1021.76)=0.41 . p=.525$; Childhood trauma*mastery*time: $F(1,1017.77)=0.24 . p=.625)$.

Table 2:

\begin{tabular}{|c|c|c|c|}
\hline \multirow[b]{2}{*}{ Predictor } & \multicolumn{3}{|c|}{ Course of anxiety } \\
\hline & B (S.E.) & $F$ & $P$ \\
\hline \multicolumn{4}{|l|}{ Neuroticism } \\
\hline Neuroticism*time & $-0.25(0.10)$ & 6.86 & .009 \\
\hline Neuroticism $*$ time $^{2}$ & $0.05(0.02)$ & 5.44 & .020 \\
\hline \multicolumn{4}{|l|}{ Negative life-events burden } \\
\hline NLE*time & $-0.83(0.63)$ & 1.74 & .188 \\
\hline NLE*time ${ }^{2}$ & $0.17(0.16)$ & 1.11 & .293 \\
\hline Neuroticism*NLE*time & $0.03(0.02)$ & 2.86 & .091 \\
\hline Neuroticism*NLE*time ${ }^{2}$ & $-0.01(0.00)$ & 1.87 & .172 \\
\hline \multicolumn{4}{|l|}{ Sense of Mastery } \\
\hline Mastery*time & $-0.53(0.20)$ & 7.26 & .150 \\
\hline Mastery $*$ time $^{2}$ & $0.11(0.05)$ & 5.43 & .020 \\
\hline \multicolumn{4}{|l|}{ Negative life-events burden } \\
\hline NLE*time & $-0.70(0.48)$ & 2.08 & .188 \\
\hline NLE*time ${ }^{2}$ & $0.13(0.12)$ & 1.19 & .276 \\
\hline Mastery*NLE*time & $0.06(0.03)$ & 3.81 & .051 \\
\hline Mastery*NLE*time ${ }^{2}$ & $-0.01(0.01)$ & 2.29 & .130 \\
\hline
\end{tabular}

Adjusted for gender, age, education (in years), number of chronic diseases, presence of an anxiety disorder at baseline, age of onset depressive disorder, depression severity, use of any antidepressant, frequent use of benzodiazepines.

To further graphically explore the course of anxiety symptoms, stratified analyses of the significant interactions between the personality traits and NLEburden are shown in Figure 2 and 3. It shows that patients in the high neuroticism group who suffer high NLEburden tend to have a less favorable course of anxiety. In contrast with the other groups, the level of anxiety seems to revert to the initial level after a decline during six months after baseline assessment. The same trend can be seen in the low mastery group that suffers high NLEburden. 
Figure 2. Stratified analyses: high and low neuroticism and high and low NLEburden

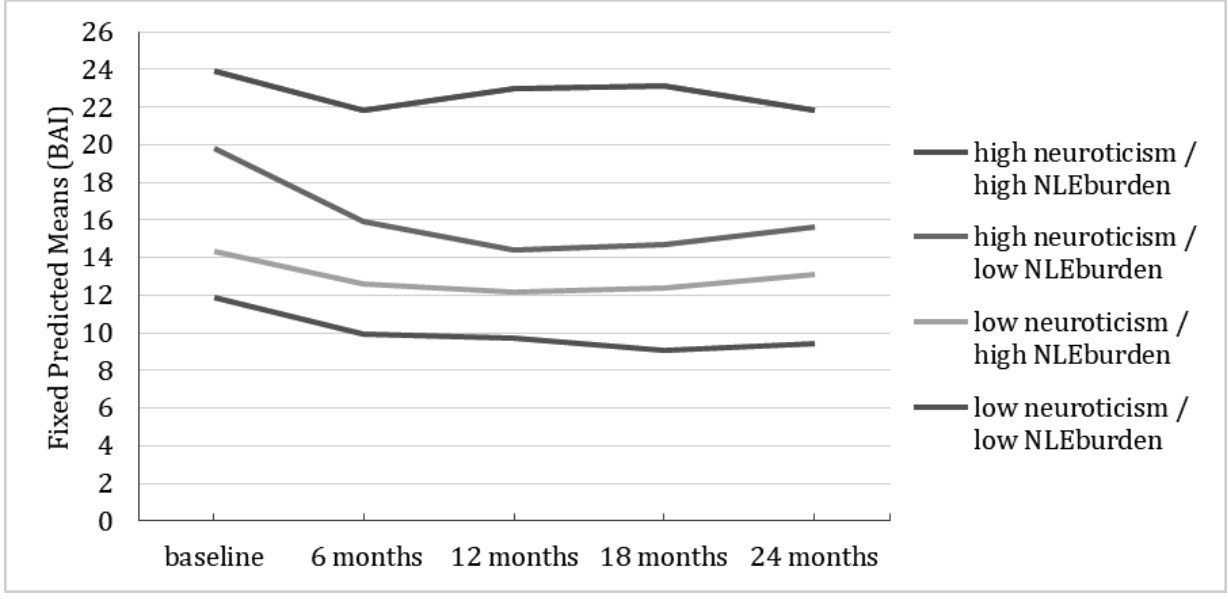

Figure 3. Stratified analyses: high and low mastery and high and low NLEburden

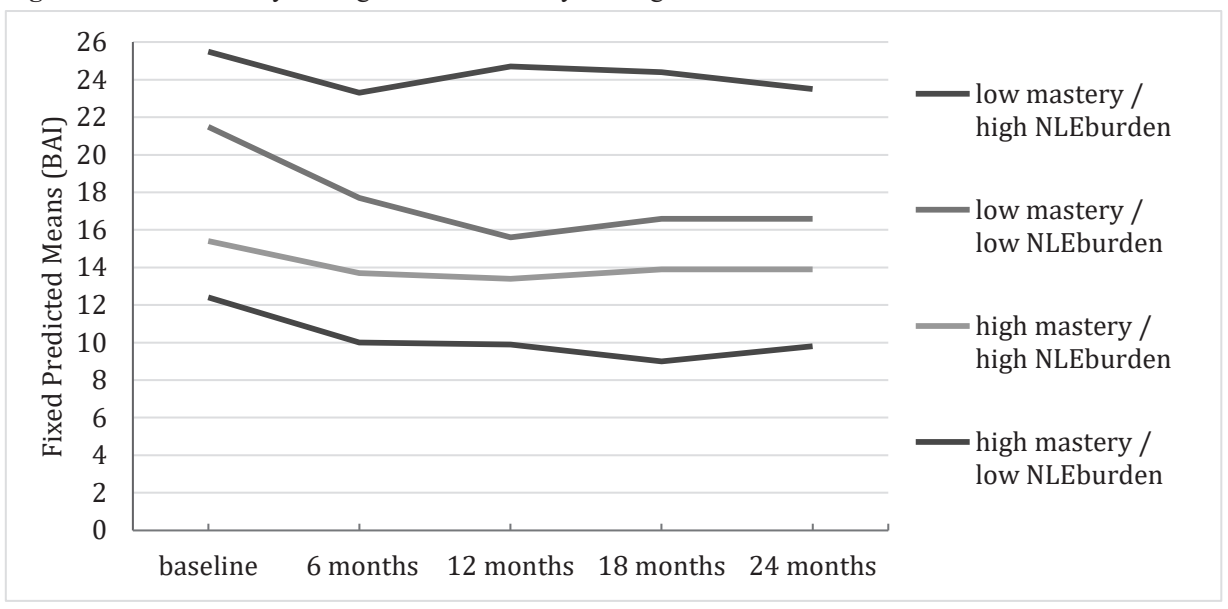

Finally, we checked whether these interactions are unique to the course of anxiety by repeating the analyses for the course of depression. No significant interactions were found for both personality traits and recent negative life-events, and childhood trauma and neuroticism. A significant interaction effect was found for childhood trauma and sense of mastery $(F(1,1039.57)=4.18 . p=.041)$ in predicting the course of depression severity. 
Chapter 5

\section{DISCUSSION}

\section{Main findings}

Among 270 older patients suffering from a major depressive disorder, a total of 135 patients $(50.0 \%)$ achieved complete remission. The severity of depressive and anxiety symptomatology, the presence of a comorbid anxiety disorder, and a poorer physical health at baseline independently predicted non-remission. Also, a higher neuroticism level was associated with non-remission. The impact of mastery on complete remission differed significantly between patients with and without childhood trauma. Patients with lower sense of mastery and childhood trauma achieved less often complete remission. In line with our hypothesis, a less favorable course of self-reported anxiety symptoms was associated with a higher NLEburden, but only among patients with a high level of neuroticism or a low level of mastery.

\section{Complete remission}

Two-year remission rates in older samples vary between $48.0 \%$ and $83.7 \%$ for depressive disorders and between $45.6 \%$ and $81.3 \%$ for anxiety disorders $(40,41)$. Despite the high level of comorbidity between depressive and anxiety disorders in later life, no studies have yet examined complete remission defined as the absence of both a depressive and anxiety disorder. This might be due to the fact that most studies rely on symptom severity scales once formal diagnoses have been established, thereby lessening the burden for patients and researchers associated with repeated administration of a full psychiatric interview. In our sample we found that $78(57.8 \%)$ of the non-remitted patients still suffered from a depressive disorder, 15 (11.1\%) still suffered from an anxiety disorder, and 42 (31.1\%) suffered from both a depressive and an anxiety at 2-year follow-up. Interestingly, the remission rate was significantly lower in the subgroup with a comorbid anxiety disorder at baseline compared to those with a pure depression $(37.0 \%$ vs $58.1 \%)$. Other independent predictors of complete remission were baseline depression and anxiety severity levels and the somatic disease burden, which are in line with a systematic review and meta-analysis of predictors of remission in 67 depression treatment studies(2) as well as community samples(40). By defining remission as a score below the cut-off on a depression severity scale, seven predictors were identified in three or more treatment studies, i.e. baseline depression severity, baseline anxiety symptoms, executive dysfunction, physical illness, current episode duration, early improvement, and age of which only the first three remained significant applying meta-analysis(2). Systematic review of community samples showed strong evidence for an association of baseline depression level, older age, external locus of control, somatic comorbidity and functional limitations with persistent depression(40).

Of the two studies identified by the review of Sami(41), one study found that the somatic disease burden was associated with the persistence of both depressive and anxiety disorders 
during a 12-month period(42), whereas the other study showed that neuroticism was associated with persistent anxiety disorders even after controlling for baseline anxiety symptom severity(43).

In contrast to our hypothesis, NLEburden and childhood trauma did not predict complete remission independent of baseline severity parameters. Neuroticism had an overall main effect on complete remission, replicating many previous studies on the predictive value of neuroticism $(44,45)$. Nonetheless, the impact of mastery was conditional upon the presence of childhood trauma. A lower sense of mastery predicted non-remission in the presence of childhood trauma. A relatively low sense of mastery is common in patients suffering from a depressive or anxiety disorder $(46,47)$. Having a lower sense of control seems to be especially hindering recovery when this feeling activates an 'old' feeling of loss of control during any kind of childhood trauma(21). Interventions (e.g. Cognitive Behavioral Therapy) that promote more adaptive perceptions of control are associated with recovery from anxiety(48) and depression(49).

\section{Course of anxiety symptoms}

Among the 267 patients with BAI data at follow-up, 72 (26.7\%) of our patients still suffered from clinically relevant comorbid anxiety symptoms at the end of this period. This is clinically relevant as even subthreshold anxiety among currently depressed patients is associated with greater psychosocial morbidity $(50,51)$. Thus, residual anxiety symptoms have a significant impact on remitted patients' well-being.

Neuroticism and stressors are not necessarily inert until they interact. Instead, stressors and neuroticism have predicted depression and anxiety directly (as statistical main effects), as well as via their interactions $(17,52,53)$. Persons with high neuroticism may also produce or worsen stressors in their lives (e.g. through avoidance behavior or ineffective social interactions $(54,55)$.

Our results showed that older patients with high neuroticism or low mastery who suffer a high NLE-burden tend to have a less favorable course of anxiety. Stressors, including negative life events often $(17,56,57)$ but not always $(58,59)$ interact with high neuroticism to predict depression and anxiety. Interestingly, de Beurs(58) studied these interactions in an elderly sample. They did find an association between low mastery, high neuroticism, and an increase in negative affect, lack of

positive affect, and anxiety. Furthermore, high mastery protected against the negative impact of loss events, but neuroticism did not augment the negative impact of threat events on emotional health.

\section{Strengths and weaknesses}

The main strength of this study is the large sample of clinically depressed patients followed in a naturalistic setting with repeated measures of NLE, depression and anxiety during 
follow-up. The sample is representative for routine mental health care. On the other hand, it should be noted that our findings cannot be generalized to community dwelling older persons. The study design, with repeated diagnostic measurements in addition to symptom severity scales, made it possible to evaluate complete diagnostic remission rates.

Another strength of this study is the comprehensive assessment of clinically relevant personality factors and life events. While we were interested in the moderating effects of personality and life events to find at-risk patients for a particularly poor course of anxiety symptoms in depression, it was beyond the scope of this project to analyze all interesting associations. Future research is needed to study these, including potential mediating and bidirectional pathways.

In general, studies show that neuroticism remains rather stable in middle and older adulthood, with some apparent increase in late life(60). The measurement of personality traits may be partly biased due to a depressed state. Although, personality traits are considered to be stable, the presence of depression is known to amplify the personality profile of people prone to depression. After recovery of depression, however, the overall shape of the profile does not change(61). Nonetheless, the relationship between change in personality and change in depressive symptoms is at most moderate(62-64).

\section{Clinical implications}

In clinical practice, depression and anxiety are strongly entangled and residual symptoms increase the risk of relapse. When evaluating remission rates, it is important that depressive and anxiety disorders are absent at follow-up. Because the pathology of depression with concurrent anxiety is believed to be more complex, case conceptualization is needed to unravel this 'Gordian knot' and some have suggested it requires specialized interventions(65-67). Interventions to reduce depression and anxiety symptomology need to incorporate techniques that enhance aspect of psychological well-being, like the sense of mastery(68) for daily life-stress continues to be a risk factor among non- or partly remitted(69). 


\section{REFERENCES}

1. Lenze EJ, Mulsant BH, Shear MK, et al: Comorbidity of depression and anxiety disorders in later life. Depress Anxiety 2001; 14:86-93

2. Tunvirachaisakul C, Gould RL, Coulson MC, et al: Predictors of treatment outcome in depression in later life: A systematic review and meta-analysis. J Affect Disord 2018; 227:164-182

3. Baumeister H, Parker G: A second thought on subtyping major depression. Psychother Psychosom 2010; 79:388-389

4. Ionescu DF, Niciu MJ, Henter ID, et al: Defining anxious depression: a review of the literature. CNS Spectr 2013; 18:252-260

5. van der Veen, D C, Comijs HC, van Zelst WH, et al: Defining anxious depression in later life: a scaring heterogeneity in results. Am J Geriatr Psychiatry 2014; 22:1375-1378

6. Andreescu C, Chang CC, Mulsant BH, et al: Twelve-year depressive symptom trajectories and their predictors in a community sample of older adults. Int Psychogeriatr 2008; 20:221-236

7. Byers AL, Vittinghoff E, Lui LY, et al: Twenty-year depressive trajectories among older women. Arch Gen Psychiatry 2012; 69:1073-1079

8. de Beurs E, Beekman AT, Deeg DJ, et al: Predictors of change in anxiety symptoms of older persons: results from the Longitudinal Aging Study Amsterdam. Psychol Med 2000; 30:515-527

9. Schuurmans J, Comijs H, Emmelkamp PM, et al: Long-term effectiveness and prediction of treatment outcome in cognitive behavioral therapy and sertraline for late-life anxiety disorders. Int Psychogeriatr 2009; 21:1148-1159

10. Spinhoven P, van der Veen, D C, Voshaar RCO, et al: Worry and cognitive control predict course trajectories of anxiety in older adults with late-life depression. Eur Psychiatry 2017; 44:134-140

11. Kraaij V, Arensman E, Spinhoven P: Negative life events and depression in elderly persons: a metaanalysis. J Gerontol B Psychol Sci Soc Sci 2002; 57:P87-94

12. Gibb BE, Chelminski I, Zimmerman M: Childhood emotional, physical, and sexual abuse, and diagnoses of depressive and anxiety disorders in adult psychiatric outpatients. Depress Anxiety 2007; 24:256-263

13. Paykel ES: Life events, social support and depression. Acta Psychiatr Scand Suppl 1994; 377:50-58

14. de Beurs E, Blankers M, Delespaul P, et al: Treatment results for severe psychiatric illness: which method is best suited to denote the outcome of mental health care?. BMC Psychiatry 2018; 18:225018

15. Clark LA, Watson D, Mineka S: Temperament, personality, and the mood and anxiety disorders. J Abnorm Psychol 1994; 103:103-116

16. Ormel J, Stewart R, Sanderman R: Personality as modifier of the life change-distress relationship. A longitudinal modelling approach. Soc Psychiatry Psychiatr Epidemiol 1989; 24:187-195

17. Kendler KS, Kuhn J, Prescott CA: The interrelationship of neuroticism, sex, and stressful life events in the prediction of episodes of major depression. Am J Psychiatry 2004; 161:631-636

18. Spinhoven P, Elzinga BM, Hovens JG, et al: Positive and negative life events and personality traits in predicting course of depression and anxiety. Acta Psychiatr Scand 2011; 124:462-473

19. Vasunilashorn S, Lynch SM, Glei DA, et al: Exposure to stressors and trajectories of perceived stress among older adults. J Gerontol B Psychol Sci Soc Sci 2015; 70:329-337

20. Kotov R, Gamez W, Schmidt F, et al: Linking "big” personality traits to anxiety, depressive, and substance use disorders: a meta-analysis. Psychol Bull 2010; 136:768-821

21. Chorpita BF, Barlow DH: The development of anxiety: the role of control in the early environment. Psychol Bull 1998; 124:3-21 
22. Mirowsky J, - Ross CE: - Well-being across the life course. - A handbook for the study of mental health: Social contexts, theories, and systems.:- 328

23. Comijs HC, van Marwijk HW, van der Mast, R C, et al: The Netherlands study of depression in older persons (NESDO); a prospective cohort study. BMC Res Notes 2011; 4:524-0500

24. Comijs HC, Nieuwesteeg J, Kok R, et al: The two-year course of late-life depression; results from the Netherlands study of depression in older persons. BMC Psychiatry 2015; 15:20-015

25. Wittchen HU: Reliability and validity studies of the WHO--Composite International Diagnostic Interview (CIDI): a critical review. J Psychiatr Res 1994; 28:57-84

26. Beck AT, Epstein N, Brown G, et al: An inventory for measuring clinical anxiety: psychometric properties. J Consult Clin Psychol 1988; 56:893-897

27. Rush AJ, Gullion CM, Basco MR, et al: The Inventory of Depressive Symptomatology (IDS): psychometric properties. Psychol Med 1996; 26:477-486

28. de Graaf R, Bijl RV, Ten Have M, et al: Pathways to comorbidity: the transition of pure mood, anxiety and substance use disorders into comorbid conditions in a longitudinal population-based study. J Affect Disord 2004; 82:461-467

29. Penninx BW, Beekman AT, Smit JH, et al: The Netherlands Study of Depression and Anxiety (NESDA): rationale, objectives and methods. Int J Methods Psychiatr Res 2008; 17:121-140

30. Hovens JG, Wiersma JE, Giltay EJ, et al: Childhood life events and childhood trauma in adult patients with depressive, anxiety and comorbid disorders vs. controls. Acta Psychiatr Scand 2010; 122:66-74

31. Brugha T, Bebbington P, Tennant C, et al: The List of Threatening Experiences: a subset of 12 life event categories with considerable long-term contextual threat. Psychol Med 1985; 15:189-194

32. Shields GS, Slavich GM: Lifetime Stress Exposure and Health: A Review of Contemporary Assessment Methods and Biological Mechanisms. Soc Personal Psychol Compass 2017; 11:10.1111/ spc3.12335. Epub 2017 Aug 3

33. No title. - Nature Reviews Neuroscience:- 434

34. Costa PT, McCrae RR: Domains and facets: hierarchical personality assessment using the revised NEO personality inventory. J Pers Assess 1995; 64:21-50

35. Pearlin LI, Schooler C: The structure of coping. J Health Soc Behav 1978; 19:2-21

36. Schulte-van Maaren YW, Carlier IV, Zitman FG, et al: Reference values for major depression questionnaires: the Leiden Routine Outcome Monitoring Study. J Affect Disord 2013; 149:342-349

37. Aiken LS, West SG; Multiple regression: Testing and interpreting interactions. Thousand Oaks, CA, US, Sage Publications, Inc, 1991

38. West BT: Analyzing longitudinal data with the linear mixed models procedure in SPSS. Eval Health Prof 2009; 32:207-228

39. Shek DT, Ma CM: Longitudinal data analyses using linear mixed models in SPSS: concepts, procedures and illustrations. ScientificWorldJournal 2011; 11:42-76

40. Licht-Strunk E, van der Windt, D A, van Marwijk HW, et al: The prognosis of depression in older patients in general practice and the community. A systematic review. Fam Pract 2007; 24:168-180

41. Sami MB, Nilforooshan R: The natural course of anxiety disorders in the elderly: a systematic review of longitudinal trials. Int Psychogeriatr 2015; 27:1061-1069

42. Preville M, Boyer R, Vasiliadis HM, et al: Persistence and remission of psychiatric disorders in the quebec older adult population. Can J Psychiatry 2010; 55:514-522

43. Schuurmans J, Comijs HC, Beekman AT, et al: The outcome of anxiety disorders in older people at 6-year follow-up: results from the Longitudinal Aging Study Amsterdam. Acta Psychiatr Scand $2005 ; 111: 420-428$ 
44. Vittengl JR: Who pays the price for high neuroticism? Moderators of longitudinal risks for depression and anxiety. Psychol Med 2017; 47:1794-1805

45. Jeronimus BF, Kotov R, Riese H, et al: Neuroticism's prospective association with mental disorders halves after adjustment for baseline symptoms and psychiatric history, but the adjusted association hardly decays with time: a meta-analysis on 59 longitudinal/prospective studies with 443313 participants. Psychol Med 2016; 46:2883-2906

46. Abramson LY, Metalsky GI, Alloy LB: Hopelessness depression: A theory-based subtype of depression. Psychol Rev 1989; 96:358-372

47. Gallagher MW, Naragon-Gainey K, Brown TA: Perceived Control is a Transdiagnostic Predictor of Cognitive-Behavior Therapy Outcome for Anxiety Disorders. Cognit Ther Res 2014; 38:10-22

48. Gallagher MW, Bentley KH, Barlow DH: Perceived Control and Vulnerability to Anxiety Disorders: A Meta-analytic Review. Cognitive Therapy and Research 2014; 38:571-584

49. Craske MG, Farchione TJ, Allen LB, et al: Cognitive behavioral therapy for panic disorder and comorbidity: more of the same or less of more? Behav Res Ther 2007; 45:1095-1109

50. Mendlowicz MV, Stein MB: Quality of life in individuals with anxiety disorders. Am J Psychiatry 2000; 157:669-682

51. Grenier S, Schuurmans J, Goldfarb M, et al: The epidemiology of specific phobia and subthreshold fear subtypes in a community-based sample of older adults. Depress Anxiety 2011; 28:456-463

52. Oddone CG, Hybels CF, McQuoid DR, et al: Social support modifies the relationship between personality and depressive symptoms in older adults. Am J Geriatr Psychiatry 2011; 19:123-131

53. Caska CM, Renshaw KD: Personality traits as moderators of the associations between deployment experiences and PTSD symptoms in OEF/OIF service members. Anxiety Stress Coping 2013; 26:3651

54. Lahey BB: Public health significance of neuroticism. Am Psychol 2009; 64:241-256

55. Barlow DH, Sauer-Zavala S, Carl JR, et al: The nature, diagnosis, and treatment of neuroticism: Back to the future. Clinical Psychological Science 2014; 2:344-365

56. Cox BJ, Taylor S, Clara IP, et al: Anxiety sensitivity and panic-related symptomatology in a representative community-based sample: A 1-year longitudinal analysis. Journal of Cognitive Psychotherapy 2008; 22:48-56

57. Brown TA, Rosellini AJ: The direct and interactive effects of neuroticism and life stress on the severity and longitudinal course of depressive symptoms. J Abnorm Psychol 2011; 120:844-856

58. de Beurs E, Comijs H, Twisk JW, et al: Stability and change of emotional functioning in late life: modelling of vulnerability profiles. J Affect Disord 2005; 84:53-62

59. Spinhoven P, Elzinga BM, Hovens JG, et al: Positive and negative life events and personality traits in predicting course of depression and anxiety. Acta Psychiatr Scand 2011; 124:462-473

60. Steunenberg B, Twisk JW, Beekman AT, et al: Stability and change of neuroticism in aging. J Gerontol B Psychol Sci Soc Sci 2005; 60:P27-33

61. Santor DA, Bagby RM, Joffe RT: Evaluating stability and change in personality and depression. J Pers Soc Psychol 1997; 73:1354-1362

62. Costa PT, Bagby RM, Herbst JH, et al: Personality self-reports are concurrently reliable and valid during acute depressive episodes. J Affect Disord 2005; 89:45-55

63. Ormel J, Oldehinkel AJ, Vollebergh W: Vulnerability before, during, and after a major depressive episode: a 3-wave population-based study. Arch Gen Psychiatry 2004; 61:990-996

64. Spinhoven P, Penelo E, de Rooij M, et al: Reciprocal effects of stable and temporary components of neuroticism and affective disorders: results of a longitudinal cohort study. Psychol Med 2014; $44: 337-348$ 
65. Petersen T, Andreotti CF, Chelminski I, et al: Do comorbid anxiety disorders impact treatment planning for outpatients with major depressive disorder?. Psychiatry Res 2009; 169:7-11

66. Kush FR: An Operationalized Cognitive Therapy Approach With Mixed Anxiety and Depression. Psychotherapy: Theory, Research, Practice, Training 2004; 41:266-275

67. Papakostas GI, Clain A, Ameral VE, et al: Fluoxetine-clonazepam cotherapy for anxious depression: an exploratory, post-hoc analysis of a randomized, double blind study. Int Clin Psychopharmacol $2010 ; 25: 17-21$

68. Burns RA, Anstey KJ, Windsor TD: Subjective well-being mediates the effects of resilience and mastery on depression and anxiety in a large community sample of young and middle-aged adults. Aust N Z J Psychiatry 2011; 45:240-248

69. van Winkel M, Nicolson NA, Wichers $M$, et al: Daily life stress reactivity in remitted versus nonremitted depressed individuals. Eur Psychiatry 2015; 30:441-447 



\title{
Chapter 6
}

\section{The impact of personality pathology on treatment outcome in late-life panic disorder}

\author{
Based on: \\ Gulpers BJA \\ Oude Voshaar RC \\ Kampman M \\ Verhey F \\ van Alphen SPJ \\ Hendriks GJ
}


Chapter 6

\begin{abstract}
Background - Comorbid personality disorders are assumed to negatively interfere with treatment outcome of affective disorders. Data on late-life panic disorder remain unknown. We examined the association of personality pathology and treatment outcome related to age and treatment modality.
\end{abstract}

Method - An observational study on the effectiveness of cognitive behavioural therapy (CBT) for panic disorder with agoraphobia among patients aged 18-74 years and a randomized controlled comparison of paroxetine and CBT in older patients ( $\geq 60$ years) was performed. The diagnosis of panic disorder was confirmed by the Anxiety Disorder Interview Schedule-Revised (ADIS-IV) and personality features were assessed with the Personality Diagnostic Questionnaire. The impact of personality features on either agoraphobic cognitions (Agoraphobic Cognitions Questionnaire) or avoidance behaviour (Mobility Inventory Avoidance Scale) was examined by multiple linear regression analyses adjusted for sex, level of education, duration of illness, comorbid psychopathology and baseline severity. Interaction between personality and age was examined among those treated with CBT $(n=90)$; interaction between personality and treatment modality was examined among the older subgroup $(\mathrm{n}=34)$.

Results - Cluster B personality pathology was negatively associated with CBT in both younger and older adults with panic disorder and agoraphobia. Older adults with a higher number of features of any personality pathology or cluster A pathology had a worse treatment outcome when treated with paroxetine compared to CBT.

Conclusion - Cluster B pathology has a detrimental effect on CBT treatment outcome for panic disorder in both age groups. In late-life panic disorder with comorbid personality pathology CBT might be preferred over treatment with Paroxetine. 


\section{INTRODUCTION}

Research on late-life anxiety disorders is scarce despite the high prevalence rates and is predominantly focussed on generalized anxiety disorder or mixed anxiety groups.(Kessler et al., 2005) Empirical findings for panic disorder in later life are hardly available, whereas the 6-month prevalence is estimated between 1-2\%.(Grant, 2009) Panic disorder is associated with a significantly lower quality of life and pervasive social and health consequences that seem to be similar to or even greater than those associated with a major depression. (Markowitz et al., 1989, Schuurmans and Van Balkom, 2011) In older adults with anxiety disorders the effectiveness of CBT is generally lower compared to younger adults (Gould et al., 2012a), although this might not necessarily hold true for panic disorder.(Hendriks et al., 2014a)

In clinical practice treatment is often complicated by somatic and psychiatric comorbid conditions, which are often excluded when studying the effectiveness of CBT. Comorbid personality pathology is highly prevalent in adults with panic disorder and is estimated between 40 and 65\%.(Marshall, 1996) Most clinicians suppose that the presence of a personality disorder is negatively associated with outcome in the treatment of anxiety disorders, due to several, underlying factors, like poor compliance to treatment regimes, problems in the therapeutic alliance or a poor motivation for treatment .(Padesky, 1988, Slaap and den Boer, 2001, Reich, 2003) Moreover, in case of comorbid personality pathology, it is suggested that the panic disorder is often more severe.(Dreessen et al., 1994) A recent systematic review shows that in adults personality pathology is associated with a negative treatment outcome for panic disorder.(Reich et al., 2018) Data on the effect of personality disorders on treatment-outcome in late-life panic disorder are unfortunately lacking.

To improve treatment for late-life panic disorder it is important to identify the predictors for treatment outcome while such knowledge is scarce. Moreover, predictors in adults cannot be generalized to older adults as in general the age of onset and the chronicity of symptoms will differ between older and younger patients and may interact with treatment outcome.(Hendriks et al., 2012)

To our knowledge this is the first study to evaluate: 1) the impact of personality pathology on cognitive-behavioural therapy (CBT) outcome in younger versus older patients with panic disorder, and 2) the differential effect of personality pathology in treatment of late-life panic disorder with CBT or paroxetine. 
Chapter 6

\section{METHODS}

\section{Patient recruitment and selection}

This study was conducted on a consecutive series of patients with panic disorder with agoraphobia referred to a specialized outpatient anxiety clinic (Overwaal Centre of Expertise for Anxiety Disorders, the Netherlands). Therefore, all patients were treated by the same team of professionals according to the same treatment protocols (in case of CBT). For the present study, we combined patients who had participated in two former studies.(Hendriks et al., 2014b) One study on consecutive treatment steps was performed in patients aged 18 through 65 years who had received CBT (Kampman et al., 2008) as their first treatment step. The other study was a randomized controlled trial evaluating CBT and paroxetine versus a waiting list control group in patients aged 60 years or older.(Hendriks et al., 2010) Older patients non-eligible or refusing randomisation were treated by their treatment of choice, which was without exception CBT, using the same protocol and measurements as those participating in one of the two studies. All patients gave informed consent to participate in these studies.

In the present study older patients are defined as 60 years or older. To enable a valid comparison between younger and older patients who received CBT, we combined older patients from the two previous studies, i.e. those randomised to CBT as well as those who refused, or were not offered randomisation as they participated in the observational study. All older patients were thus treated by CBT as the initial treatment step at our clinic (study objective 1). Furthermore, as the number of younger patients largely exceeded those of older patients, we have included two younger patients per older patient matched on the severity of avoidance behaviour, as the frequency of panic attacks is dependent on the severity of avoidance behaviour. Matching was performed blind to study purpose by an independent researcher not related to the study (see acknowledgements).

To enable a valid comparison between older patients receiving paroxetine and older patients receiving CBT (study objective 2), only participants of the randomized controlled trial were included. Figure 1 provides a summary of the patient flow and how the comparison groups are composed.

The clinical diagnosis of panic disorder with agoraphobia was verified by experienced, licensed clinical psychologists or psychiatrists using the Dutch version of the Anxiety Disorders Interview Schedule-Revised (ADIS-IV). Exclusion criteria were 1) severe somatic illnesses that could interfere with the therapy 2) current use of an antidepressant 3) current psychological treatment, and 4) the presence of a primary psychiatric diagnosis of a psychotic, bipolar, or substance use disorder and, dementia. Any psychiatric comorbid disorder (for example other anxiety disorders, depression etc) was allowed as long as the primary diagnosis was panic disorder with agoraphobia. Patients who were using benzodiazepines at baseline were asked to use a fixed dosage for the duration of the protocolized treatment 
period. Before and after treatment completion (i.e after 14 weeks), the patients completed various questionnaires (see below).(Hendriks et al., 2014b)

\section{Figure 1}

Summary of patient recruitment and comparison groups

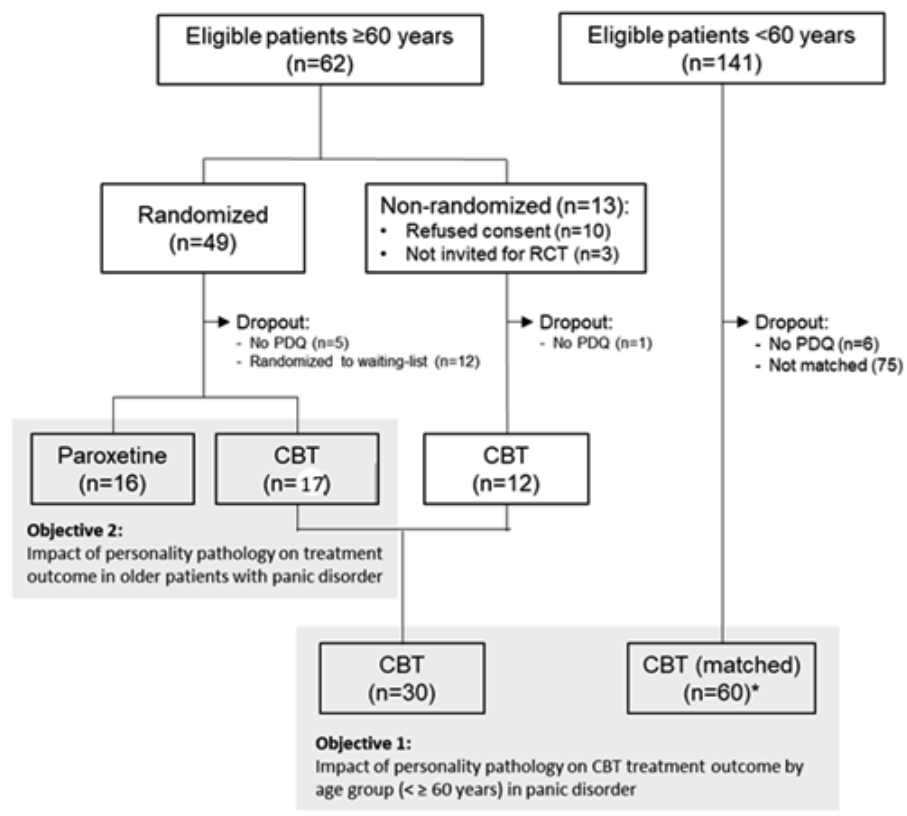

\section{Treatment}

The majority $(\mathrm{n}=169)$ was treated with manual-based CBT. The CBT was given to individuals and consisted of 14 weekly sessions of 50 minutes. It followed the Craske and Barlow protocol(Craske and Barlow, 1993, Craske et al., 1994) and compromised: 1) psycho-education about panic, anxiety and avoidance behavior, 2) relaxation techniques (applied relaxation), 3) interoceptive exposure, 4) cognitive therapy, and 5) in-vivo exposure. Therapists were psychologists (MSc level) who had received extensive training at the clinic and were highly experienced with the CBT protocol for panic disorder with agoraphobia. They were weekly supervised by certified supervisors of the Dutch Association for Behavioral and Cognitive Therapy to ensure adequate application of the CBT techniques and adherence to the protocol. There were no age-specific adaptions for the older adults. (Hendriks et al., 2014b)

Due to randomization 17 older adults were treated with Paroxetine according to a fixed-dose schedule. The Paroxetine protocol started with a daily dose of $10 \mathrm{mg}$ and was gradually increased $40 \mathrm{mg}$ in week 4 . In this period subjects were seen in 30-minutes weekly consultations. This was due to control for any adverse events and to encourage 
patients to adhere to the treatment protocol. From week 5 to week 14, all patients attended five 30-minute medical consultations once every 2 weeks during which their queries were addressed and information about the expected (side) effects of the treatment was provided. (Hendriks et al., 2010)

\section{Personality assessment}

Personality pathology according to DSM-criteria was measured at baseline with the Dutch version of the Personality Diagnostic Questionnaire (PDQ).(Ouwersloot et al., 1994, Dingemans and Sno, 2004) The PDQ is a self-report questionnaire and validation studies have shown that the PDQ is a screening instrument with a high sensitivity and a moderate specificity.(Wilberg et al., 2000) Since patients were recruited between 1997 and 2005, two versions of the PDQ were used; the PDQ-R (133 items) based upon the DSM-III-R criteria and the PDQ-4+(99 items) based upon the DSM-IV-TR. The Dutch translations of the PDQ-R and the PDQ-4+ have been cross-validated.(Ouwersloot et al., 1994, Dingemans and Sno, 2004)

Differences between both versions can be explained by 1) the specific personality disorders of which the features are assessed, 2) whether one or more questions are asked to assess the presence of a specific feature, and 3) differences between the personality features and cut-off scores in the DSM-III-R and DSM-IV-TR. We made the following adaptations to guarantee comparability of both measures.

First, we analysed only those personality disorders of which the concepts are sufficiently validated and therefore are still used in the DSM-5. Therefore, we excluded features related to a passive-aggressive, depressive, masochistic, and a sadistic personality disorder.

Secondly, some personality features are asked with the aid of 2 sub items in the PDQ-R of which one needs to be present, whereas in the PDQ-4+ these items were combined to one overall item by combining both items into one item, by leaving out one item (done for $5 / 133$ (3.8\%) features) or by rephrasing both items. Where possible, 2 subitems were recalculated to represent the corresponding items in the PDS-4+.

Taken these adaptations into account and administering the same numbering for both versions, the total amount of items of the current personality disorders are 96 and 94 for the PDQ-R and PDQ-4+, respectively. This final difference could be explained by differences between the DSM-III and DSM-IV-TR and are considered minimal.

\section{Treatment outcome assessment}

The primary outcome measure was agoraphobic avoidance as measured with the Dutch version of the Mobility Inventory Avoidance scale (MI-A). (Chambless et al., 1985, De Beurs, 1993) The MI-A has three subscales: avoidance when alone (MI-AAL), avoidance when accompanied (MI-AAC) and frequency of panic attacks (MI-PF).(Hendriks et al., 2014b) We used the two MI avoidance scales as avoidance has shown to be a better predictor of 
outcome than panic attack frequency. Higher level of avoidance behaviour generally results in less frequent panic attacks.(Basoglu et al., 1994, De Beurs et al., 1995)

The secondary outcome measure was the severity of the agoraphobic cognitions assessed with the Dutch adaptation of the Agoraphobic Cognitions Questionnaire (ACQ).(De Beurs, 1993, Chambless et al., 1984)

Both instruments use 5-point Likert-scales for the individual items. The MI-A, the ACQ and their Dutch adaptations are frequently used in panic disorder treatment outcome studies and have good test-retest reliability, high internal consistencies and reasonable concurrent validity.(Hendriks et al., 2014b, Chambless et al., 1985, De Beurs, 1993, Chambless et al., 1984)

\section{Statistical analysis}

Differences between both comparison groups at baseline (younger versus older patients and older patients treated with paroxetine versus $\mathrm{CBT}$ ) were compared with the Chi-square test for categorical variables and the independent-samples T-test for dimensional variables. The duration of illness was skewed, therefore in all analyses the ln-transformed were used.

The impact of personality pathology (as measured by number of personality features) on treatment outcome was studied by multiple linear regression analyses with study outcome (either avoidance behaviour based on MI-A or agoraphobic cognitions based on the ACQ) as the dependent variable. Both bi- and multivariate analyses will be presented. As patient groups are rather small, we include the covariates (age, sex, level of education, duration of illness, and comorbid psychopathology in addition to baseline severity of either avoidance behaviour or agoraphobic cognitions) in step 1 using a stepwise procedure, where after the independent variable of interest (number of personality features) is included.

In order to test a differential effect of personality pathology by age, we tested the interaction of age by number of personality features when examining the impact of personality pathology on CBT treatment outcome (objective 1). In order to test a differential effect of personality pathology by treatment modality, we tested the interaction of treatment modality (paroxetine versus CBT) by personality pathology. In case of significant interaction terms, stratified results will be presented.

All analyses were conducted in SPSS version 22.0 (Chicage, Inc). P-values below .05 are considered significant. 


\section{RESULTS}

\section{Objective 1: The impact of personality pathology on CBT outcome for panic disorder across the lifespan.}

\section{Baseline comparisons}

As shown in table 1, socio-demographic characteristics did not differ between both age groups. With respect to the psychopathology, the older adults group had a significant longer duration of illness, less agoraphobic cognitions and less often a comorbid personality disorder compared to their younger counterparts. The lower frequencies of personality disorders in older adults were explained by less cluster B personality disorders. The number of personality features of any personality pathology and cluster B pathology was lower in older adults but higher for cluster $\mathrm{C}$ pathology, compared to the younger adults.

Table 1: Baseline characteristics of patients receiving CBT by age group

\begin{tabular}{|c|c|c|c|c|}
\hline \multirow[b]{2}{*}{ Characteristics } & \multicolumn{4}{|c|}{$\begin{array}{c}\text { Patients receiving } \\
\text { CBT } \\
\end{array}$} \\
\hline & Expression & $\begin{array}{c}<60 \text { years } \\
(\mathrm{n}=60)\end{array}$ & $\begin{array}{c}\geq 60 \text { years } \\
(n=30)\end{array}$ & Statistics \\
\hline \multicolumn{5}{|l|}{ Socio-demographic: } \\
\hline Age (years) & mean (SD) & $35.9(11.1)$ & $67.2(4.8)$ & $\mathrm{t}=-14.7, \mathrm{df}=88, \mathrm{p}<.001$ \\
\hline Female sex & $\mathrm{n}(\%)$ & $39(65 \%)$ & $21(70 \%)$ & $\mathrm{X}^{2}=0.2, \mathrm{df}=1, \mathrm{p}=.635$ \\
\hline \multicolumn{5}{|l|}{ Level of education: } \\
\hline - Low & $\mathrm{n}(\%)$ & $16(27 \%)$ & $11(37 \%)$ & \\
\hline - $\quad$ Medium & $\mathrm{n}(\%)$ & $22(37 \%)$ & $12(40 \%)$ & $\mathrm{X}^{2}=1.6, \mathrm{df}=2, \mathrm{p}=.452$ \\
\hline - High & $\mathrm{n}(\%)$ & $21(36 \%)$ & $7(23 \%)$ & \\
\hline \multicolumn{5}{|l|}{ Psychopathology: } \\
\hline Duration of illness panic disorder (years) & Median (IQR) & $4.1(8.2)$ & $6.0(18.6)$ & $\mathrm{t}=-0.7, \mathrm{df}=88, \mathrm{p}=.060 *$ \\
\hline Avoidance behaviour (MI) & mean (SD) & $2.4(0.9)$ & $2.5(1.0)$ & $\mathrm{t}=-0.4, \mathrm{df}=88, \mathrm{p}=.669$ \\
\hline Agoraphobic cognitions (ACQ) & mean $(\mathrm{SD})$ & $2.1(0.6)$ & $1.6(0.5)$ & $\mathrm{t}=4.2, \mathrm{df}=88, \mathrm{p}<.001$ \\
\hline Comorbid psychiatric disorder & $\mathrm{n}(\%)$ & $23(38 \%)$ & $8(27 \%)$ & $\mathrm{X}^{2}=1.2, \mathrm{df}=1, \mathrm{p}=.272$ \\
\hline \multicolumn{5}{|l|}{ Personality pathology: } \\
\hline Personality disorder present & $\mathrm{n}(\%)$ & $44(73 \%)$ & $17(57 \%)$ & $\mathrm{X}^{2}=7.8, \mathrm{df}=1, \mathrm{p}=.005$ \\
\hline - Cluster A & $\mathrm{n}(\%)$ & $20(33 \%)$ & $9(30 \%)$ & $\mathrm{X}^{2}=0.1, \mathrm{df}=1, \mathrm{p}=.750$ \\
\hline - Cluster B & $\mathrm{n}(\%)$ & $24(40 \%)$ & $3(10 \%)$ & $\mathrm{X}^{2}=8.6, \mathrm{df}=1, \mathrm{p}=.003$ \\
\hline - Cluster C & $\mathrm{n}(\%)$ & $33(55 \%)$ & $11(37 \%)$ & $\mathrm{X}^{2}=2.7, \mathrm{df}=1, \mathrm{p}=.101$ \\
\hline Total number of personality features & mean (SD) & $27.4(10.1)$ & $17.7(11.7)$ & $\mathrm{t}=4.1, \mathrm{df}=88, \mathrm{p}<.001$ \\
\hline - Cluster A features & mean $(\mathrm{SD})$ & $6.0(3.8)$ & $4.9(3.7)$ & $\mathrm{t}=1.3, \mathrm{df}=88, \mathrm{p}=.201$ \\
\hline - Cluster B features & mean (SD) & $9.4(3.9)$ & $8.9(3.6)$ & $\mathrm{t}=5.5, \mathrm{df}=88, \mathrm{p}<.001$ \\
\hline - $\quad$ Cluster $\mathrm{C}$ features & mean (SD) & $4.8(3.6)$ & $6.3(4.7)$ & $\mathrm{t}=2.9, \mathrm{df}=88, \mathrm{p}=.005$ \\
\hline
\end{tabular}

* Student's t-test is based on Ln-transformed values.

Abbreviations: CBT, cognitive-behavioural therapy; SD, standard deviation; IQR, interquartile range. 


\section{Impact of personality pathology on CBT outcome}

None of the personality dimensions (total number of personality features and number of features of the three clusters) significantly interacted with age in the multivariate analyses on predicting CBT outcome with respect to avoidance behaviour (lowest p-value $=.345$ ) and to agoraphobic cognitions (lowest p-value $=.175$ ). Therefore, table 2 presents the results for the younger and older age group combined.

Table 2: Impact of personality pathology on CBT outcome with respect to avoidance behaviour and agoraphobic cognitions

\begin{tabular}{|c|c|c|c|c|c|c|}
\hline \multirow[b]{3}{*}{ Personality measure: } & \multicolumn{6}{|c|}{ Avoidance behaviour } \\
\hline & \multicolumn{3}{|c|}{ Bivariate analyses } & \multicolumn{3}{|c|}{ Multivariate analyses* } \\
\hline & B (SE) & $\beta$ & p-value & B (SE) & $\beta$ & p-value \\
\hline Total number of personality features & $0.02(0.01)$ & .29 & .009 & $0.01(0.01)$ & .12 & .056 \\
\hline - Cluster A features & $0.09(0.03)$ & .370 & .001 & $<0.01(0.02)$ & .02 & .823 \\
\hline - Cluster B features & $0.04(0.02)$ & .19 & .094 & $0.03(0.01)$ & .17 & .005 \\
\hline \multirow[t]{4}{*}{ - $\quad$ Cluster $\mathrm{C}$ features } & $0.04(0.02)$ & .21 & .066 & $<0.01(<0.01)$ & $<.01$ & .974 \\
\hline & \multicolumn{6}{|c|}{ Agoraphobic cognitions } \\
\hline & \multicolumn{3}{|c|}{ Bivariate analyses } & \multicolumn{3}{|c|}{ Multivariate analyses* } \\
\hline & B (SE) & $\beta$ & p-value & B (SE) & $\beta$ & p-value \\
\hline Total number of personality features & $0.02(0.01)$ & .40 & $<.001$ & $0.01(001)$ & .10 & .329 \\
\hline Cluster A features & $0.04(0.02)$ & .26 & .019 & $0.01(0.02)$ & .04 & .716 \\
\hline Cluster B features & $0.06(0.02)$ & .41 & .018 & $0.02(0.01)$ & .14 & .168 \\
\hline Cluster C features & $0.04(0.02)$ & .30 & .007 & $0.01(0.01)$ & .04 & .710 \\
\hline
\end{tabular}

* Adjusted for baseline severity of either avoidance behaviour or agoraphobic cognitions, age, sex, level of education, duration of illness, and psychiatric comorbidity using a stepwise procedure.

For the whole sample, a higher number of cluster B personality features was associated with a worse treatment outcome for avoidance behaviour after $\mathrm{CBT}(\mathrm{B}=0.03, \mathrm{SE}=0.01$, $p=.005)$. The effect size was low $(\beta=0.17)$. There was no effect found of cluster $B$ pathology on the treatment outcome for agoraphobic cognitions $(B=0.02, S E=0.01, p=0.168)$. Cluster A or cluster $\mathrm{C}$ pathology was not associated with treatment outcome for either avoidance behaviour or agoraphobic cognitions (see table 2).

\section{Objective 2: The impact of personality pathology on treatment for late-life panic disorder with either CBT or paroxetine}

\section{Baseline comparisons}

Table 3 shows that there were no significant differences between the older adults receiving CBT or paroxetine at baseline. 
Table 3: Baseline characteristics of older patients randomised to either paroxetine or CBT

\begin{tabular}{|c|c|c|c|c|}
\hline \multirow[b]{2}{*}{ Characteristics } & \multicolumn{4}{|c|}{ Randomized older patients } \\
\hline & Expression & $\begin{array}{c}\text { Paroxetine } \\
(n=16)\end{array}$ & $\begin{array}{c}\text { CBT } \\
(n=18)\end{array}$ & Statistics \\
\hline \multicolumn{5}{|l|}{ Socio-demographic: } \\
\hline Age (years) & mean (SD) & $69.0(4.4)$ & $69.1(5.0)$ & $\mathrm{t}=-0.1, \mathrm{df}=32, \mathrm{p}=.946$ \\
\hline Female sex & $\mathrm{n}(\%)$ & $10(63 \%)$ & $10(56 \%)$ & $X^{2}=0.2, d f=1, p=.681$ \\
\hline \multicolumn{5}{|l|}{ Level of education: } \\
\hline - Low & $\mathrm{n}(\%)$ & $6(38 \%)$ & $5(28 \%)$ & \\
\hline - $\quad$ Medium & $\mathrm{n}(\%)$ & $6(38 \%)$ & $8(44 \%)$ & $\mathrm{X}^{2}=0.4, \mathrm{df}=2, \mathrm{p}=.831$ \\
\hline - High & $\mathrm{n}(\%)$ & $3(25 \%)$ & $5(28 \%)$ & \\
\hline \multicolumn{5}{|l|}{ Psychopathology: } \\
\hline Duration of illness panic disorder (years) & Median (IQR) & $6.0(17.5)$ & $6.5(21.4)$ & $\mathrm{t}=-0.2, \mathrm{df}=32, \mathrm{p}=.866^{*}$ \\
\hline Avoidance behaviour (MI) & mean (SD) & $2.4(0.7)$ & $2.4(1.0)$ & $\mathrm{t}=0.1, \mathrm{df}=32, \mathrm{p}=.937$ \\
\hline Agoraphobic cognitions (ACQ) & mean (SD) & $1.7(0.4)$ & $1.6(0.5)$ & $\mathrm{t}=0.6, \mathrm{df}=32, \mathrm{p}=.586$ \\
\hline Comorbid psychiatric disorder & $\mathrm{n}(\%)$ & $7(44 \%)$ & $3(17 \%)$ & $\mathrm{X}^{2}=3.0, \mathrm{df}=1, \mathrm{p}=.084$ \\
\hline \multicolumn{5}{|l|}{ Personality pathology: } \\
\hline Personality disorder present & $\mathrm{n}(\%)$ & $10(63 \%)$ & $8(44 \%)$ & $\mathrm{X}^{2}=1.1, \mathrm{df}=1, \mathrm{p}=.292$ \\
\hline - Cluster A & $\mathrm{n}(\%)$ & $5(31 \%)$ & $5(28 \%)$ & $\mathrm{X}^{2}=0.5, \mathrm{df}=1, \mathrm{p}=.824$ \\
\hline - Cluster B & $\mathrm{n}(\%)$ & $1(6 \%)$ & $2(11 \%)$ & $\mathrm{X}^{2}=0.2, \mathrm{df}=1, \mathrm{p}=.618$ \\
\hline - $\quad$ Cluster C & $\mathrm{n}(\%)$ & $8(50 \%)$ & $7(39 \%)$ & $\mathrm{X}^{2}=0.4, \mathrm{df}=1, \mathrm{p}=.424$ \\
\hline Total number of personality features & mean (SD) & $19.8(12.5)$ & $17.9(12.0)$ & $\mathrm{t}=0.4, \mathrm{df}=32, \mathrm{p}=.662$ \\
\hline - Cluster A features & mean $(\mathrm{SD})$ & $5.4(4.4)$ & $5.0(4.0)$ & $\mathrm{t}=0.3, \mathrm{df}=32, \mathrm{p}=.783$ \\
\hline - Cluster B features & mean $(\mathrm{SD})$ & $5.7(6.0)$ & $5.1(3.6)$ & $\mathrm{t}=0.4, \mathrm{df}=32, \mathrm{p}=.698$ \\
\hline - $\quad$ Cluster $\mathrm{C}$ features & mean $(\mathrm{SD})$ & $6.7(3.6)$ & $6.2(4.8)$ & $\mathrm{t}=0.3, \mathrm{df}=32, \mathrm{p}=.733$ \\
\hline
\end{tabular}

* Student's t-test is based on Ln-transformed values.

Abbreviations: $\mathrm{CBT}$, cognitive-behavioural therapy; SD, standard deviation; IQR, interquartile range.

\section{Differential effect of personality pathology on treatment outcome with CBT or paroxetine}

The interaction term of personality pathology by treatment modality by time was significant for avoidance behaviour in the adjusted analyses for the number of features of any personality pathology and cluster A pathology ( $p=0.028$ and $p<0.001$, respectively).

Stratified analyses showed that the interaction between treatment modality and number of features of overall personality pathology could be explained by the fact that an increased level of personality pathology worsens treatment outcome when treated with paroxetine $(\mathrm{B}=0.02, \mathrm{SE}=0.01, \mathrm{p}=0.116)$, but improves treatment outcome with $\mathrm{CBT}(\mathrm{B}=-0.02$, $\mathrm{SE}=0.01, \mathrm{p}=0.257$ ), although these stratified analyses did not reach statistical significance. Furthermore, a higher number of cluster $\mathrm{A}$ features was significantly associated with a worse treatment outcome when treated with paroxetine $(B=0.08, S E=0.03, p=0.019)$, and a 
significantly better treatment outcome with $\mathrm{CBT}(\mathrm{B}=-0.09, \mathrm{SE}=0.03, \mathrm{p}=0.017)$. The effect sizes were small to medium with $\beta$ 's ranging from 0.22 to 0.49 (see table 4 ).

The interaction term of personality pathology by treatment modality by time was not significant for all personality dimensions related to treatment outcome on agoraphobic cognitions (see table 4).

Table 4: Impact of personality pathology on treatment outcome in older patients $(n=34)$, stratified by treatment modality.

\begin{tabular}{|c|c|c|c|c|c|c|c|}
\hline \multirow[b]{3}{*}{ Personality measure: } & \multirow{3}{*}{$\begin{array}{c}\text { Whole sample } \\
\begin{array}{c}\text { PP by Treatment } \\
\text { by time }\end{array} \\
\text { p-value }\end{array}$} & \multicolumn{6}{|c|}{ Bivariate regression analyses avoidance behaviour } \\
\hline & & \multicolumn{3}{|c|}{ Paroxetine } & \multicolumn{3}{|c|}{ CBT } \\
\hline & & B (SE) & $\beta$ & p-value & B (SE) & $\beta$ & p-value \\
\hline $\begin{array}{l}\text { Total number of } \\
\text { personality features }\end{array}$ & .181 & $0.03(0.01)$ & .58 & .036 & $<-0.01(0.02)$ & -.01 & .967 \\
\hline - Cluster A features & .117 & $0.09(0.04)$ & .31 & .034 & $-0.02(0.06)$ & -.10 & .712 \\
\hline - Cluster B features & .425 & $0.05(0.03)$ & .46 & .117 & $<-0.01(0.06)$ & -.01 & .974 \\
\hline \multirow[t]{3}{*}{ - $\quad$ Cluster $\mathrm{C}$ features } & .162 & $0.12(0.05)$ & .60 & .029 & $0.01(0.05)$ & .07 & .788 \\
\hline & $\begin{array}{l}\text { PP by Treatment } \\
\text { by time }\end{array}$ & \multicolumn{6}{|c|}{ Multivariate regression analyses avoidance behaviour* } \\
\hline & p-value & B (SE) & $\beta$ & p-value & B (SE) & $\beta$ & p-value \\
\hline $\begin{array}{l}\text { Total number of } \\
\text { personality features }\end{array}$ & .028 & $0.02(0.01)$ & .32 & .116 & $-0.02(0.01)$ & -.22 & .257 \\
\hline - Cluster A features & $<.001$ & $0.08(0.03)$ & .49 & .019 & $-0.09(0.03)$ & -.44 & .017 \\
\hline - $\quad$ Cluster B features & .282 & $0.03(0.02)$ & .23 & .263 & $0.04(0.04)$ & .16 & .422 \\
\hline \multirow[t]{3}{*}{ - $\quad$ Cluster $\mathrm{C}$ features } & .183 & $0.07(0.04)$ & .33 & .117 & $<0.01(0.03)$ & -.02 & .917 \\
\hline & Whole sample & \multicolumn{6}{|c|}{ Bivariate regression analyses agoraphobic cognitions } \\
\hline & $\begin{array}{c}\text { PP by Treatment } \\
\text { by time }\end{array}$ & \multicolumn{3}{|c|}{ Paroxetine } & \multicolumn{3}{|c|}{ CBT } \\
\hline Personality measure: & p-value & B (SE) & $\beta$ & p-value & B (SE) & $\beta$ & p-value \\
\hline $\begin{array}{l}\text { Total number of } \\
\text { personality features }\end{array}$ & .076 & $<-0.01(0.01)$ & -.15 & .615 & $0.02(0.01)$ & .49 & .052 \\
\hline - Cluster A features & .318 & $-0.02(0.02)$ & -.25 & .417 & $0.02(0.03)$ & .17 & .532 \\
\hline - Cluster B features & .060 & $-0.01(0.02)$ & -.21 & .483 & $0.05(0.03)$ & .44 & .088 \\
\hline \multirow[t]{3}{*}{ - Cluster $\mathrm{C}$ features } & .283 & $0.01(0.03)$ & .09 & .766 & $0.05(0.02)$ & .56 & .023 \\
\hline & $\begin{array}{c}\text { PP by Treatment } \\
\text { by time }\end{array}$ & \multicolumn{6}{|c|}{$\begin{array}{c}\text { Multivariate regression analyses agoraphobic } \\
\text { cognitions* }\end{array}$} \\
\hline & p-value & B (SE) & $\beta$ & p-value & B (SE) & $\beta$ & p-value \\
\hline $\begin{array}{l}\text { Total number of } \\
\text { personality features }\end{array}$ & .178 & $<-0.01(0.01)$ & -.03 & .885 & $<0.01(0.01)$ & .02 & .906 \\
\hline - Cluster A features & .983 & $-0.01(0.02)$ & -.06 & .785 & $-0.02(0.02)$ & -.16 & .318 \\
\hline - Cluster B features & .125 & $<0.01(0.01)$ & -.01 & .980 & $<0.01(0.02)$ & .03 & .888 \\
\hline - $\quad$ Cluster $\mathrm{C}$ features & .206 & $-0.01(0.02)$ & -.08 & .714 & $0.01(0.01)$ & .17 & .338 \\
\hline
\end{tabular}

* Adjusted for baseline severity of either avoidance behaviour or agoraphobic cognitions, age, sex, level of education, psychiatric comorbidity, and duration of illness using a stepwise procedure.

Abbreviations: PP, personality pathology (measured by number of features). 
Chapter 6

\section{DISCUSSION}

\section{Main findings}

The impact of personality pathology on CBT treatment outcome was independent of age. Only a higher number of cluster B personality features interfered negatively with the outcome of CBT in the whole sample, but only with respect to avoidance behaviour and not for agoraphobic cognitions. Among older adults we found that the number of personality features differed significantly between treatment modalities, which seemed to be driven by the presence of cluster A pathology. In case of more cluster A personality features, treatment with paroxetine was associated with less improvement of avoidance behaviour, whereas CBT was associated with more improvement of avoidance behaviour.

\section{Impact of personality pathology on CBT outcome}

By our knowledge this is the first study to evaluate the impact of personality pathology on CBT treatment outcome including older patients with panic disorder. Although more than half of the older patients seeking treatment for panic disorder suffered from clinically relevant personality pathology, the number of personality features was significantly lower compared to younger patients. Especially the number of cluster B personality features had a lower frequency, which includes personality features like impulsiveness and self-harm that diminishes by aging.(Stevenson et al., 2003, Zanarini et al., 2011)

Despite the small sample size and small to medium effect sizes, our finding that personality pathology negatively interferes with treatment outcome is in line with findings in younger adults, as summarized in several reviews.(Reich, 2003, Mennin and Heimberg, 2000, Reich et al., 2018) The studies summarized in these reviews differed with respect to the assessment of personality pathology (self-report questionnaires versus semi-structured interviews), adjustment for baseline anxiety severity (yes/no), treatment modality (elements of CBT, CBT or pharmacotherapy) and duration of follow-up.(Reich, 2003, Mennin and Heimberg, 2000, Reich et al., 2018) These differences hamper the use of meta-regression techniques to estimate the impact of personality pathology on treatment outcome quantitatively.(Porter and Chambless, 2015) A recent systematic review on the effect of comorbid personality pathology concluded that cluster A, B and C personality pathology negatively interferes with the treatment outcome for panic disorder, also when adjusted for baseline severity of the panic disorder.(Reich et al., 2018) Nonetheless, results with respect to cluster $\mathrm{C}$ pathology was less convincing, as cluster $\mathrm{C}$ pathology was even associated with better treatment outcome in three studies.(Reich et al., 2018) We did not find any negative effect of cluster $\mathrm{C}$ personality features on the treatment outcome after adjustment for baseline anxiety severity, while cluster B pathology had a negative influence on CBT treatment outcome independent of age. 
As we found no interaction with age, this effect should be considered of a similar strength in younger and older patients. On the one hand, we should be critical as cluster B pathology was significantly less prevalent in the older adults compared to the younger adults, which might have masked any differential effect by age. On the other hand, it is known that older adults with a similar severity of personality pathology meet less DSM-criteria compared to younger adults.(Balsis et al., 2007)

In our study personality pathology did not have any influence on outcome with respect to the agoraphobic cognitions. As agoraphobic cognitions decline with treatment, this finding might suggest that patients can differentiate between maladaptive cognitions as a result of personality pathology not targeted by CBT and specific agoraphobic cognitions targeted by CBT.

\section{Personality and treatment modality in later life}

In older patients, the number of features of overall personality pathology significantly interfered with treatment modality with respect to avoidance behaviour. This effect was driven by cluster A pathology. In case more cluster A personality features were met by a patient, response to CBT was better and response to paroxetine was worse. To date, the impact of personality pathology on pharmacotherapy for panic disorder has only been evaluated in younger adults. Two reviews on benzodiazepines and antidepressants for the treatment of panic disorder showed a negative response to both short- and long-term treatment outcome in the presence of personality pathology.(Slaap and den Boer, 2001, Reich et al., 2018)

Since the effectiveness of pharmacotherapy decreases in the presence of personality pathology, CBT should be considered a first choice for older patient suffering from panic disorder and comorbid personality pathology. Effectiveness of CBT for late-life anxiety disorders has been demonstrated in several meta-analyses, although included studies were restricted to generalized anxiety disorder or included mixed anxiety disorders in which only a part of the patients suffered from panic disorder.(Hendriks et al., 2008, Gould et al., 2012b)

\section{Strengths and limitations}

By our knowledge this is the first study that focuses on the effect of comorbid personality pathology on treatment outcome in late-life panic disorder, with a direct comparison between younger and older adults according to CBT treatment, and between treatment modalities within the group of older adults.

For a proper interpretation of the current results several limitations need to be considered. First, to answer our research questions we have combined two former studies conducted in two different populations according to age. Recruitment procedures between both studies were equal with corresponding in- and exclusion criteria and both studies applied exactly the same CBT protocol by the same therapists. Nonetheless, we cannot exclude that dif- 
ferent referral rates may have led to a systematic bias. Since late-life panic disorders are frequently not recognized and subsequently left untreated, the relatively small sample size of older adults might point to referral bias. Secondly, we have recruited our population at a specialized anxiety outpatient clinic. Older adults are less inclined to seek help for psychiatric problems. This might have led to a subgroup of older patients with more severe panic disorders and/or highly motivated patients. Thirdly, the results have been presented without a Bonferroni correction. As data on the effect of personality disorders on treatment-outcome in late-life panic disorder are lacking and therefore specific hypotheses in this older age group are absent, a Bonferroni correction was not applied to avoid type II errors. It could however lead to type I errors. Finally, two different versions of the PDQ were applied in our research sample. We only applied those personality disorders that were captured by both versions and are still included in the DSM-5 (APA, 2013). Personality pathology was analysed dimensionally using the number of features, in line with more recent views on personality pathology as dimensional disorders.(Widiger and Simonsen, 2005, Clark, 2007)

\section{Conclusion}

Cluster B pathology influenced the CBT treatment outcome negatively in both younger and older adults with panic disorder and agoraphobia. Despite this negative influence it is important not to exclude patients with comorbid personality pathology from CBT as improvement is to be expected, albeit not as great as in patients without comorbid personality pathology.(Reich, 2003) In late-life panic disorder with comorbid personality pathology CBT may be recommended over antidepressants. Future research should take psychiatric comorbidity into account and with respect to personality pathology especially address longterm effects on treatment outcome which may be particularly affected.(Newton-Howes et al., 2017)

\section{Acknowledgements}

We thank dr. Rob van den Brink, senior research at the Rob Giel Research Institute of the University of Groningen, for performing the matching of older with younger patients. 


\section{REFERENCES}

BALSIS, S., GLEASON, M. E., WOODS, C. M. \& OLTMANNS, T. F. 2007. An item response theory analysis of DSM-IV personality disorder criteria across younger and older age groups. Psychol Aging, 22, 171-185.

BASOGLU, M., MARKS, I. M., SWINSON, R. P., NOSHIRVANI, H., O’SUlLIVAN, G. \& KUCH, K. 1994. Pre-treatment predictors of treatment outcome in panic disorder and agoraphobia treated with alprazolam and exposure. J Affect Disord, 30, 123-32.

CHAMBLESS, D. L., CAPUTO, G. C., BRIGHT, P. \& GALLAGHER, R. 1984. Assessment of fear of fear in agoraphobics: the body sensations questionnaire and the agoraphobic cognitions questionnaire. $J$ Consult Clin Psychol, 52, 1090-7.

CHAMBLESS, D. L., CAPUTO, G. C., JASIN, S. E., GRACELY, E. J. \& WILLIAMS, C. 1985. The mobility inventory for agoraphobia. . Behav Res Ther. , 23, 35-44.

CLARK, L. A. 2007. Assessment and diagnosis of personality disorder: perennial issues and an emerging reconceptualization. Annu Rev Psychol, 58, 227-57.

CRASKE, M. G. \& BARLOW, D. H. 1993. Panic disorders and agoraphobia. . Clinical Handbook of Psychological Disorders. New York, Guilford, 1-47.

CRASKE, M. G., MEADOWS, E. \& BARLOW, D. H. 1994. Therapist Guide for the Mastery of Your Anxiety and Panic II and Agoraphobia Supplement. . Albany, New York, Graywind Publications.

DE BEURS, E. 1993. The Assessment and Treatment of Panic Disorder and Agoraphobia. Amsterdam The Netherlands: Thesis Publishers.

DE BEURS, E., LANGE, A., VAN DYCK, R. \& KOELE, P. 1995. Respiratory training prior to exposure in vivo in the treatment of panic disorder with agoraphobia: efficacy and predictors of outcome. Aust N Z J Psychiatry, 29, 104-13.

DINGEMANS, P. M. A. J. \& SNO, H. N. 2004. Meetinstrumenten bij persoonlijkheids-stoornissen. . Tijdschrift voor Psychiatrie., 46, 705-709.

DREESSEN, L., ARNTZ, A., LUTTELS, A. \& SALLAERTS, S. 1994. Personality disorders do not influence the results of cognitive-behaviour therapies for anxiety disorders. Comprehensive psychiatry, $35,265-274$.

GOULD, R. L., COULSON, M. C. \& HOWARD, R. J. 2012a. Efficacy of cognitive behavioral therapy for anxiety disorders in older people: a meta-analysis and meta-regression of randomized controlled trials. J Am Geriatr Soc, 60, 218-229.

GOULD, R. L., COULSON, M. C. \& HOWARD, R. J. 2012b. Efficacy of cognitive behavioral therapy for anxiety disorders in older people: a meta-analysis and meta-regression of randomized controlled trials. J Am Geriatr So, 60, 218-229.

GRANT, B. F. 2009. Sociodemographic and Psychopathologic Predictors of First Incidence of DSM-IV Substance Use, Mood, and Anxiety Disorders: Results from the Wave 2 National Epidemiologic Survey on Alcohol and Related Conditions. . Mol Psychiatry. , 14, 1051-1066.

HENDRIKS, G. J., KAMPMAN, M., KEIJSERS, G. P., HOOGDUIN, C. A. \& VOSHAAR, R. C. 2014a. Cognitive-behavioral therapy for panic disorder with agoraphobia in older people: a comparison with younger patients. Depress Anxiety, 31, 669-677.

HENDRIKS, G. J., KAMPMAN, M., KEIJSERS, G. P., HOOGDUIN, C. A. \& VOSHAAR, R. C. 2014 b. Cognitive-behavioral therapy for panic disorder with agoraphobia in older people: a comparison with younger patients. Depress Anxiety, 31, 669-77. 
HENDRIKS, G. J., KEIJSERS, G. P., KAMPMAN, M., HOOGDUIN, C. A. \& OUDE VOSHAAR, R. C. 2012. Predictors of outcome of pharmacological and psychological treatment of late-life panic disorder with agoraphobia. Int J Geriatr Psychiatry, 27, 146-50.

HENDRIKS, G. J., KEIJSERS, G. P., KAMPMAN, M., OUDE VOSHAAR, R. C., VERBRAAK, M. J., BROEKMAN, T. G. \& HOOGDUIN, C. A. 2010. A randomized controlled study of paroxetine and cognitive-behavioural therapy for late-life panic disorder. Acta Psychiatr Scand, 122, 11-9.

HENDRIKS, G. J., OUDE VOSHAAR, R. C., KEIJSERS, G. P., HOOGDUIN, C. A. \& VAN BALKOM, A. J. 2008. Cognitive-behavioural therapy for late-life anxiety disorders: a systematic review and meta-analysis. Acta Psychiatr Scand, 117, 403-11.

KAMPMAN, M., KEIJSERS, G. P. J., HOOGDUIN, C. A. L. \& HENDRIKS, G. J. 2008. Outcome prediction of cognitive behavior therapy for panic disorder: Initial symptom severity is predictive for treatment outcome, comorbid anxiety or depressive disorder, cluster $\mathrm{C}$ personality disorders and initial motivation are not. . Behavioral and Cognitive Psychotherapy 36, 99-112.

KESSleR, R. C., BERGlund, P., DEMLER, O., JIN, R., MERIKANGAS, K. R. \& WALTERS, E. E. 2005. Lifetime prevalence and age-of-onset distributions of DSM-IV disorders in the National Comorbidity Survey Replication. Arch Gen Psychiatry, 62, 593-602.

MARKOWITZ, J. S., WEISSMAN, M. M., OUELletTE, R., LISH, J. D. \& KLERMAN, G. L. 1989. Quality of life in panic disorder. Arch Gen Psychiatry, 46, 984-92.

MARSHALL, J. R. 1996. Comorbidity and its effect on panic disorder. . Bulletin of the Menninger Clinic. , 60, 39-53.

MENNIN, D. S. \& HEIMBERG, R. G. 2000. The impact of comorbid mood and personality disorder in the cognitive-behavioral treatment of panic disorder. Clinical Psychology Review, 20, 339-357.

NEWTON-HOWES, G., MULDER, R., ELLIS, P. M., BODEN, J. M. \& JOYCE, P. 2017. Predictive Utility of Personality Disorder in Depression: Comparison of Outcomes and Taxonomic Approach. J Pers Disord, 19, 1-14.

OUWERSLOOT, G., VAN DER BRINK, W. \& DIEKSTRA, R. F. W. 1994. Diagnostiek van persoonlijkheidsstoornissen. Een evaluatie van Nederlandstalig instrumentarium. . Tijdschrift voor Psychiatrie., 36, 558-570.

PADESKY, C. A. 1988. Schema-focused CT: comments and questions. Int Cogn Ther Newsletter, 4, 5-7.

PORTER, E. \& CHAMBLESS, D. L. 2015. A systematic review of predictors and moderators of improvement in cognitive-behavioral therapy for panic disorder and agoraphobia. Clin Psychol Rev, 42, 179-192.

REICH, J. 2003. The effect of Axis II disorders on the outcome of treatment of anxiety and unipolar depressive disorders: a review. J Pers Disord, 17, 387-405.

REICH, J., SCHATZBERG, A. \& DELUCCHI, K. 2018. Empirical evidence of the effect of personality pathology on the outcome of panic disorder. J Psychiatr Res, 107, 42-47.

SCHUURMANS, J. \& VAN BALKOM, A. 2011. Late-life anxiety disorders: a review. Curr Psychiatry Rep, 13, 267-73.

SLAAP, B. R. \& DEN BOER, J. A. 2001. The prediction of nonresponse to pharmacotherapy in panic disorder: a review. Depress Anxiety, 14, 112-22.

STEVENSON, J., MEARES, R. \& COMERFORD, A. 2003. Diminished impulsivity in older patients with borderline personality disorder. Am J Psychiatry, 160, 165-166.

WIDIGER, T. A. \& SIMONSEN, E. 2005. Alternative dimensional models of personality disorder: finding a common ground. J Pers Disord, 19, 110-30. 
WILBERG, T., DAMMEN, T. \& FRIIS, S. 2000. Comparing Personality Diagnostic questionnaire-4+ with Longitudinal, Expert, All Data (LEAD) standard diagnoses in a sample with a high prevalence of axis I and axis II disorders. . Compr Psychiatry., 41, 295-302.

ZANARINI, M. C., LAUDATE, C. S., FRANKENBURG, F. R., REICH, D. B. \& FITZMAURICE, G. 2011. Predictors of self-mutilation in patients with borderline personality disorder: A 10-year follow-up study. J Psychiatr Res, 45, 823-828. 



\section{Chapter 7}

General discussion 


\section{GENERAL DISCUSSION}

In this thesis, we describe several studies on the correlates, comorbidities, and prognosis of anxiety in older adults from a lifespan perspective. In general, anxiety is not well studied in the elderly, although it can have great impact on relevant patient outcomes. On the one hand, anxiety may impact on incidence and course of cognitive decline. On the other hand, other factors may also impact on the course and the treatment outcome of anxiety in older patients.

Therefore this thesis consisted of two related parts. In the first part, anxiety has been studied as a risk factor for cognitive impairment and dementia. In the second part, the impact of comorbid personality pathology has been studied on the course of anxiety symptoms and treatment outcome. In this final chapter, findings are summarized to answer our original research questions and the clinical implications of these findings are discussed. Furthermore, we will discuss the strengths and limitations of our studies. Finally, implications for further research are suggested.

\section{PART A}

\section{Correlates and comorbidities of anxiety related to cognitive functioning}

In order to study whether and to what extent anxiety in people both in the general community and in clinical settings is a risk factor for cognitive impairment, a meta-analysis of the current literature was carried out and presented in chapter 2. We showed that in the community anxiety is a risk factor for cognitive impairment, and probably for dementia as data was heterogeneous.(Gulpers et al., 2016) However, anxiety did not predict conversion from MCI to dementia in clinical samples, as was previously shown in the systematic review and meta-analysis of Cooper et al.(Cooper et al., 2015) This is most likely explained by the selection of different study samples due to different settings. In clinical samples people with mild cognitive impairment, usually from specialized memory clinics, there is likely an overrepresentation of transient cognitive impairment that is caused by primary psychopathology instead of an underlying neurodegenerative disorder. Cooper et al showed that also for depressive symptoms there is a difference according to the risk for dementia between community and clinical studies.(Cooper et al., 2015) Depressive symptoms predicts dementia in subjects with mild cognitive impairment in community-based studies only, and not in clinical studies, and this finding is already replicated.(Cooper et al., 2015, Tan et al., 2019) These findings highlight that people should be cautious to interpret results from clinical samples, and to generalize these to the general population. The current data about anxiety as a risk factor for dementia is heterogeneous with e.g. differences in anxiety measures, differences in cognitive measures, differences in follow-up duration, and dif- 
ferences in adjustment for relevant confounders, sometimes even without any adjustment. Also, the number of studies about anxiety as a risk factor for cognitive decline are relatively small. Therefore, replication studies with good methodology are needed to confirm our finding, especially according to the risk for developing dementia.

In our systematic review and meta-analysis, it remained unclear which cognitive domains are affected mostly by anxiety. As individual studies used different neuropsychological instruments to assess specific cognitive domains, data were too heterogeneous to be pooled in a meta-analysis. There were only suggestions that anxiety may specifically lead to a decline of executive functioning. Therefore, we studied this more in depth in chapter 3 and 4 . In chapter 3 we investigated in 82,360 community-dwelling people participating in the Lifelines cohort, the cross-sectional relationship between anxiety disorders and figural fluency, as a measure of executive functioning in adults aged 18 years or older (range 18-93). We found a small association between the presence of any anxiety disorder and worse executive functioning, and this relationship was driven by agoraphobia. People who suffered from agoraphobia performed worse on the figural fluency task compared to those not suffering from an anxiety disorder. In contrast to our hypothesis, this association was not dependent on age. Therefore, it is unlikely that this association can be explained by an underlying neurodegenerative process as cause of the anxiety disorder. It should however be noted that participants with a MMSE score lower than 26 were excluded at baseline, which minimalizes the risk of including participants with an underlying neurodegenerative disease in this cohort. Furthermore, executive functioning was measured with the Ruff Figural Fluency Test (RFFT). The RFFT was developed by Ruff and colleagues to be able to differentiate between left and right frontal lobe lesions due to trauma or cardiovascular accidents (CVA's), as verbal fluency or other neuropsychological tests did not specifically measure right frontal lobe functioning.(Ruff et al., 1987) In general it is assumed that the left frontal lobe is involved with language related movements (tested by verbal fluency), and the right verbal lobe with non-verbal abilities (tested by figural fluency). Thus, the RFFT was not designed to measure overall executive functioning.

Sex differences according to the relationship between executive functioning and anxiety were noted in chapter 3 and 4 . In chapter 3 , sex had no effect on the association between any anxiety disorder and worse executive functioning. Nonetheless, among persons suffering from both an anxiety and depressive disorder, women had worse scores on a measure for executive functioning compared to men. In chapter 4 we studied anxiety and executive functioning over time in 918 participants of the Maastricht Aging Study. We did not find an overall effect of anxiety on the course of executive functioning over time due to differential findings in man and woman. Again among women, increasing anxiety symptoms were associated with decline of executive functioning over time, while in men a trend towards improvement of executive functioning over time was found. Similar sex-specific findings in this study were also found on tasks measuring processing speed and fluency 
over time. The stronger associations in women might be due to a more severe anxiety phenotype. Indeed, women in our sample had a higher prevalence of anxiety symptoms, and a higher severity of anxiety symptoms. Previous research has also shown an increased risk for coronary heart disease in women with anxiety symptoms.(Nabi et al., 2010) Since the vascular disease burden could potentially mediate the association between anxiety and deterioration of executive function, this may explain this sex-specific finding, as well for processing speed and fluency. For future research it is important to be aware of differences between sexes. In the last years a lot of attention has been given to the fact that, in general, research data cannot be easily generalized across genders.(Regitz-Zagrosek, 2012) Our findings on anxiety supports this claim.

Besides executive functioning, other cognitive domains related to anxiety were studied longitudinally in chapter 4 . Comparing older adults ( $>65$ years) with increasing levels of anxiety to those with lower anxiety levels, we found a greater decline of verbal memory in the former group. This was not found in the younger adults (50-65 years). Progressive decline of verbal memory is considered a marker for Alzheimer's disease, as memory deficits (especially delayed recall) are almost always present in an early phase.(Cummings, 2004) Previous research showed conflicting results, and the seven studies addressing this problem could not be pooled due to methodological differences.(Gulpers et al., 2016) As described in our systematic review, only one of these studies showed a significant association between anxiety and decline of memory over time. The two studies with the longest follow-up duration and with a good methodological quality did not find a significant association between anxiety and decline of memory.(Bierman et al., 2008, Bunce et al., 2012) Further research is needed to better understand which cognitive domains are affected by anxiety. It is possible that anxiety can effect different cognitive domains. In cross-sectional studies, anxiety influences the cognitive scores directly. People with anxiety score lower on attention tasks (Bierman et al., 2008), or measurements of executive function due to interference with their working memory.(Eysenck and Calvo, 1992, Beaudreau and O'Hara, 2008) Anxiety could be related to neurodegeneration, with memory deficits in Alzheimer's disease or deficits in attention, processing speed and/or executive functioning due to cerebrovascular disease.

Whether anxiety is a prodromal sign of neurodegenerative disorder, or an independent cause for neurodegeneration remains unclear. Our meta-analysis in chapter 2 found suggestions for anxiety as a prodromal symptom of neurodegenerative diseases, since the associations were the strongest among those aged 80 years and over. Previous research has also found that anxiety symptoms may reflect underlying Alzheimer pathology.(Ramakers et al., 2013, Wilson et al., 2011) In case of late-onset anxiety, as less than $1 \%$ of lifetime anxiety disorders has an onset in later life, clinicians should therefore especially be aware of underlying neurodegenerative disease.(Kessler et al., 2005) Anxiety could then be a consequence of diminished cognitive capacities, which are experienced as an increased emotional vulnerability only at a subjective level. People with such increased vulnerability 
may benefit from structuring of daily life. However, when it is causally related, the older adults with anxiety complaints present throughout their lifespan are at a higher risk for an underlying neurodegenerative disease. Treating anxiety vigorously may then lead to lowered risk for dementia later on. In chapter 4 we found that older adults ( $>65$ years) with increasing levels of anxiety had a greater decline of verbal memory compared to older adults ( $>65$ years) with lower anxiety levels. This association was not found in the younger adults (50-65 years). In this study the older participants (65+ years) had a mean age of 72 years and therefore had a lower a-priori chance of underlying neuropathology compared to the group of 80 years and older in the meta-analysis. However, participants with cognitive problems were excluded in this study at baseline and participants were followed for a long period of twelve years. Given these considerations, the finding that older adults with increasing anxiety levels had a greater decline of verbal memory, could also be explained by anxiety being causally related. A recent systematic review showed that mid-life anxiety is a risk factor for dementia over an interval of at least ten years, which could also be explained by a causal relationship due to the long follow-up duration.(Gimson et al., 2018)

In general, the discussion about anxiety either being a prodromal symptom of an underlying neurodegenerative disease or a causal factor leading to a neurodegenerative disease is an ongoing discussion in the literature, and has sometimes been polarized into either the one or the other option. It is important to consider the possibility that both explanations are valid. Also, anxiety could be caused by an unknown factor also causing dementia. Furthermore, besides the effect of anxiety as a risk factor for dementia, there may also be a state effect of anxiety due to symptoms of psychopathology, present throughout all ages and likely to be transient. It is important to notice that in epidemiological studies, there are always multiple factors present influencing the outcome. For example, mid-life depression has been associated with vascular dementia in the future.(Barnes et al., 2012) Late-life depression however, was only associated with dementia due to Alzheimer's disease(Barnes et al., 2012), illustrating that more factors besides depression influences the outcome.

Further research should include different cognitive domains with even multiple tests for executive functioning, testing all of its elements. Longitudinal replication studies with a long follow-up duration are necessary, holding into account the effect of age and sex on possible associations. The cohorts that have been used in the past for prospective studies could also be used for retrospective studies by adding data about cause of death. When dementia is the cause of death, anxiety as a risk factor can be studied retrospectively. For example Burton et al, studied anxiety as a risk factor retrospectively and found large relative risks compared to the other studies.(Gulpers et al., 2016, Burton et al., 2013)

\section{Clinical implications}

For now, clinicians should be aware of a possible underlying neurodegenerative disease when older adults present with anxiety. When patients present themselves with anxiety, 
treatment should be started. In older adults with anxiety and cognitive disorders pharmacotherapy, psychological treatments and practical interventions should be considered. Exposure in vivo could potentially increase anxiety symptoms and patients might not be capable of cognitive therapy. Structuring in daily life could be helpful in patients not suitable for psychological interventions. A meta-analysis however showed a potential positive effect of CBT on anxiety in patients with light to moderate dementia. Anxiety was measured with three different questionnaires or interviews, and only one showed a positive significant association. There was no significant effect on the Quality of Life. It should also be noted that only two studies were included. (Orgeta et al., 2015)

Furthermore, clinicians should know that problems specifically with executive functioning can interfere with treatment for affective disorders.(Alexopoulos, 2005, Mohlman, 2005) Other treatment strategies, like problem-solving therapy, showed better improvement in persons with executive dysfunction and depression.(Alexopoulos et al., 2008) Since the effect sizes in our study in chapter 3 were small, regular treatment for anxiety should not be adapted in advance. However, when regular treatment fails it could be relevant to test executive functioning and when executive dysfunctions are present to adapt the treatment to it.

\section{PART B}

\section{Comorbidities and prognosis of anxiety with lifespan perspectives}

We focused on comorbid personality pathology as a possible prognostic variable for nonremission and the course of comorbid anxiety in older patients with a depressive disorder, and treatment outcome in late-life panic disorder.

In clinical practice, anxiety disorders and depressive disorders are often comorbid to each other. In scientific research often only 'pure' depressions or 'pure' anxiety disorders are studied, which makes it harder to extrapolate the findings to clinical patients. Depression and anxiety disorder are also regarded as separate entities in the Diagnostic and Statistical Manual (DSM). In reality these diagnoses are often comorbid to each other and are often hard to disentangle from one another. This is a side-effect of the simplification of real life when diagnosing with categorical syndromes. When developing the DSM-5 a dimensional approach was considered instead of a categorical approach, which would better show that there can be smooth transitions between the current categorical diagnoses.(Möller, 2009)

In chapter 5 we studied the predictors of complete remission in older adults with a major depressive disorder, and often a comorbid anxiety disorder, with complete remission defined as no depressive and no anxiety disorder at follow-up. The presence of a comorbid anxiety disorder was a predictor for non-remission, which highlights the importance of adequately diagnosing comorbid anxiety also in the presence of a comorbid depressive disorder. 
Comorbid personality pathology is highly prevalent in older adults with anxiety disorders, and in clinical practice it is often assumed to interfere negatively with the treatment outcome. Clinicians should be aware of comorbid personality pathology when the anxiety complaints are chronic or have high relapse rates.(Pollack et al., 1992, Green and Curtis, 1988) Personality features were also studied in chapter 5 as potential predictors for nonremission (no depressive and no anxiety disorder). High neuroticism was directly associated with non-remission. Low mastery was only a predictor in the presence of childhood trauma. The course of the comorbid anxiety symptoms during the two year follow-up was dependent upon these personality features (high neuroticism and low mastery), but only in the presence of negative life events. As personality features have an influence on the course of comorbid anxiety symptoms in depressive disorder and on non-remission rates, it is important to consider psychotherapy for older adults. Multiple meta-analyses have demonstrated the effectiveness of psychotherapy in older adults with anxiety disorders. (Gould et al., 2012, Goncalves and Byrne, 2012) That older adults are less opportune for psychotherapy as complaints are often more chronic, or the assumption that older adults are too inflexible to change their behavior, appears to be untrue. When personality features like high neuroticism or low mastery are present, psychotherapeutic interventions should not per se aim for complete remission of the personality dysfunction, but more the increase of adaptive coping strategies, while diminishing maladaptive behaviors and symptoms (for example avoidance behavior in patients with anxiety complaints).(Morse and Lynch, 2000) Psychotherapy that also targets the personality features that influences the course of symptoms, can improve the remission and relapse rates. By our knowledge, no study yet has specifically focused on psychological treatment of personality disorders in older adults.

The influence of neuroticism or mastery in the presence of negative life events was specific for the course of anxiety symptoms and not for the depressive symptoms, which is an interesting finding. Previous studies showed mixed results.(Brown and Rosellini, 2011, Spinhoven et al., 2011) We hypothesize that anxiety reacts more directly on negative life events than depression does, and therefore shows more fluctuations. There is no direct evidence for this hypothesis, yet.

Future research should focus on patients with depressive disorder and with an anxiety disorder as there is a high comorbidity between these diagnoses in clinical patients. Previous research showed that the subtype of depression with the anxious specifier is associated with more impairment, and worse treatment outcome in younger and older adults. It is important to gain more knowledge as it can lead to more effective treatment regimes. Some studies have already suggested specialized interventions for this subtype of depression. (Kush, 2004, Papakostas et al., 2010) Also anxiety disorders with a comorbid depression have a worse treatment outcome.(Gorman, 1997)

In chapter 6 , we showed that, in contrast to common beliefs that late-life anxiety is more treatment resistant, the impact of personality pathology on treatment outcome was 
not dependent on age. In the whole sample, only cluster B personality features had a detrimental effect on treatment outcome with CBT. Both groups however, with or without personality pathology, improved. Therefore, patients with panic disorder should not be excluded for manual-based CBT based on age or personality pathology. Despite minimal impact of personality pathology on manual-based CBT, we argue for more research. First, meta-analyses have shown that personality pathology negatively interfere with treatment of depression (Newton-Howes et al., 2014), as well as for substance use disorders.(NewtonHowes and Foulds, 2018) Second, recent meta-analyses showed that personality pathology had especially a detrimental effect on relapse in substance use disorders(Foulds et al., 2017) and functional outcomes at follow-up for depression.(Newton-Howes et al., 2018) In our sample differences according to complete remission rates remained unknown, as well as possible differences in relapse rates. Future research should include the long-term effects of comorbid personality pathology in the treatment of older adults with comorbid personality pathology.

Our data showed different results for pharmacotherapy compared to CBT in the presence of comorbid personality pathology. Older adults with panic disorder and comorbid personality pathology that were treated with Paroxetine, did not improve as much as older adults without comorbid personality pathology. Future research should investigate different treatment modalities in older adults with comorbid personality pathology more in depth, as small numbers of older adults in each treatment modality were present in our study.

\section{Clinical implications}

It is important to consider psychotherapy for older adults with anxiety complaints, as it has proven to be effective. Comorbid personality features that influences the course of anxiety complaints are another reason to offer psychotherapy with a focus on increasing adaptive coping mechanisms. Our studies showed that patients with panic disorder should not be excluded for manual-based CBT based on age or personality pathology. Our finding that treatment with CBT is superior to pharmacotherapy in older adults with comorbid personality pathology, strengthens the recommendation in guidelines to offer primarily CBT for the treatment of panic disorder.(Instituut, 2013) In guidelines a combination of CBT and SSRI is suggested when treatment with CBT fails or when the panic disorder is severe.(Instituut, 2013) We advise to follow these guidelines, also in the presence of comorbid personality pathology.

Furthermore, it is important to adequately diagnose comorbid disorders, especially when regular treatment strategies fails. For example, a comorbid anxiety disorder next to a depressive disorder had a negative impact on remission rates. Also comorbid personality pathology influences the course of anxiety symptoms negatively. Adequate diagnosis of comorbid disorders could lead to other and more effective treatment regimes. 


\section{Limitations and strengths}

One of the strengths of this thesis is that different settings have been studied related to anxiety as a risk factor for cognitive impairment and/or dementia. As previously showed, results from clinical samples cannot be generalized to the general population. Sex differences have been also studied, with results confirming that there are differences between males and females.

We often studied comorbidities defined by the DSM. Nonetheless, patients suffering from clinically relevant levels of anxiety do not always meet the DSM-criteria of a formal anxiety disorder. For example, patients not meeting all criteria for a specific anxiety disorder may experience a similar level of impairment, as well as those scoring above the cut-off for clinical relevant anxiety symptoms do not always meet the criteria of a DSM-anxiety disorder.(Grenier et al., 2011) Thus, the diagnostic DSM criteria are a simplification of real life. In this thesis we tried to be attentive to this problem by studying anxiety dimensionally (anxiety symptom severity) next to a dichotomous measure (yes/no anxiety disorder according to the DSM criteria). Personality pathology was also studied dimensionally (number of personality features), and not dichotomous. For cognitive decline, we studied the decline of cognitive domains compared to the baseline scores.

On the other hand, it might be important to differentiate different types of anxiety. Conflicting results by previous research might partly be explained by not taking into account the different types of anxiety. It is possible that patients with generalized anxiety complaints have a higher risk for an underlying neurodegenerative disease, compared to patients with social phobia. Also subsyndromal anxiety complaints might be more predictive for cognitive decline, compared to the DSM anxiety disorders. There are not enough studies to be able to disentangle the subtypes of anxiety and their consequences.

Anxiety in general has received few attention in scientific research; late-life anxiety even fewer attention. In previous studies with research questions about other areas than anxiety, anxiety has often been measured. To gain more knowledge about anxiety, it is a good first step to first analyze the current available data for anxiety. We also re-used old data to answer our research questions, but therefor we were limited by the information that was available. Despite the limitations, significant findings were found. Replication studies specifically designed to address the effect of anxiety are warranted. 


\section{REFERENCES}

ALEXOPOULOS, G. S. 2005. Depression in the elderly. Lancet, 365, 1961-1970.

ALEXOPOUlOS, G. S., RAUE, P. J., KANELlOPOUlOS, D., MACKIN, S. \& AREAN, P. A. 2008. Problem solving therapy for the depression-executive dysfunction syndrome of late life. Int J Geriatr Psychiatry, 23, 782-788.

BARNES, D. E., YAFFE, K., BYERS, A. L., MCCORMICK, M., SCHAEFER, C. \& WHITMER, R. A. 2012. Midlife vs late-life depressive symptoms and risk of dementia: differential effects for Alzheimer disease and vascular dementia. Arch Gen Psychiatry, 69, 493-498.

BEAUDREAU, S. A. \& O'HARA, R. 2008. Late-life anxiety and cognitive impairment: a review. Am J Geriatr Psychiatry, 16, 790-803.

BIERMAN, E. J., COMIJS, H. C., RIJMEN, F., JONKER, C. \& BEEKMAN, A. T. 2008. Anxiety symptoms and cognitive performance in later life: results from the longitudinal aging study Amsterdam. Aging Ment Health, 12, 517-523.

BROWN, T. A. \& ROSELLINI, A. J. 2011. The direct and interactive effects of neuroticism and life stress on the severity and longitudinal course of depressive symptoms. J Abnorm Psychol, 120, 844-856.

BUNCE, D., BATTERHAM, P. J., MACKINNON, A. J. \& CHRISTENSEN, H. 2012. Depression, anxiety and cognition in community-dwelling adults aged 70 years and over. J Psychiatr Res, 46, 1662-1666.

BURTON, C., CAMPBEll, P., JORDAN, K., STRAUSS, V. \& MALLEN, C. 2013. The association of anxiety and depression with future dementia diagnosis: a case-control study in primary care. Fam Pract, 30, 25-30.

COOPER, C., SOMMERLAD, A., LYKETSOS, C. G. \& LIVINGSTON, G. 2015. Modifiable Predictors of Dementia in Mild Cognitive Impairment: A Systematic Review and Meta-Analysis. Am J Psychiatry.

CUMMINGS, J. L. 2004. Alzheimer's disease. N Engl J Med., 351, 56-67.

EYSENCK, M. W. \& CALVO, M. G. 1992. Anxiety and performance: the processing efficiency theory. . Cogn. Emot., 6, 409-434.

FOULDS, J., NEWTON-HOWES, G., GUY, N. H., BODEN, J. M. \& MULDER, R. T. 2017. Dimensional personality traits and alcohol treatment outcome: a systematic review and meta-analysis. Addiction, $112,1345-1357$.

GIMSON, A., SCHLOSSER, M., HUNTLEY, J. D. \& MARCHANT, N. L. 2018. Support for midlife anxiety diagnosis as an independent risk factor for dementia: a systematic review. BMJ open.

GONCALVES, D. C. \& BYRNE, G. J. 2012. Interventionsforgeneralizedanxiety disorder in olderadults: Systematic review and meta-analysis. J Anx Disord, 26, 1-11.

GORMAN, J. M. 1997. Comorbid depression and anxiety spectrum disorders. 4, 4.

GOULD, R. L., COULSON, M. C. \& HOWARD, R. J. 2012. Efficacy of cognitive behavioral therapy for anxiety disorders in older people: a meta-analysis and meta-regression of randomized controlled trials. J Am Geriatr Soc, 60, 218-229.

GREEN, M. \& CURTIS, G. C. 1988. Personality disorders and panic patients: Response to termination of antipanic medication. J Person Disord, 2, 303-314.

GRENIER, S., PRÉVILle, M., BOYER, R., O’CONNOR, K., BÉLAND, S. G., POTVIN, O., HUDON, C., BRASSARD, J. \& STUDY, S. C. O. T. E. 2011. The impact of DSM-IV symptom and clinical significance criteria on the prevalence estimates of subthreshold and threshold anxiety in the older adult population. Am J Geriatr Psychiatry, 19, 316-326.

GULPERS, B., RAMAKERS, I., HAMEL, R., KOHLER, S., OUDE VOSHAAR, R. \& VERHEY, F. 2016. Anxiety as a predictor for cognitive decline and dementie: a review and meta-analysis. The American Journal of Geriatric Psychiatry, 24, 823-842. 
INSTITUUT, T. 2013. Multidisciplinaire richtlijn angststoornissen. https://assets-sites.trimbos.nl/docs/ cc5b0f4e-9398-452d-8792-1453a38bf0a8.pdf.

KESSLER, R. C., BERGlund, P., DEMLER, O., JIN, R., MERIKANGAS, K. R. \& WALTERS, E. E. 2005. Lifetime prevalence and age-of-onset distributions of DSM-IV disorders in the National Comorbidity Survey Replication. Arch Gen Psychiatry, 62, 593-602.

KUSH, F. R. 2004. An Operationalized Cognitive Therapy Approach With Mixed Anxiety and Depression. Psychotherapy: Theory, Research, Practice, Training, 41, 266-275.

MOHLMAN, J. 2005. Does executive dysfunction affect treatment outcome in late-life mood and anxiety disorders? J Geriatr Psychiatry Neurol, 18, 97-108.

MÖLLER, H. J. 2009. Development of DSM-V and ICD-11: tendencies and potential of new classifications in psychiatry at the current state of knowledge. Psychiatry Clin Neurosci, 63, 595-612.

MORSE, J. Q. \& LYNCH, T. R. 2000. Personality disorders in late life. Curr Psychiatry Rep, 2, 24-31.

NABI, H., HAll, M., KOSKENVUO, M., SINGH-MANOUX, A., OKSANEN, T., SUOMINEN, S., KIVIMÄKI, M. \& VAHTERA, J. 2010. Psychological and Somatic Symptoms of Anxiety and Risk of Coronary Heart Disease: The Health and Social Support Prospective Cohort Study. BIOL PSYCHIATRY, 67, 378-385.

NEWTON-HOWES, G. \& FOULDS, J. 2018. Personality disorder and treatment outcome in alcohol use disorder. Curr Opin Psychiatry, 31, 50-56.

NEWTON-HOWES, G., MULDER, R., ELLIS, P. M., BODEN, J. M. \& JOYCE, P. 2018. Predictive Utility of Personality Disorder in Depression: Comparison of Outcomes and Taxonomic Approach. J Pers Disord, 32, 513-526.

NEWTON-HOWES, G., TYRER, P., JOHNSON, T., MULDER, R., KOOL, S., DEKKER, J. \& SCHOEVERS, R. 2014. Influence of personality on the outcome of treatment in depression: systematic review and meta-analysis. J Pers Disord, 28, 577-593.

ORGETA, V., QAZI, A., SPECTOR, A. \& ORRELL, M. 2015. Psychological treatments for depression and anxiety in dementia and mild cognitive impairment: systematic review and meta-analysis. $\mathrm{Br} J$ Psychiatry, 207, 293-298.

PAPAKOSTAS, G. I., CLAIN, A., AMERAL, V. E., BAER, L., BRINTZ, C., SMITH, W. T., LONDBORG, P. D., GLAUDIN, V., PAINTER, J. R. \& FAVA, M. 2010. Fluoxetine-clonazepam cotherapy for anxious depression: an exploratory, post-hoc analysis of a randomized, double blind study. Int Clin Psychopharmacol, 25, 17-21.

POLLACK, M. H., OTTO, M. W., ROSENBAUM, J. F. \& SACHS, G. S. 1992. Personality disorders in patients with panic disorder: association with childhood anxiety disorders, early trauma, comorbidity, and chronicity. Compr Psychiatry, 33, 78-83.

RAMAKERS, I. H., VERHEY, F. R., SCHELTENS, P., HAMPEL, H., SOININEN, H., AALTEN, P., RIKKERT, M. O., VERBEEK, M. M., SPIRU, L., BLENNOW, K., TROJANOWSKI, J. Q., SHAW, L. M. \& VISSER, P. J. 2013. Anxiety is related to Alzheimer cerebrospinal fluid markers in subjects with mild cognitive impairment. Psychol Med, 43, 911-920.

REGITZ-ZAGROSEK, V. 2012. Sex and gender differences in health. EMBO, 13, 596-603.

RUFF, R. M., LIGHT, R. \& EVANS, R. 1987. The Ruff Figural Fluency Test: A normative study with adults. Developmental Neuropsychology, 3, 37-51.

SPINHOVEN, P., ELZINGA, B. M., HOVENS, J. G. \& AL., E. 2011. Positive and negative life events and personality traits in predicting course of depression and anxiety. Acta Psychiatr Scand, 124, 462-473.

TAN, E. Y. L., KÖHLER, S., HAMEL, R. E. G., MUÑOZ-SÁNCHEZ, J. L., VERHEY, F. R. J. \& RAMAKERS, I. H. G. B. 2019. Depressive symptoms in mild cognitive impairment and the risk of dementia: 
a systematic review and comparative meta-analysis of clinical and community-based studies. Journal Alzheimer's Disease, Epub ahead of print.

WILSON, R. S., BEGENY, C. T., BOYLE, P. A., SCHNEIDER, J. A. \& BENNETT, D. A. 2011. Vulnerability to stress, anxiety, and development of dementia in old age. Am J Geriatr Psychiatry, 19, 327-334. 

Summary 


\section{Summary}

This thesis consists of two parts for pragmatic reasons. The first part is about correlates and comorbidities of anxiety related to cognitive functioning. Lifespan perspectives are included as the influence of age is thoroughly studied. The second part is about comorbidities and prognosis of anxiety. More specifically, the influence of comorbid personality pathology on the course of anxiety in older adults, and the treatment outcome in younger and older adults with anxiety is studied.

Chapter 1 provides an introduction to the topic. It states that anxiety disorders are the most common psychiatric disorders in older adults. In clinical practice, anxiety disorders are often missed due to various reasons. Recognition of anxiety in older adults is important, especially since research showed that older adults benefit from treatment as similar to younger adults. In the clinical practice of specialized mental health care however, patients are encountered with less favorable treatment outcomes. It is important to understand the predictors of non-response or partial-response to be able to adapt the treatment for the individual patient leading to better results. Next to the treatment effects for anxiety, the value of anxiety as a prognostic factor might also make it important to adequately diagnose anxiety. Previous research has postulated anxiety as a risk factor for cognitive decline in older adults. Despite the importance of recognizing and treating the high prevalent anxiety disorders in older adults, relative little research is done compared to the bulk of research about depression in older adults.

Chapter 2 describes a systematic review and meta-analysis studying anxiety as a possible risk factor for cognitive impairment or dementia. The association was studied in different settings: in the general population and in clinical populations. In the general population anxiety is a risk factor for cognitive impairment, and probably for dementia. Anxiety, however, did not predict conversion from mild cognitive impairment to dementia in clinical samples

Chapter 3 describes a cross-sectional study in 82,360 community-dwelling people participating in the Lifelines cohort, studying the relationship between anxiety disorders and figural fluency, as a measure of executive functioning in adults aged 18 years or older (range 18-93). A significant association between the presence of any anxiety disorder and executive functioning was found, and this relationship was driven by agoraphobia. People who suffered from agoraphobia performed worse on the figural fluency task compared to those not suffering from an anxiety disorder. This association was not dependent on age.

Chapter 4 describes a twelve year follow-up cohort study in 918 participants of the Maastricht Aging Study, studying the association between anxiety and cognitive functioning over time. There was no overall effect of anxiety on the course of executive functioning over time due to differential findings in man and woman. Among women, increasing anxiety symptoms were associated with decline of executive functioning over time, while 
in men a trend towards improvement of executive functioning over time was found. Similar sex-specific findings in this study were also found on tasks measuring processing speed and fluency over time, with a worse cognitive trajectory in women compared to men. Comparing older adults ( $>65$ years) with increasing levels of anxiety to those with lower anxiety levels, a greater decline of verbal memory in the former group was found. This was not found in the younger adults (50-65 years).

Chapter 5 describes the predictors of complete remission in older adults with a major depressive disorder, and often a comorbid anxiety disorder, with complete remission defined as no depressive and no anxiety disorder at follow-up. The severity of depressive and anxiety symptomatology, the presence of a comorbid anxiety disorder, poorer physical health and higher neuroticism at baseline independently predicted non-remission. The impact of mastery on complete remission differed significantly between patients with and without childhood trauma. Patients with a lower sense of mastery and childhood trauma achieved less often complete remission. Chapter 5 also describes whether negative life events in older adults predicts the course of anxiety symptoms comorbid to a depressive disorder and whether this impact is moderated by personality features. A less favorable course of anxiety symptoms was associated with a high level of neuroticism or a low level of mastery in the presence of negative life events.

Chapter 6 describes a cohort of 60 younger and 30 older adults that were treated with cognitive behavioural therapy (CBT) as the first treatment step in panic disorder with agoraphobia. The association between comorbid personality pathology and CBT outcome was studied, showing that only cluster B personality features had a detrimental effect on treatment outcome with CBT. The impact of personality pathology on treatment outcome was not dependent on age. In chapter 6 it was also studied whether personality pathology had a differential impact on evidence-based treatment modalities for panic disorder in later life (i.e. SSRI versus CBT). This was studied in 34 older adults either being randomized in the CBT group or in the group that received Paroxetine. Older adults with comorbid personality pathology that were treated with Paroxetine, did not improve as much as older adults without comorbid personality pathology. Comorbid personality pathology had no negative effect on the treatment outcome with CBT.

Chapter 7 summarizes the main findings of the studies to answer our original research questions, and the clinical implications of these findings are discussed. Implications for further research are suggested. 



\section{Samenvatting}




\section{Samenvatting}

Deze thesis bestaat uit twee delen omwille van pragmatische redenen. Het eerste deel gaat over correlaten en comorbiditeiten van angst, gerelateerd aan cognitief functioneren. De invloed van leeftijd wordt hierbij uitgebreid onderzocht. Het tweede deel gaat over comorbiditeiten en de prognose van angst. Meer specifiek, de invloed van comorbide persoonlijkheidspathologie op het beloop van angst bij ouderen, en de invloed op de behandeluitkomst bij jongere volwassenen en ouderen met angst is onderzocht.

Hoofdstuk 1 bestaat uit een introductie over het onderwerp. Angststoornissen zijn de meest voorkomende psychiatrische stoornissen bij ouderen. In de klinische praktijk worden angststoornissen vaak gemist om verschillende redenen. Herkenning van angst bij ouderen is belangrijk, omdat onderzoek heeft aangetoond dat ouderen goed reageren op behandeling met een vergelijkbaar effect als bij jongere volwassenen. Echter in de gespecialiseerde geestelijke gezondheidszorg, worden patiënten gezien met een minder goede behandeluitkomst. Het is belangrijk de voorspellers van een non-respons dan wel een partiële respons te onderkennen om de behandeling aan te kunnen passen aan de individuele patiënt, hetgeen moet leiden tot betere behandeluitkomsten. Naast de positieve effecten van de behandeling van angst, is angst mogelijk ook een belangrijke prognostische factor. Vorig onderzoek heeft angst gesuggereerd als een risicofactor voor cognitieve achteruitgang bij ouderen. Ondanks het belang van het adequaat herkennen en behandelen van de hoog prevalente angststoornissen bij ouderen, is er relatief weinig onderzoek gedaan naar dit onderwerp in vergelijking met de hoeveelheid onderzoek over depressie bij ouderen.

Hoofdstuk 2 beschrijft een systematische review en meta-analyse die angst als een mogelijke risicofactor voor cognitieve stoornissen of dementie onderzoekt. Deze associatie is bestudeerd in verschillende settingen: in de algehele populatie en in poliklinische populaties. In de algehele populatie is angst een risicofactor voor cognitieve stoornissen, en waarschijnlijk ook voor dementie. Angst voorspelt geen conversie van mild cognitive impairment (MCI) naar dementie in poliklinische populaties.

Hoofdstuk 3 beschrijft een cross-sectioneel onderzoek bij 82.360 personen uit de algehele populatie die deelnemen aan het Lifelines cohort, waarbij de relatie tussen angststoornissen en figural fluency, als een maat voor executief functioneren, is onderzocht bij volwassenen van 18 jaar en ouder (range 18-93). Een significante associatie is gevonden tussen de aanwezigheid van een angststoornis en het executief functioneren, waarbij deze associatie wordt gedreven door agorafobie. Personen met agorafobie scoren slechter op de taak voor figural fluency in vergelijking met mensen zonder een angststoornis. Deze associatie is onafhankelijk van de leeftijd.

Hoofdstuk 4 beschrijft een cohort studie met 918 deelnemers van de Maastricht Aging Study met een follow-up duur van twaalf jaar, waarbij de associatie tussen angst en het cognitief functioneren in de loop van de tijd wordt onderzocht. Er is geen algeheel effect 
van angst op het beloop van het executief functioneren vanwege differentiële bevindingen tussen mannen en vrouwen. Bij vrouwen is een hogere mate van angstsymptomen geassocieerd met een achteruitgang van het executief functioneren in de loop van de tijd, terwijl bij mannen een trend richting verbetering van het executief functioneren is te zien. Vergelijkbare geslachtsverschillen worden gezien ten aanzien van de snelheid van informatieverwerking en fluency in de loop van de tijd, waarbij vrouwen slechter scoren in vergelijking met mannen. Ouderen ( $>65$ jaar) met een hogere mate van angstklachten in vergelijking met ouderen ( $>65$ jaar) met een lagere mate van angstklachten, gaan sneller achteruit op het gebied van het geheugen. Dit is niet geconstateerd bij de jongere volwassenen (50-65 jaar).

Hoofdstuk 5 beschrijft de voorspellers van volledige remissie bij ouderen met een depressie, en vaak een comorbide angststoornis, met volledige remissie gedefinieerd als geen depressie en geen angststoornis bij follow-up. De ernst van de depressieve- en angstklachten, de aanwezigheid van een comorbide angststoornis, een slechtere somatische gezondheid en een hoge mate van neuroticisme op baseline voorspellen onafhankelijk nonremissie. De impact van mastery op volledige remissie verschilt significant tussen ouderen met en zonder jeugdtrauma. Ouderen met een jeugdtrauma in de voorgeschiedenis en een lagere mate van mastery bereiken minder vaak volledige remissie. Hoofdstuk 5 beschrijft ook of stressfactoren het beloop van comorbide angstklachten voorspelt bij ouderen met een depressie, en of dit effect gemodereerd wordt door persoonlijkheidskenmerken. Een minder gunstig beloop van angstsymptomen is geassocieerd met een hoge mate van neuroticisme of een lage mate van mastery in de aanwezigheid van stressfactoren. Deze onderzoeksvragen zijn onderzocht met behulp van de longitudinale data van de NESDO studie (Netherlands Study of Depression in Older persons), hetgeen een multi-site naturalistische cohort studie is.

Hoofdstuk 6 beschrijft een cohort van 60 jongere volwassenen en 30 ouderen die behandeld zijn met cognitieve gedragstherapie (CGT) als eerste stap in de behandeling van een paniekstoornis met agorafobie. De associatie tussen comorbide persoonlijkheidspathologie en de CGT behandeluitkomst is onderzocht, waarbij uitsluitend cluster B persoonlijkheidskenmerken een negatief effect bleken te hebben op de CGT behandeluitkomst. Het effect van persoonlijkheidspathologie op de behandeluitkomst is niet afhankelijk van leeftijd. In hoofdstuk 6 is tevens onderzocht of persoonlijkheidspathologie een differentieel effect heeft op evidence-based behandelingen voor paniekstoornis op oudere leeftijd (SSRI versus CGT). Dit is onderzocht bij 34 ouderen die gerandomiseerd werden in de groep die CGT als behandeling kregen, dan wel in de groep die behandeld werden met Paroxetine. Ouderen met comorbide persoonlijkheidspathologie die werden behandeld met Paroxetine, verbeteren minder dan ouderen zonder comorbide persoonlijkheidspathologie. Comorbide persoonlijkheidspathologie heeft geen negatief effect op de behandeluitkomst met CGT. 
Hoofdstuk 7 vat de hoofdbevindingen van de studies samen om onze initiële onderzoeksvragen te kunnen beantwoorden. De klinische implicaties van deze bevindingen worden bediscussieerd. Implicaties voor toekomstig onderzoek worden aangedragen. 



\section{Valorisation addendum}


In this thesis anxiety in older adults is studied. This thesis is of interest of researchers, but also for clinicians and the general population. As anxiety disorders are the most common psychiatric disorders in older adults and as subsyndromal anxiety is even more prevalent than anxiety disorders, it is important to study this highly prevalent complaint. In general there is relative little research done about anxiety compared to the bulk of research about depression in older adults. This thesis tries to fill this gap of research by examining anxiety in later life from a lifespan perspective. It contributes conceptually, theoretically and practically to the knowledge about anxiety in older adults.

As mentioned before anxiety in older adults is often not recognized, partly because anxiety complaints, especially avoidance behavior, in older adults are more accepted in the society.(Farabaugh et al., 2012) It is important to accomplish awareness in the general population that anxiety in older adults can be problematic and that effective treatments are available. There needs to be awareness that next to pharmacotherapy, also psychological treatments are effective in older adults. Age is not an exclusion criterion for treatment of anxiety. Awareness that anxiety is a risk factor for cognitive impairment or dementia can result in patients sooner reporting their complaints to their clinician. It is important to discuss anxiety as older adults often do not feel comfortable discussing their mental health due to the stigma. The dialogue about the high prevalent anxiety complaints in older adults can diminish this stigma.

The valorization of each individual study is written in more detail below.

Chapter 2 shows that anxiety in the general population is a risk factor for cognitive impairment and probably for dementia. Anxiety does not predict conversion from mild cognitive impairment to dementia in clinical samples, for example patients visiting the memory clinic. Anxiety could be a prodromal symptom of dementia, caused by an unknown third factor also causing the dementia, or a causal factor itself. Irrespective of the association is causal or not, it is important for the clinician to be aware of anxiety as a possible predictor for dementia, especially when the anxiety emerges at late life. Late-life anxiety disorders have a low incidence rate, since $95^{\text {th }}$ percentile of all anxiety complaints have already been exposed at the age of 51 years and $99^{\text {th }}$ percentile at 65 years.(Kessler et al., 2005a) When patients present themselves with anxiety, treatment should be started.

Anxiety in the presence of an underlying neurodegenerative process will possibly respond better to the structuring of daily life instead of cognitive behavioural therapy. Exposure in vivo could potentially increase the anxiety complaints. However, a systematic review and meta-analysis showed that psychological treatments, like cognitive-behavioral therapy or interpersonal therapy, are effective for anxiety and depression in patients with cognitive problems, even with dementia.(Orgeta et al., 2015) When causally related, adequate treatment of anxiety could lower the risk for developing cognitive impairment or dementia. Regular treatment steps should then be applied with for example cognitive behavioral therapy as a recommended first treatment step. 
Chapter 3 shows in a cross-sectional study that younger and older adults who suffer from any anxiety disorder perform worse on the figural fluency task, as a measure of executive functioning, compared to those not suffering from an anxiety disorder. This association is driven by agoraphobia, and is not dependent on age. Clinicians should know that problems specifically with executive functioning can interfere with treatment for affective disorders. (Alexopoulos, 2005, Mohlman, 2005) Other treatment strategies, like problem-solving therapy, showed better improvement in persons with executive dysfunction and depression. (Alexopoulos et al., 2008) Since the effect sizes in our study were small, regular treatment for anxiety should not be adapted in advance. However, when regular treatment fails it could be relevant to test executive functioning and when executive dysfunctions are present to adapt the treatment to it.

Chapter 4 shows in a longitudinal study that anxiety symptoms predict decline in executive functioning over time in women, and decline in verbal memory in the older age group (65+ years). Women often have a higher prevalence of anxiety complaints, a more severe, and more chronic anxiety phenotype, compared to men.(Kessler et al., 2005b, Yonkers et al., 2003, de Beurs et al., 2000) Whether late-life anxiety could be prodromal or causally related to neurodegeneration remains unclear. Adequate treatment of anxiety symptoms could potentially beneficially influence the risk for developing neurodegenerative disease.

Chapter 5 states that meaningful remission for a patient with depression consists of remission of the depression as well as the remission of the highly prevalent comorbid anxiety symptoms. Amongst other things, the severity of anxiety symptomatology and the presence of a comorbid anxiety disorder had a negative impact on the complete remission rates, with complete remission defined as no depressive and no anxiety disorder at follow-up. This highlights the importance of adequately diagnosing comorbid anxiety also in the presence of a depressive disorder. Also personality features influenced the complete remission rates, as high neuroticism was associated with non-remission, as was low mastery in the presence of childhood trauma. Clinicians should be aware of comorbid personality pathology when the anxiety complaints are chronic or have high relapse rates.(Pollack et al., 1992, Green and Curtis, 1988)The course of the comorbid anxiety symptoms during the two year followup was dependent upon these personality features (high neuroticism and low mastery), but only in the presence of negative life events. As personality features have an influence on the course of comorbid anxiety symptoms in depressive disorder and on non-remission rates, it is important to consider psychotherapy for older adults. Multiple meta-analyses have demonstrated the effectiveness of psychotherapy in older adults with anxiety disorders. (Gould et al., 2012, Goncalves and Byrne, 2012) That older adults are less opportune for psychotherapy as complaints are often more chronic, or the assumption that older adults are too inflexible to change their behavior, appears to be untrue. When personality features like high neuroticism or low mastery are present, psychotherapeutic interventions should not per se aim for complete remission of the personality dysfunction, but more the increase 
of adaptive coping strategies, while diminishing maladaptive behaviors and symptoms (for example avoidance behavior in patients with anxiety complaints).(Morse and Lynch, 2000)

Chapter 6 studies the influence of comorbid personality pathology on CBT outcome in younger and older adults with panic disorder with agoraphobia. Chapter 6 shows that only cluster B personality features has a detrimental effect on treatment outcome with CBT. The impact of personality pathology on treatment outcome is not dependent on age. Chapter 6 also studies whether personality pathology has a differential impact on evidence-based treatment modalities for panic disorder in later life (i.e. SSRI versus CBT). Older adults with comorbid personality pathology being treated with Paroxetine, did not improve as much as older adults without comorbid personality pathology. Comorbid personality pathology has no negative effect on the treatment outcome with CBT.

Patients with panic disorder should not be excluded for manual-based CBT based on age or personality pathology. Our finding that treatment with CBT is superior to pharmacotherapy in older adults with comorbid personality pathology, strengthens the recommendation in guidelines to offer primarily CBT for the treatment of panic disorder.(Instituut, 2013) In guidelines a combination of CBT and SSRI is suggested when treatment with CBT fails or when the panic disorder is severe.(Instituut, 2013) We advise to follow these guidelines, also in the presence of comorbid personality pathology. 


\section{REFERENCES}

ALEXOPOULOS, G. S. 2005. Depression in the elderly. Lancet, 365, 1961-1970.

ALEXOPOUlOS, G. S., RAUE, P. J., KANELlOPOUlOS, D., MACKIN, S. \& AREAN, P. A. 2008. Problem solving therapy for the depression-executive dysfunction syndrome of late life. Int $J$ Geriatr Psychiatry, 23, 782-788.

DE BEURS, E., BEEKMAN, A. T., DEEG, D. J., VAN DYCK, R. \& VAN TILBURG, W. 2000. Predictors of change in anxiety symptoms of older persons: results from the Longitudinal Aging Study Amsterdam. Psychol Med., 30, 515-527.

FARABAUGH, A., ALPERT, J., WISNIEWSKI, S. R., OTTO, M. W., FAVA, M., BAER, L. \& THASE, M. E. 2012. Cognitive therapy for anxious depression in STAR(*) D: What have we learned? Journal of Affective Disorders, 142, 213-218.

GONCALVES, D. C. \& BYRNE, G. J. 2012. Interventionsforgeneralizedanxiety disorder in olderadults: Systematic review and meta-analysis. J Anx Disord, 26, 1-11.

GOULD, R. L., COULSON, M. C. \& HOWARD, R. J. 2012. Efficacy of cognitive behavioral therapy for anxiety disorders in older people: a meta-analysis and meta-regression of randomized controlled trials. J Am Geriatr Soc, 60, 218-229.

GREEN, M. \& CURTIS, G. C. 1988. Personality disorders and panic patients: Response to termination of antipanic medication. J Person Disord, 2, 303-314.

INSTITUUT, T. 2013. Multidisciplinaire richtlijn angststoornissen. https://assets-sites.trimbos.nl/docs/ cc5b0f4e-9398-452d-8792-1453a38bf0a8.pdf.

KESSler, R. C., BERGlund, P., DEMler, O., JIN, R., MERIKANGAS, K. R. \& WALTERS, E. E. 2005a. Lifetime prevalence and age-of-onset distributions of DSM-IV disorders in the National Comorbidity Survey Replication. Arch Gen Psychiatry, 62, 593-602.

KESSLER, R. C., BERGlund, P., DEMLER, O., JIN, R., MERIKANGAS, K. R. \& WALTERS, E. E. 2005b. Lifetime Prevalence and Age-of-Onset Distributions of DSM-IV Disorders in the National Comorbidity Survey Replication. Arch Gen Psychiatry, 62, 593-602.

MOHLMAN, J. 2005. Does executive dysfunction affect treatment outcome in late-life mood and anxiety disorders? J Geriatr Psychiatry Neurol, 18, 97-108.

MORSE, J. Q. \& LYNCH, T. R. 2000. Personality disorders in late life. Curr Psychiatry Rep, 2, 24-31.

ORGETA, V., QAZI, A., SPECTOR, A. \& ORRELL, M. 2015. Psychological treatments for depression and anxiety in dementia and mild cognitive impairment: systematic review and meta-analysis. $\mathrm{Br} J$ Psychiatry, 207, 293-298.

POLLACK, M. H., OTTO, M. W., ROSENBAUM, J. F. \& SACHS, G. S. 1992. Personality disorders in patients with panic disorder: association with childhood anxiety disorders, early trauma, comorbidity, and chronicity. Compr Psychiatry, 33, 78-83.

YONKERS, K. A., BRUCE, S. E., DYCK, I. R. \& KELLER, M. B. 2003. Chronicity, relapse, and illness-course of panic disorder, social phobia, and generalized anxiety disorder: findings in men and women from 8 years of follow-up. Depress Anxiety, 17, 173-179. 

Acknowledgements

Dankwoord 
Ik wil iedereen bedanken die, al dan niet bij naam genoemd zijn, een bijdrage hebben geleverd aan de totstandkoming van dit proefschrift.

Ik wil graag mijn promotor Prof. Dr. Richard Oude Voshaar bedanken. Dit hele promotietraject is ontstaan op basis van zijn aanstekelijke enthousiasme rondom wetenschappelijk onderzoek. Voor het eindreferaat van mijn opleiding tot psychiater wilde ik onderzoek doen naar angst bij ouderen. Vanwege het ontbreken van datasets aangaande angst bij ouderen bij zuidelijke collega's kwam ik via Bas van Alphen, in contact met Richard. Ten tijde van de kennismaking heb ik nog met enige twijfel aangegeven, dat ik naast het inzetten van de data voor mijn eindreferaat, er ook een wetenschappelijk artikel over wilde schrijven. Door echter het hele proces te hebben doorlopen om tot een wetenschappelijk artikel te komen in samenwerking met Richard, werd ik aangestoken door het enthousiasme van Richard en ging er vervolgens een promotietraject van start. Richard is voor mij een grote steun geweest in dit promotietraject. Zijn betrokkenheid, het laagdrempelig benaderbaar zijn, zijn snelle reacties als ik even vast zat, zijn humor en zijn nuchtere houding zijn eigenschappen die ik zeer waardeer. Ik heb ontzettend veel geleerd van Richard. Ook buiten het gebied van wetenschappelijk onderzoek, heb ik Richard leren kennen bij het onderwijs ouderenpsychiatrie waar dezelfde energie en hetzelfde enthousiasme deel van hem zijn en ik als inspirerend heb ervaren.

Mijn promotor Prof. Dr. Frans Verhey wil ik ook bedanken voor zijn waardevolle bijdrage aan mijn proefschrift. Tijdens mijn verdieping ouderenpsychiatrie als onderdeel van mijn opleiding tot psychiater, heeft Frans me enthousiast gemaakt ten aanzien van de cognitieve problematiek bij ouderen. Een onderwerp wat een groot aandeel heeft gekregen in mijn proefschrift, en ook een groot deel uitmaakt van mijn dagelijkse werkzaamheden bij METggz. Frans heeft zich ingezet om mijn promotietraject mogelijk te maken, waar ik hem dankbaar voor ben. Verder heeft hij gefungeerd als mentor toen ik net afgestudeerd was en startte met mijn eerste baan als psychiater. Dat heb ik ontzettend gewaardeerd en heeft me een betere psychiater gemaakt.

Mijn co-promotor Dr. Sebastian Köhler was mijn steun en toeverlaat rondom statistiek. Zijn kennis en kunde hebben mij geholpen om een basis op te bouwen op dit gebied. Er valt nog altijd meer over te leren. Daarnaast bewonder ik zijn constructieve kritische blik om artikelen verder te verbeteren.

Verder wil ik mijn andere collega's bedanken waarmee ik heb samengewerkt in dit promotietraject. Gert-Jan Hendriks, Inez Ramakers, Marij Zuidersma, Astrid Lugtenburg, Martin van Boxtel, Renske Hamel, Bas van Alphen, Mirjam Kampman en Date van Veen bedankt voor de fijne samenwerking.

Ik wil de leescommissie bedanken: Prof. Dr. M.E. de Vugt, Prof. Dr. M.L. Stek, Dr. A.M. Roest, Prof. Dr. K.R.J Schruers en Dr. J.M.H. Joosten, voor het beoordelen van mijn proefschrift. 
Els heeft me geholpen bij de regelzaken rondom mijn proefschrift en verdediging. Daarnaast ken ik je al langer als secretaresse van Frans. Je bent altijd even behulpzaam. Dank.

Ik wil graag Kittie D'Hoine bedanken voor het mogelijk maken van mijn promotietraject door het beschikbaar stellen van een aantal uren binnen de verschillende organisaties waarvoor we gewerkt hebben. Verder wil ik graag mijn collega's van de afdeling ouderenzorg binnen METggz (eerder RIAGG en Virenze-RIAGG) bedanken voor de fijne werksfeer en plezierige samenwerking, ondanks de chaotische en turbulente tijden die we met elkaar hebben meegemaakt door herhaaldelijke financiële problemen in de organisaties waarvoor we werkten.

Mijn paranimfen, Nynke en Tessa, wil ik bedanken voor hun steun tijdens mijn verdediging en daarbuiten. Ik ben heel blij, dat jullie hier samen met mij staan.

Mijn lieve vriendinnen, die ik op allerlei plekken heb mogen ontmoeten, wil ik graag bedanken voor hun vriendschap.

Ik ben dankbaar voor mijn familie en schoonfamilie. In het bijzonder wil ik mijn lieve vader, Annie en mijn broer Cyril bedanken. Zij staan altijd voor me klaar, wanneer ik ze nodig heb. Humor heeft altijd een belangrijk aandeel gehad in ons gezin gehad, en is nog altijd volop aanwezig als we samen zijn. Ik hou van jullie.

Lieve mama, helaas kan jij er vandaag niet bij zijn. Ik weet zeker dat je trots op me zult zijn. Het gemis van jou zal ik altijd bij me blijven dragen, en op bijzondere momenten komt dit sterker naar voren. Ik ben dankbaar dat je 21 jaar deel hebt uitgemaakt van mijn leven en dat ik mede gevormd ben door jou. Ik hoop dat ik een beetje op jou lijk.

De belangrijkste steunpilaar is mijn lieve vriend, Eduard. Je bent een rots in de branding voor mij. Samen hebben we het belangrijkste werk geleverd; de geboorte van ons zoontje Mathias. We genieten volop samen van dit kleine ondeugende en vrolijke mannetje. Ik hou ontzettend veel van jullie en geniet er iedere dag van om bij jullie thuis te komen. 



\section{Curriculum vitae}


Bernice Gulpers was born on Octobre $1^{\text {st }} 1985$ in Kerkrade, The Netherlands. She started her medicine study in 2003 at the Maastricht University and graduated in 2009. During her medicine study she already focused on psychiatry. In her final year she choose an internship at a FACT-team (flexible assertive community treatment) at the Mondriaan in Maastricht, where patients with severe mental illnesses are treated. In her final year she also engaged in research that focused on the role of the HPA-axis in psychosis. After her graduation she started to work at a clinical ward for old age psychiatry in Orbis GGZ, Sittard (20092010). Her fascination for old age psychiatry originated from there. She started her study to become a psychiatrist in 2010, and was a resident between 2010-2014 at the "Universitaire Opleiding Psychiatrie Zuid-Limburg". In the last two years of her residency she specialized in old age psychiatry, and again engaged in research. For her graduation she studied the influence of comorbid personality pathology on the treatment outcome in older adults with panic disorder. After her graduation she started to work in 2014 at the department for old age psychiatry at the RIAGG Maastricht, a regional institute for mental health care in outpatients. Simultaneous, she started with her PhD project. She still works for the same department, but turbulent periods with financial problems for the institute(s) has led to multiple employers: RIAGG, Virenze-RIAGG and now METggz. 

List of publications 
Gulpers B, Ramakers I, Hamel R, Köhler S, Oude Voshaar R, Verhey F. Anxiety as a Predictor for Cognitive Decline and Dementia: A Systematic Review and Meta-Analysis. Am J Geriatr Psychiatry. 2016. 24(10): 823-42.

Gulpers B, Lugtenburg A, Zuidersma M, Verhey FRJ, Voshaar RCO. Anxiety disorders and figural fluency: A measure of executive function. J Affect Disord. 2018. 234:38-44.

Gulpers BJA, Oude Voshaar RC, van Boxtel MPJ, Verhey FRJ, Köhler S. Anxiety as a Risk Factor for Cognitive Decline: A 12-Year Follow-Up Cohort Study. Am J Geriatr Psychiatry. 2019. 27(1):42-52.

van der Veen DC, Gulpers BJA, van Zelst W, Köhler S, Comijs HC, Schoevers RA, Oude Voshaar RC.Personality and negative life-events predicts course of anxiety in older adults with late-life depression. Am J Ger Psychiatry submitted.

Gulpers BJA, Oude Voshaar RC, Kampman M, Verhey F, van Alphen SPJ, Hendriks GJ. The impact of personality pathology on treatment outcome in late-life panic disorder. Journal of psychiatric practice submitted. 
